\section{Pacific Northwest}

National Laboratory

Operated by Battelle for the

U.S. Department of Energy

\title{
Vadose Zone Transport Field Study: FY 2002 Status Report
}

\author{
A. L. Ward \\ G. W. Gee \\ Z.F. Zhang \\ J.M. Keller
}

December 2002

Prepared for the U.S. Department of Energy under Contract DE-AC0 -76RL01830 


\title{
DISCLAIMER
}

This report was prepared as an account of work sponsored by an agency of the United States Government. Neither the United States Government nor any agency thereof, nor Battelle Memorial Institute, nor any of their employees, makes any warranty, express or implied, or assumes any legal liability or responsibility for the accuracy, completeness, or usefulness of any information, apparatus, product, or process disclosed, or represents that its use would not infringe privately owned rights. Reference herein to any specific commercial product, process, or service by trade name, trademark, manufacturer, or otherwise does not necessarily constitute or imply its endorsement, recommendation, or favoring by the United States Government or any agency thereof, or Battelle Memorial Institute. The views and opinions of authors expressed herein do not necessarily state or reflect those of the United States Government or any agency thereof.

\author{
PACIFIC NORTHWEST NATIONAL LABORATORY \\ operated by \\ BATTELLE \\ for the \\ UNITED STATES DEPARTMENT OF ENERGY
}

under Contract DE-AC06-76RL01830

Printed in the United States of America

Available to DOE and DOE contractors from the

Office of Scientific and Technical Information,

P.O. Box 62, Oak Ridge, TN 37831-0062;

ph: (865) 576-8401

fax: (865) 576-5728

email: reports@adonis.osti.gov

\begin{abstract}
Available to the public from the National Technical Information Service, U.S. Department of Commerce, 5285 Port Royal Rd., Springfield, VA 22161 ph: (800) 553-6847 fax: (703) 605-6900

email: orders@ntis.fedworld.gov

online ordering: http://www.ntis.gov/ordering.htm
\end{abstract}

This document was printed on recycled paper.

$(8 / 00)$ 


\section{Vadose Zone Transport Field Study FY 2002 Status Report}
A. L. Ward
G. W. Gee
Z.F. Zhang
J.M. Keller

December 2002

Prepared for the U.S. Department of Energy

under Contract DE-AC06-76RL01830

Pacific Northwest National Laboratory

Richland, Washington 99352 


\section{Summary}

The work reported in this paper is part of the U.S. Department of Energy's Science and Technology Initiative to develop improved conceptual models of flow and transport in the vadose zone, particularly for the Hanford Site, Washington. The National Academy of Sciences has identified significant knowledge gaps in conceptual model development as one reason for the discovery of subsurface contamination in unexpected places (NAS 2000). Inadequate conceptualization limits include, not only the understanding of long-term fate and transport, but also the selection and design of remediation technologies. Current conceptual models are limited, partly because they do not account for the random heterogeneity that contributes to the extremes of very nonlinear flow behavior typical of the Hanford vadose zone. A major improvement in the conceptual model of the Hanford vadose zone includes a better understanding and description of soil anisotropy, a property that appears to control much of the subsurface flow and transport in layered sediments at the Hanford Site.

This project used a combination of geophysical and soil-physics techniques to investigate the infiltration and redistribution of water and dilute tracers in a controlled field experiment at the Army loop Road clastic dike study area at the Hanford Site, near Richland, Washington. In the FY 2002 tests, surfacedeployed ground-penetrating radar was used to identify the discrete pattern of horizontal layering that comprises the coarse component of the heterogeneity along a 60-m transect. The transect was instrumented to allow water to be applied along its length from a line source. Localscale water content, matric potential, and tracer concentrations were monitored as a function of spatial scale by multipurpose time-domain reflectometry probes and suction lysimeters (solution samplers). The resulting data were used to characterize fine-scale heterogeneity as well as correlation lengths of hydraulic and transport parameters. Tracer breakthrough data were used to determine longitudinal and transverse dispersivit ies and their scale dependence. Parameters were analyzed to identify a suitable averaging (upscaling) procedure for field-scale infiltration predictions. Distributions of water and solute were found to be spatially dependent and controlled by the fine-scale features present both at the clastic dike and near the horizontal sill that was found to emanate from the dike. A theory of anisotropy was developed and successfully tested based on observations at the clastic dike site. The results of this study will help to bridge the gap between localscale transport observations and field-scale transport behavior. It will allow the validation of recently developed inverse procedures for predicting field-scale parameters and will improve our prediction capability for heterogeneous sediments at Hanford. The improved conceptualizations will permit DOE to make defensible corrective and remedial-action decisions at the Hanford Site.

\section{Reference}

National Academy of Science (NAS). 2000. Research Needs in Subsurface Science. National Academy Press, Washington, D.C. 


\section{Glossary}

\begin{tabular}{|c|c|}
\hline $2-\mathrm{D}$ & Two Dimensional \\
\hline $3-\mathrm{D}$ & Three Dimensional \\
\hline BTC & Breakthrough Curve \\
\hline BWTF & Buried Waste Test Facility \\
\hline $\mathrm{CDE}$ & Convective-Dispersive Equation \\
\hline CLT & Convective Lognormal Transport \\
\hline CMP & Common Mid Point \\
\hline $\mathrm{CPN}$ & Campbell Pacific Nuclear \\
\hline CPT & Cone Penetrometer technology \\
\hline DOE & U.S. Department of Energy \\
\hline DOE-RL & U.S. Department of Energy/Richland Operations Office \\
\hline EM & Electromagnetic \\
\hline EMSP & Environmental Management Science Program \\
\hline GPR & Ground Penetrating Radar \\
\hline GSLIB & Geostatistic al Software Library \\
\hline HMS & Hanford Meteorological Station \\
\hline HRR & High Resolution Resistivity \\
\hline ILAW & Immobilized Low Activity Waste \\
\hline LMHC & Lockheed Martin Hanford Company \\
\hline LRB & Laboratory Record Book \\
\hline NAS & National Academy of Science \\
\hline NMO & Normal Moveout \\
\hline PNNL & Pacific Northwest National Laboratory \\
\hline
\end{tabular}




$\begin{array}{ll}\text { SGSIM } & \text { Sequential Gaussian Simulation } \\ \text { SSWR } & \text { Sum of the Squared Weighted Residue } \\ \text { TCT } & \text { Tensorial Connectivity-Tortuosity } \\ \text { TDR } & \text { Time-Domain Reflectometry } \\ \text { USDA } & \text { U.S. Department of Agriculture } \\ \text { VZTFS } & \text { Vadose Zone Transport Field Study } \\ \text { XBR } & \text { Cross-Borehole Radar }\end{array}$




\section{Contents}

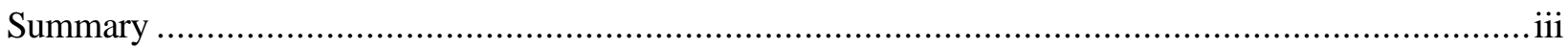

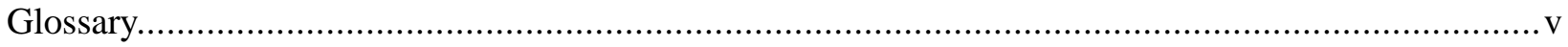

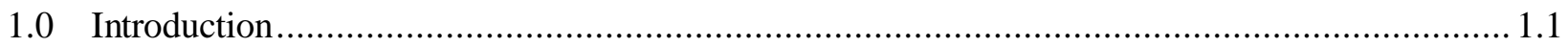

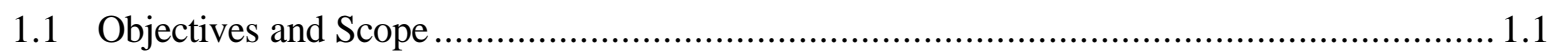

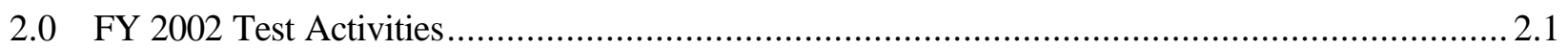

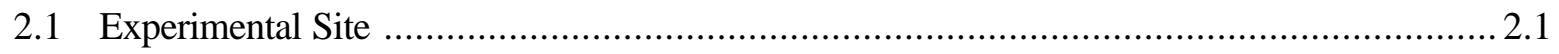

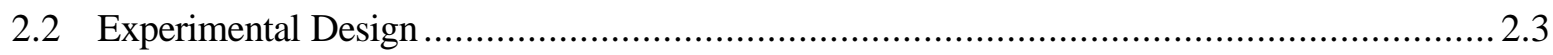

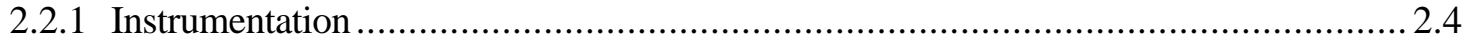

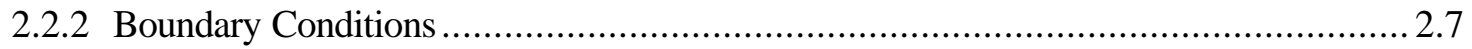

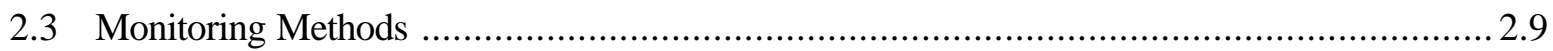

2.3.1 Time Domain Reflectometry ........................................................................ 2.10

2.3.2 Neutron Moisture Logging ............................................................................ 2.12

2.3.3 Cross Borehole Radar...................................................................................... 2.12

2.3.4 Surface Ground Penetrating Radar ................................................................... 2.12

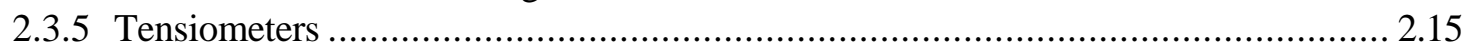

2.3.6 Suction Lysimetry and Tracer Methods ……….............................................. 2.15

2.4 Modeling the Experiment ………………………..................................................... 2.19

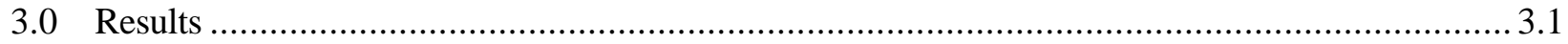

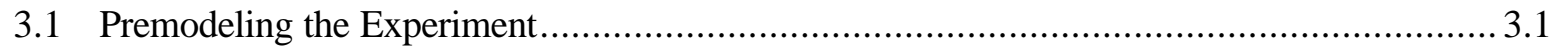

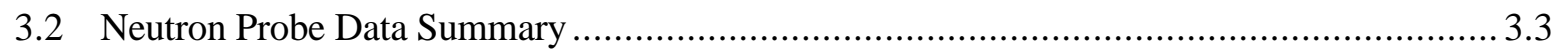

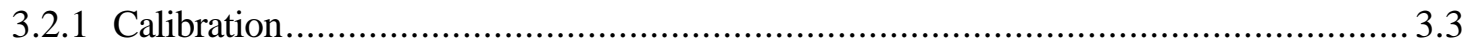

3.2.2 Water-Content Distributions ............................................................................ 3.6

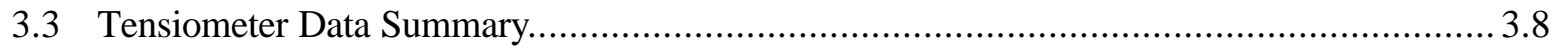

3.4 Surface Ground Penetrating Radar ……………........................................................ 3.10

3.5 Cross-Hole Ground Penetrating Radar..................................................................... 3.13

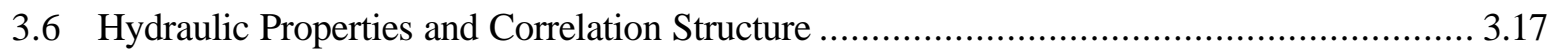

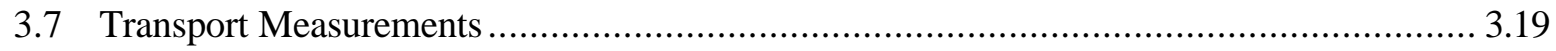

3.7.1 Multi-component Transport .......................................................................... 3.19

3.7.2 Flux-Averaged Versus Volume-Averaged Concentrations ..................................... 3.21 


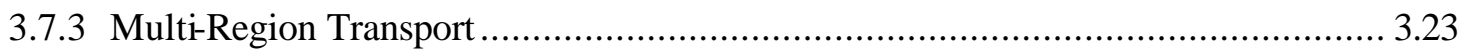

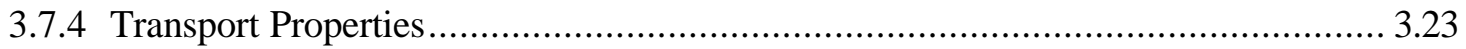

3.8 Measurement of Hydraulic Conductivity and its Anisotropy …................................. 3.24

3.9 Parameter Scaling and Inverse Modeling ................................................................ 3.30

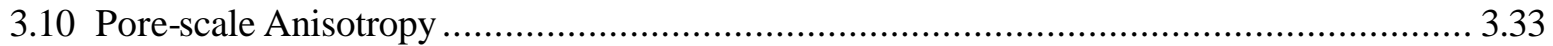

3.11 A New Conceptual Model for State-Dependent Anisotropy ….................................. 3.34

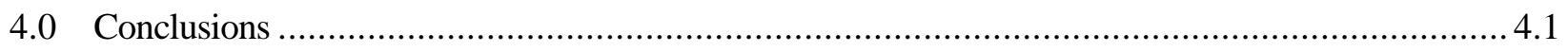

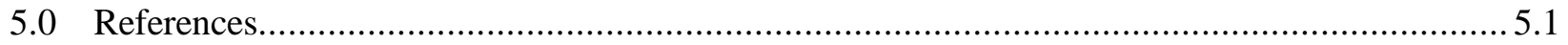




\section{Figures}

2.1. Location of the VZTFS Site Near Army Loop Road

2.2. Field Site Outcrop Showing Multiple Scales at Which Heterogeneity is Manifested and its

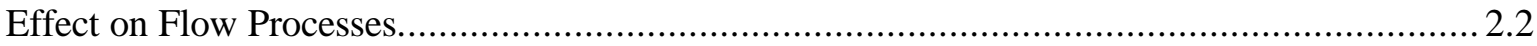

2.3. Schematic of 2-D Convection and 2-D Dispersion in a Half Plane of a Porous Medium............. 2.4

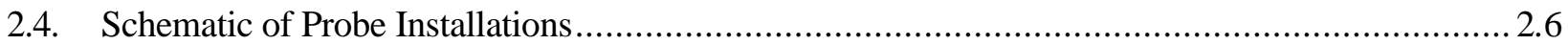

2.5. Schematic Layout Showing Common Offset Profiles and Borehole Radar Locations ................ 2.6

2.6. The FIELD SITE During Instrumentation Looking in an Easterly Direction Along the Transect. 2.7

2.7. Cumulative Volume of Water Applied During the FY 2002 Field Experiment..........................2.8

2.8. Illustration of the Acquisition Modes Used for Surface GPR Operation ............................. 2.13

2.9. Schematic of CMP Sounding-Ray Paths and Idealized Event Arrival Time Versus Antenna Spacing

2.10. Schematic of Transect Showing Direction of Data Collection with Surface GPR................... 2.15

2.11. Schematic of Tensiometer and Wiring for Automated Matric Potential Measurements............. 2.16

2.12. Schematic of Stainless Steel Suction Lysimeter/Tensiometer and Vacuum System Used for Collecting Water Samples

3.1. Schematic of Stainless Steel Suction Lysimeter/Tensiometer and Vacuum System Used for

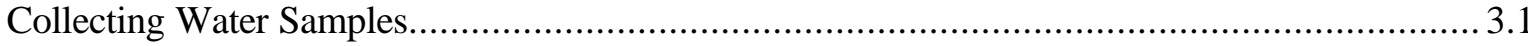

3.2. Predicted Water Content Profiles at 0.15-m (0.5-ft) Increments from the Line Source................ 3.2

3.3. Predicted Flux Concentrations of a Conservative Tracer at Locations $(y, z)=(0.15,0.8)$ and $(0.30,0.4)$

3.4. Calibration Relations for the Neutron Probe in PVC Tubes at the FY 2002 Field Site

3.5. Water Content Profiles Measured During the FY 2002 Infiltration Experiments ....................... 3.6

3.6. Water Content Profiles Measured During the FY 2001 Infiltration Experiments ...................... 3.7

3.7. Wet Sill Observed West of the Dike and Adjacent to CPT-8 (Tube \#5).................................. 3.8

3.8. Measured Water Content-Matric Potential Relationships from Experiment 1........................ 3.9 
3.9. Steady-State Matric Potentials Along the Transect in Experiment 1

3.10. Common Offset GPR Data Collected $0.8 \mathrm{~m}$ (0.26 ft) from the Line Source on May 21, 2002 .... 3.11

3.11. Example of Common Mid-Point Data with Arrivals Labeled.

3.12. Change in $\theta_{\mathrm{v}}$ of Sediment Overlying Reflector "red9" over 3-Month Period

3.13. Crosshole Velocity Tomograms (a) Before and (b-d) During Infiltration Experiment.

3.14. Comparison of Moisture Content Derived from GPR TravelTime Tomography and Neutron-Probe Measurements.

3.15. Spatial Distribution of Steady-State Water Content Measured with 1-m (3.3-ft)-long TDR Probes

3.16. Experimental Variogram for Steady-State Water Content Measured with 1-m (3.3-ft)-long TDR Probes..

3.17. Example of Multi-Component Flux Concentration Breakthrough Curves at $x=24 \mathrm{~m}(78 \mathrm{ft}) \ldots . .3 .20$

3.18. Comparison of Flux Concentrations Derived from Pore Water Samples of Br- and Resident Concentrations Derived from TDR Measurements at $\mathrm{x}=46 \mathrm{~m}(151 \mathrm{ft})$

3.19. Comparison of Flux Concentrations Derived from Pore Water Samples of Br- at $0.8 \mathrm{~m}$ $(2.6 \mathrm{ft})$ in the Sand Matric $(\mathrm{x}=20 \mathrm{~m}[65.6 \mathrm{ft}])$ and Dike $(\mathrm{x}=8 \mathrm{~m}[26 \mathrm{ft}])$

3.20. Schematic of Mini Disk-Infiltrometer 3.25

3.21. Cumulative Infiltration Versus Square Root of Time 3.28

3.22. Wetting Fronts Resulting from Infiltration of Water from a Modified Disk Infiltrometer.

3.23. Comparison of the Observations and the Predictions of Water Content and Pressure Head Using the Local-Scale Parameter Values.....

3.24. Comparison of the Observations and the Predictions of Water Content and Pressure Head Using the Field-Scale Parameter Values Determined Inversely Based on the Non-Similar Scaling Concept.

3.25. Schematic of an Isotropic Soil

3.26. Effect of Particle Shape on Directional Electrical Conductivity as Measured by TDR. 3.35

3.27. Realizations of Different Degrees of Heterogeneity and Connectivity for Hypothetical Soils ..... 3.37

3.28. Retention Curves of Anisotropic Soils with Different Levels of Heterogeneities and the Correlation Ratio of 50 Between the Correlation Lengths at the Direction Parallel to and Those Perpendicular to the Strata. 
3.29. The Unsaturated Hydraulic Conductivity of Anisotropic Heterogeneous Soils with the $\sigma_{\mathrm{Y}}^{2}=2.0-$ Cross: Parallel to Soil Strata; and Circle: Normal to Soil Strata.

\section{Tables}

2.1. Schedule for the First FY 2002 Infiltration Experiment........................................... 2.9

2.2. Schedule for the Second FY 2002 Infiltration Experiment............................................ 2.10

2.3. Characterization and Monitoring Technologies Selected for FY -2002 Field Tests.................. 2.11

3.1. Predicted Water Storage and $\bar{?}_{\mathrm{L}}$ for Different Probe Lengths.......................................... 3.2

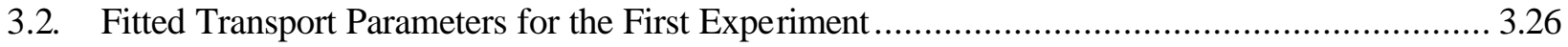

3.3. Fitted Transport Parameters for the Second Experiment ............................................. 3.27

3.4. Vertical and Horizontal Hydraulic Conductivities Measured by Mini Infiltrometer and the Resulting Anisotropy Ratios. Horizontal measurements were conducted with a modified mini disk infiltrometer. 


\subsection{Introduction}

Modeling water flow and contaminant transport in the vadose zone has become an important tool for guiding site characterization, conducting risk assessments, and evaluating remedial options at Hanford and other U.S. Department of Energy (DOE) Sites. It is also well recognized that the process can be subject to much uncertainty. The various sources of uncertainty can interact in a complex manner, and without a systematic and consistent approach for treating the various sources, the credibility and defensibility of model analyses become questionable. It was only recently that the National Academy of Sciences (NAS) identified knowledge gaps in conceptual model development as being partly responsible for the discovery of subsurface contamination in unexpected places at Hanford (NAS 2000). The major sources of uncertainty affecting the use of vadose-zone models at Hanford are conceptual model uncertainty, parameter uncertainty, and spatial variability of parameters due to multiple scales of heterogeneity. A conceptual model is merely an assemblage of assumptions about features, events, and processes expected to represent field-scale flow-and-transport behavior. Field experiments conducted over the last 2 years suggested that the assumptions about transport were insufficient to assure credible and technically defensible analyses. A significant observation was the importance of anisotropy in field scale flow and transport. It was also recognized that many of the required parameters that could be easily obtained from well-designed field experiments were unknown. In addition, measured values were quite variable and typically represented averaged or calculated quantities that could not be verified. Despite the recognition that many of these parameters were spatially variable, there were insufficient data to allow analysis of the spatial correlation structure or to permit upscaling to length scales appropriate to the geometry of the transport domain or remedial system. Several needs emerged from the review and analysis of existing data and were incorporated into the design of the experiments described in the following sections.

The study was conceived to help to bridge the gap between localscale transport observations and fieldscale transport behavior. Ideally, flow parameters are determined by calibrating the Ric hard's water-flow equation to observations of water content and matric potential while transport parameters are obtained by calibrating the convective-dispersive equation (CDE) to observed solute-concentration profiles. The study was designed to allow multiple spatial and temporal observations of flow-and-transport processes in a domain encompassing multiple scales of heterogeneity. It was important that observations be made at length scales appropriate to the geometry of the formation and to the design and operation of remedial technologies. The study was conducted on a 60-m-long transect at the Army loop Road clastic dike site. The transect was instrumented with sensors for monitoring local-scale water content, matric potential, electrical conductivity, and tracer concentrations while at the same time, allowing larger scale measurements with non-invasive geophysical tools (Ward and Gee 2001; Gee and Ward 2001; Ward and Gee 2002). This report documents the experimental design and monitoring protocols and provides an overall status of the study at the end of the fiscal year. Although data analysis is in progress, we provide an overview of the preliminary results, focusing on observations that will be important to the design of the next series of experiments.

\subsection{Objectives and Scope}

The primary objective of the Vadose Zone Transport Field Study (VZTFS), as identified by Ward and Gee (2000), is to obtain hydrologic, geophysical, and geochemical data from controlled field studies to 
reduce the uncertainty in vadose-zone conceptual models and to facilitate the calibration of numerical models for water flow and contaminant transport through Hanford's heterogeneous vadose zone. A secondary objective is to evaluate advanced, cost-effective characterization methods with the potential to assess changing conditions in the vadose zone, particularly as surrogates of currently undetectable highrisk contaminants. The study is designed to assure the observation of flow-and-transport properties over multiple scales of heterogeneity, a pre-requisite for developing suitable techniques for upscaling and extrapolating parameters from clean representative sites to contaminated sites with minimal characterization.

Hanford's soils show extreme heterogeneity, and the constitutive properties (for example, the water retention function $\psi[\theta]$, the hydraulic conductivity tensor, $\mathbf{K}[\theta]$, dispersivity, $\lambda$, and the retardation coefficient, R) can be expected to vary in space. These soils also exhibit structural elements (lenses, clastic dikes) that redirect and focus water and solute fluxes at the local scale. Consequently, it is necessary to characterize the soil at length scales comparable to the total transport distance to derive parameters useful for describing infiltration and transport behavior. In this series of tests, we observed transport processes from the sediment core scale to the intermediate ( $\approx 60 \mathrm{~m}[197 \mathrm{ft}])$ scale with a goal of identifying the relation transport parameters and the scale of observation. The resulting data will facilitate developing an understanding of the influence of depositional processes on heterogeneity, a necessary step for integrating facies models, geostatistics, and subsurface monitoring into a useful tool for subsurface characterization and model calibration. The product of the completed study will be an improved understanding of the relationships between the spatial variations in constitutive properties, observed flow and transport phenomena, and their scale dependence. This will improve our ability to develop representative conceptual and numerical models of vadose-zone flow and transport. This result, in turn, will overcome a major hindrance to the evaluation of remediation and disposal options at different waste sites and assessment of the associated risk. 


\subsection{FY 2002 Test Activities}

Ward and Gee (2001) summarized the major geohydrological and geochemical knowledge gaps limiting the prediction of vadose-zone transport at Hanford. The data required to estimate objectively the spatial correlation structure of transport properties in Hanford's vadose zone are mostly unavailable, and model parameterization field-scale flow prediction continues to be a major limitation. Furthermore, the extreme heterogeneity of the Upper Hanford Formation strongly influences the water-distribution patterns, which may limit access to reactive surfaces and the distribution of sorbed contaminants. Defensible prediction of reactive transport therefore requires accurate description of sorption processes for conditions where the soil water content is less than satiated and is changing, i.e., transient flow in unsaturated systems. However, this aspect of transport has received little attention in experimental procedures. The test plan developed by Ward and Gee (2002) described a series of experiments designed to reduce conceptual model uncertainty and model parameterization and ultimately to evaluate remediation and disposal options at different waste sites. This report documents the status of studies conducted in FY 2002. These experiments were conducted at the clastic dike site near the Army Loop Road.

\subsection{Experimental Site}

The site is located in the 200 East Area of Hanford's elevated 200 Area (Figure 2.1). More specifically, it is $3 \mathrm{~km}$ south of the 200 East Separations Area, $0.1 \mathrm{~km}(328 \mathrm{ft}$ ) south of Army Loop Road, and $1.5 \mathrm{~km}$ east of Goose Egg Hill (Figure 2.1).

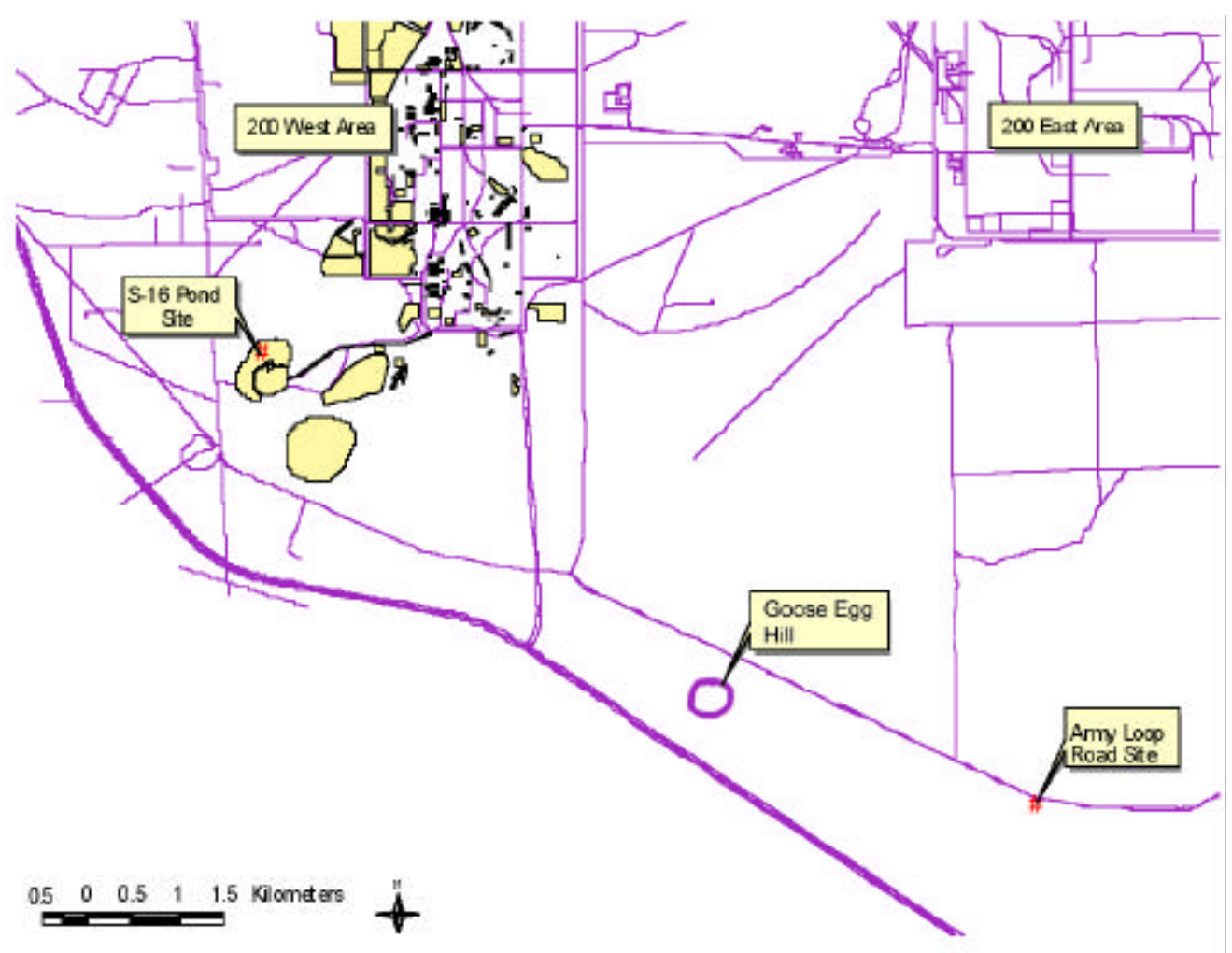

Figure 2.1. Location of the VZTFS Site Near Army Loop Road 
The site is characterized by cool, wet winters and hot, dry summers. Precipitation at the Hanford Meteorological Station (HMS), located about $10 \mathrm{~km}$ west of the test site, averages $174 \mathrm{~mm}\left(6.85 \mathrm{in}\right.$.) $\mathrm{yr}^{-1}$ since 1946. Nearly half of the precipitation normally comes in the winter months (November through February). The average monthly temperature ranges from $-1.5^{\circ} \mathrm{C}$ in January to $25^{\circ} \mathrm{C}$ in July. Humidity ranges from $75 \%$ in winter to $35 \%$ or less in summer.

The upper portion of the 200-Area plateau formed during catastrophic glacial flooding. Flood sediments were deposited when ice dams in western Montana and northern Idaho were breached, and massive volumes of water spilled across eastern and central Washington. This process repeated itself numerous times prior to about 13,000 years, bringing to the Plateau a thick sequence of sediments known as the Hanford formation (Reidel and Horton 1999). The surface soil at the site is a coarse sand, locally known as a Quincy sand, which is associated with the Quincy soil series (mixed, mesic, Xeric Torripsamments). The sand matrix has a high infiltration capacity $\left(>50 \mathrm{~mm}[>2 \mathrm{in}.] \mathrm{hr}^{-1}\right)$; thus, precipitation infiltrates readily with little or no runoff. However, the subsurface is highly heterogeneous with manifestations over a wide range of length scales (Figure 2.2a,b). Heterogeneities include clastic intrusions of both vertical (dikes) and horizontal (sills) intrusions (Figure 2.2c,d,e,f). Although the origin of these inclusions is not well defined, there are some hypotheses based on a review of the literature.
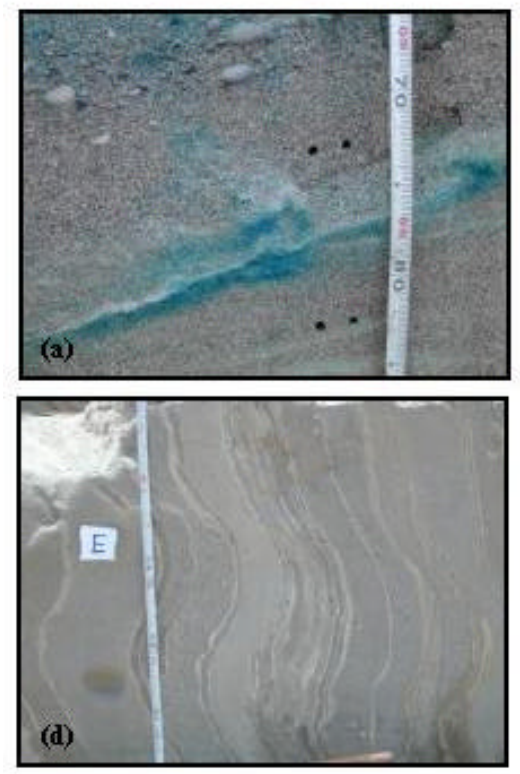
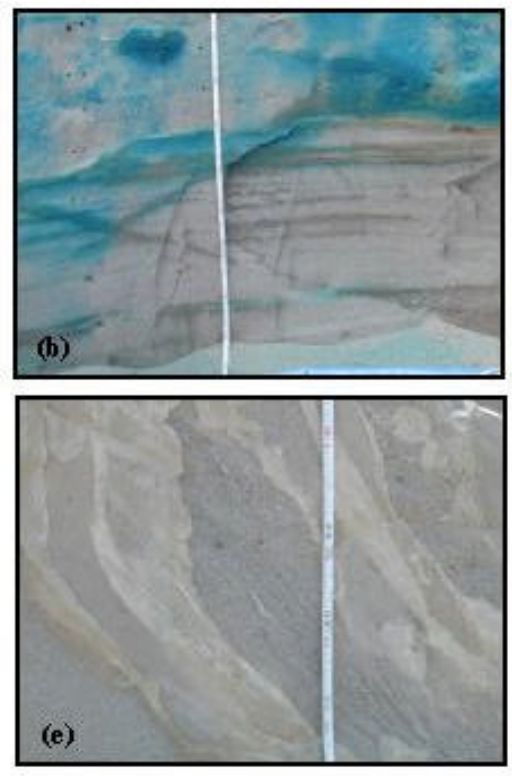
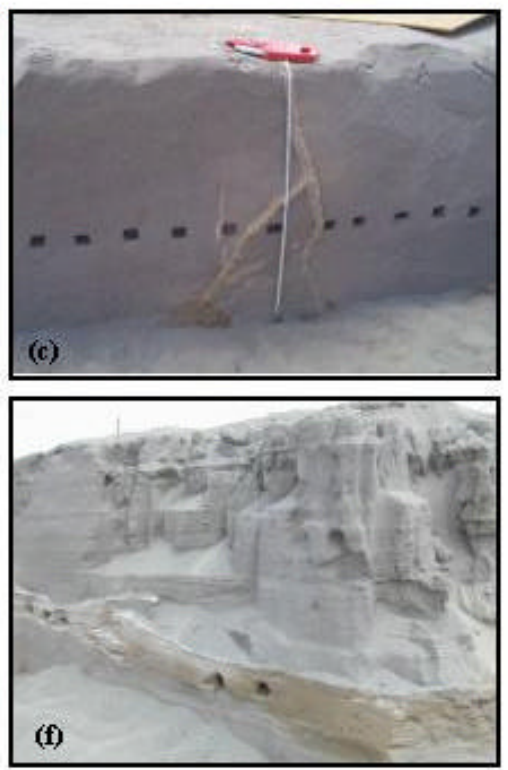

Figure 2.2. Field Site Outcrop Showing Multiple Scales at Which Heterogeneity is Manifested and its Effect on Flow Processes: (a) Cross Bedded Fine Lens Underlying a Coarse Sand, (b) Multi-Region Flow, Perhaps Due to Anisotropy. Clastic Intrusions Are also Shown: (c) Clastic Intrusion with Branching, (d) Planar Bedding Discordant Intrusion (dike), (e) Fine -Textured Laminations and Short-Range Structure, (f) Planar Bedding Concordant Intrusion (sill), Large-Scale Structure.

Clastic intrusions are typically planar structures filled by a forceful injection of sediment either from below or above (Dreimanis and Rappol 1997). These intrusions may be bedding discordant (dikes) or concordant (sills) and are characteristic of unstable environments. They have been observed in a variety of geological settings. Several hypotheses about their formation have been advanced to describe their 
formation, but according to Allen (1984, pp. 593-663), they tend to form when three conditions are met: (1) a state of horizontal tension, (2) the presence of suitable source materials, and (3) excess pore-water pressure. Such conditions typically existed in glacial and subglacial environments when a glacier or ice sheet overran saturated, unconsolidated fine-grained sediments (Boultan and Caban 1995). Many of the dikes reported in the literature have been interpreted as downward injections caused by glacial tectonism, e.g., ice wedges, with a lesser number being attributed to upward in trusions.

As seen in Figure 2.2, the main dike is mostly a planar structure of irregular geometry, with evidence of branching, and flanked by laminated silty sand sheets of variable thickness and extent. Dikes generally consist of laminated sand and silt, often with sand at the center and silt along the outer edges (silt/clay skins). The dikes in these networks typically range from $3 \mathrm{~cm}(1.2 \mathrm{in}$.) to $1 \mathrm{~m}(3.3 \mathrm{ft})$ in width, from $2 \mathrm{~m}$ $(6.6 \mathrm{ft})$ to greater than $55 \mathrm{~m}(180 \mathrm{ft})$ in depth, and from 1.5 to $100 \mathrm{~m}(5.0$ to $328 \mathrm{ft})$ along strike. The material adjacent to the dikes in this area is sand to gravelly sand. At the microscopic scale, the clastic dike is composed of an outer lining or skin of clay and/or silt with coarser in-filling material or inclusions (Figure $2.2 \mathrm{~b}$ ). These linings typically vary from 0.03 to $1.0 \mathrm{~mm}$ (0.0012 to $0.04 \mathrm{in}$.) in thickness, but can be as thick as $10 \mathrm{~mm}(0.4 \mathrm{in}$.). The effect of these linings on flow-and-transport processes is currently unknown. The width of individual in-filling layers ranges from as little as $0.01 \mathrm{~mm}(0.0004 \mathrm{in}$.) to more than $30 \mathrm{~cm}$ (11.8 in.), and their length can vary from about $0.2 \mathrm{~m}(0.66 \mathrm{ft})$ to more than $20 \mathrm{~m}$. In-filling sediments are typically poor to well-sorted sand, but may contain clay, silt, and gravel (Figure 2.2 inset). These characteristics suggest that the intrusions at this site could have formed as sediment dikes filling tension fractures in frozen overlying material (Dreimanis 1992) or as hydraulic dewatering structures of water-saturated sediments formed under the load of an advancing glacier (Broster 1991). Such intrusions typically appear as vertical pipes filled with underlying and overlying sediments with minor joints and faults infilled with sand.

At the macroscopic scale, the vertical structures may serve as preferential paths or impediments to flow, depending on the flow regime. The horizontal structures may act as capillary breaks, redirecting flow laterally until conditions are such that the underlying coarse layers can be penetrated. Given the range of structural, hydrogeological features present at this site, a wide range of geochemical characteristics might also be expected, making this site ideal for a study aimed at understanding the effects of heterogeneity and evaluating upscaling methodologies.

Vegetation at the site was originally a mixture of sagebrush and cheatgrass until the shrubs were destroyed by fire in the mid 80s. Before the tests in FY 2002, vegetation at the site was dominated with a sparse cover of cheatgrass. In preparation for the experiment, the site was cleared and leveled, and the

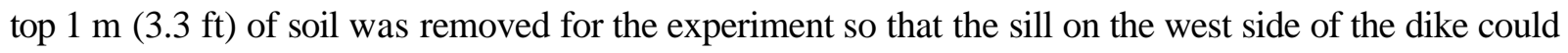
be closer to the surface.

\subsection{Experimental Design}

The rationale and details of the experimental design are described by Ward and Gee (2001), and only a brief summary is presented here. While a variety of methods exist for measuring the hydraulic and transport properties in unsaturated soils, not many are practical for use over multiple length scales or measuring the directional effects. This experiment was designed to allow measurement of the temporal and spatial relationships of constitutive properties over multiple scales, hence their scale dependence, and to allow estimation of longitudinal and transverse transport properties (Figure 2.3). The approach is 
based on the concept proposed by Leij et al. (1991) and the theory of steady flow from a surface line source proposed by Philip (1971). The objective is to conduct a field infiltration experiment and to measure the steady-state distributions of matric potential, $\psi$, water content, $\theta$, water storage, $\mathrm{W}$, and tracer travel time, $t$, beneath a surface line source. The resulting data are then used to calibrate the Richards water-flow equation coupled with the CDE to derive hydraulic and transport properties. The use of the analytical solution assumes that at the local scale, the flow is steady with 2-D convection and that the $\mathrm{CDE}$ adequately describes solute transport. Measurements of $\psi, \theta, \mathrm{W}$, and $\mathrm{t}$ are made at multiple water fluxes, $\mathrm{J}_{\mathrm{w}}$, and used to calculate constitutive properties and their spatial dependence.

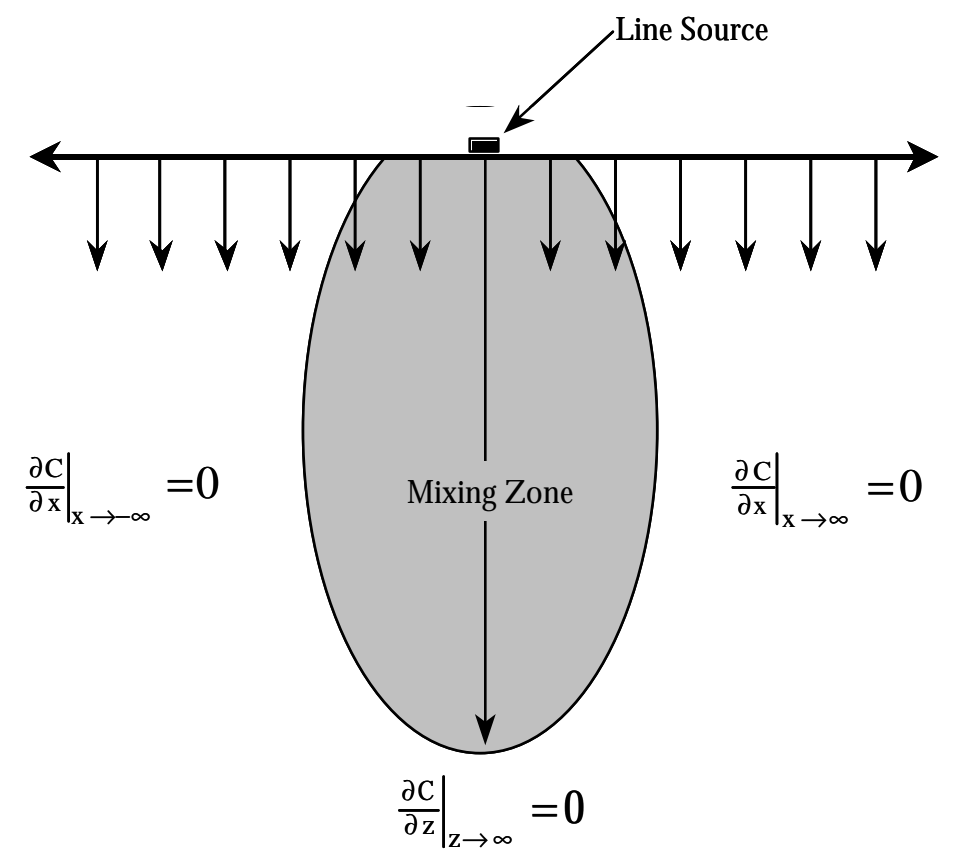

Figure 2.3. Schematic of 2-D Convection and 2-D Dispersion in a Half Plane of a Porous Medium

The water content and matric potential data provide a direct in situ measurement of the $\theta(\psi)$ function. At steady-state conditions, relating $\mathbf{J}_{\mathrm{w}}$ to the resulting equilibrium water content and matric potential provides a direct measure of the unsaturated hydraulic conductivity, $K(\theta)$ or $K(\psi)$, for the specific conditions. At the local scale, steady-state distributions of $\theta, \psi$, and $\mathrm{W}$ can be analyzed by inverse methods to determine the macroscopic capillary length, $\alpha$, and the saturated hydraulic conductivity, $\mathrm{K}_{\mathrm{s}}$, using the method reported by Zhang et al. (2000). Localscale analysis is simplified by using the analytical solutions to the advective-dispersive equation presented by Leij et al. (1991) modified to handle 2-D advection. However, a more rigorous analysis is needed for inversion of the coupled flow and transport equations. For this purpose, the coupled STOMP-UCODE technique, developed in FY 2000, will be improved to allow the analysis of transport measurements and to simultaneously optimize transport parameters.

\subsubsection{Instrumentation}

The experiments were conducted on a 60-m (197-ft) long transect at the Army Loop Road. Twin-rod time-domain reflectometry (TDR) probes were installed at $0.5-\mathrm{m}(1.6-\mathrm{ft})$ intervals along the transect to 
depths of $1.0 \mathrm{~m}, 0.8 \mathrm{~m}, 0.4 \mathrm{~m}$, and $0.2 \mathrm{~m}$. The probes were constructed of $1 / 4$-in.-diameter stainless steel rods spaced $7.6 \mathrm{~cm}(3 \mathrm{in}$.) apart parallel to the transect. Probes were spaced $0.15 \mathrm{~m}(0.5 \mathrm{ft})$ apart perpendicular to the transect. The longest $(1 \mathrm{~m}[3.3 \mathrm{ft}])$ probe was installed along the mid line of the transect, near the line source, with probes of decreasing length installed with increasing distance from the line-source increase (Figure 2.4). At the outer edge of the transect, a second set of 1-m (3.3-ft)-long probes were installed to capture any deeper lateral movement from the line source. These probes were installed on a 2-m (6.6-ft) interval along the transect. At 2-m (6.6-ft) intervals along the transect, one stainless steel rod of the 2-wire TDR probe was replaced with a stainless steel suction lysimeter configured to form a multipurpose TDR probe (Baumgartner et al. 1994). This configuration was used only at the 0.4 and $0.8-\mathrm{m}$ (1.3- and 2.6-ft) depths. The probes served the dual purpose of monitoring matric potential, $\psi$, and collecting pore-water samples for tracer analysis. Measurements of y were made during the transient phase of the experiment until steady-flow conditions were attained. At steady state,

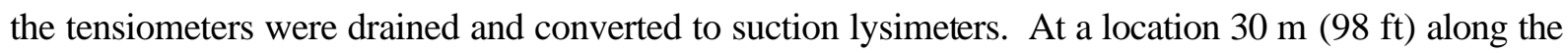
transect, a set of bimetallic thermocouples was installed to depths of $0.1,0.2$, and $0.8 \mathrm{~m}(0.3,0.7$, and $2.6 \mathrm{ft}$ ) to monitor soil temperature. A miniature tipping bucket was installed midway along each 10-m (32.8-ft) block to monitor the flow rate from the irrigation system. Eight 2-in.-diameter PVC tubes, part of the infrastructure from the FY 2000 Environmental Management Science Program (EMSP) experiment, remained as part of the monitoring system for use with a cross-borehole ground-penetrating radar (GPR) neutron probe. The layout of the transect, including the location of instrumentation and the PVC access tubes, is illustrated in Figure 2.5.

Following instrumentation, the soil surface was raked level and a polyethylene sheet laid on the surface to minimize evaporation, keep out natural precipitation, and insulate electrical connections from contact with the soil surface. All electrical connections were then made and a second sheet of plastic applied to cover the entire plot. The cover was designed to allow easy removal from the southern half to facilitate surface GPR measurements. Water was applied from a surface-line source located about $3 \mathrm{~cm}$ from the 1.0-m (3.3-ft) deep probe (Figure 2.5). Figure 2.6 is a photograph of the plot, just before it was covered with the plastic sheeting. 


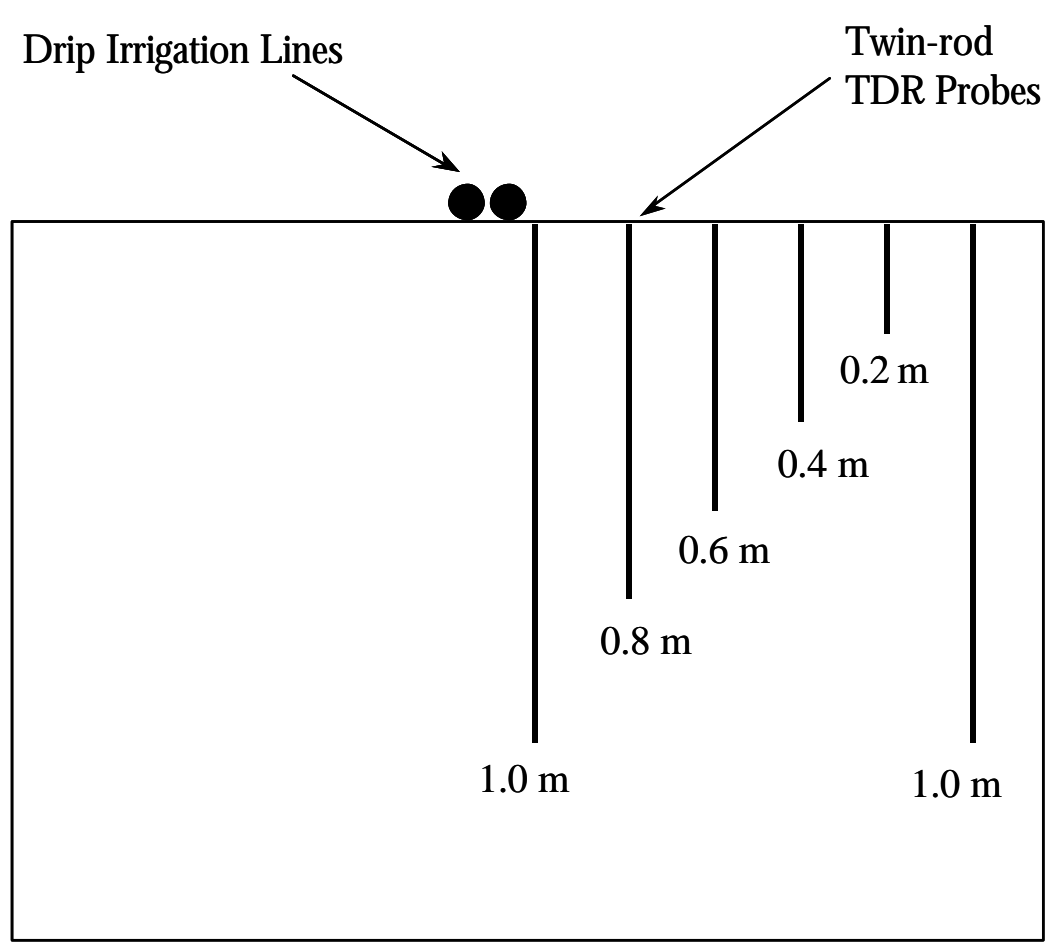

Figure 2.4. Schematic of Probe Installations. Each probe consists of a 2-rod TDR probe with a 5-cm (2-in.) inter rod s pacing. Probes are spaced $0.5 \mathrm{~m}(1.6-\mathrm{ft})$ apart, parallel to the long axis of the trench and $0.15 \mathrm{~m}(0.5 \mathrm{ft})$ perpendicular to the long axis.

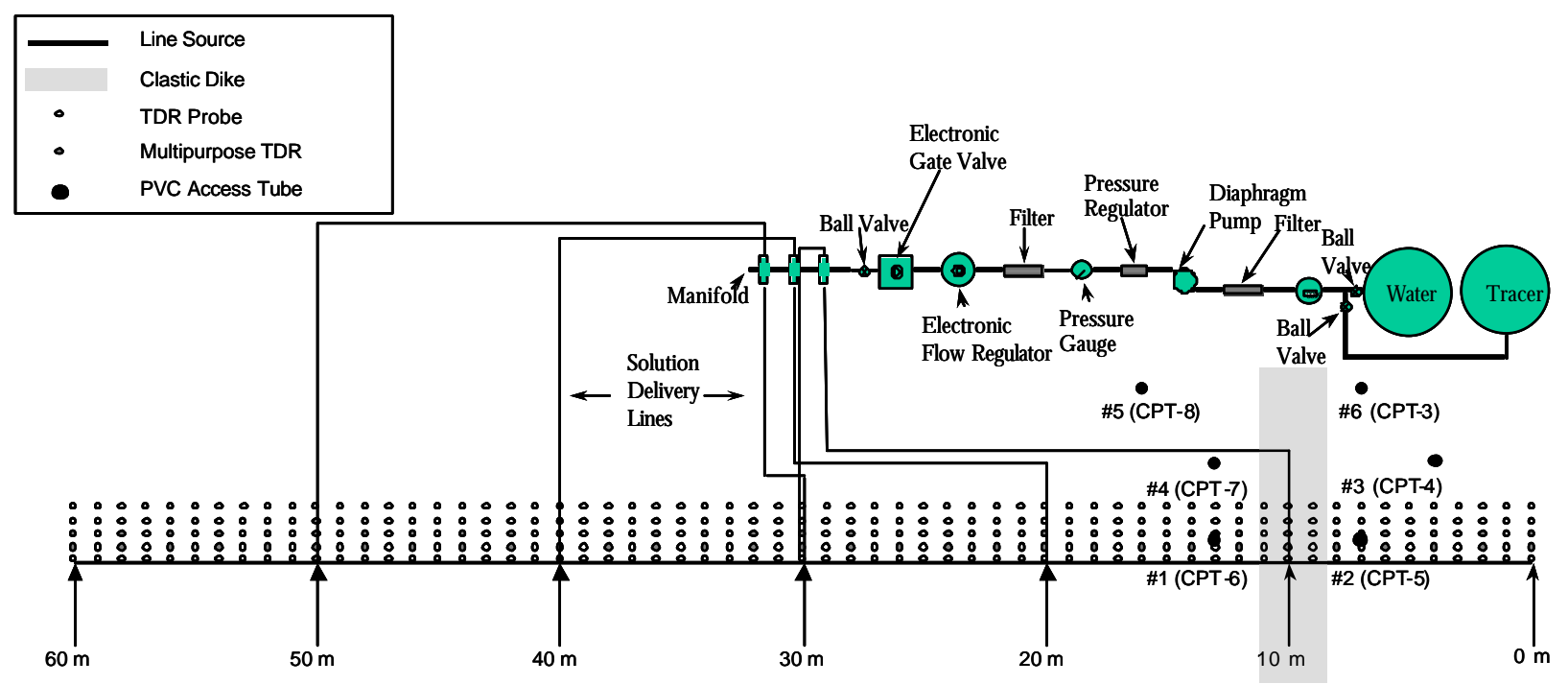

Figure 2.5. Schematic Layout Showing Common Offset Profiles and Borehole Radar Locations 


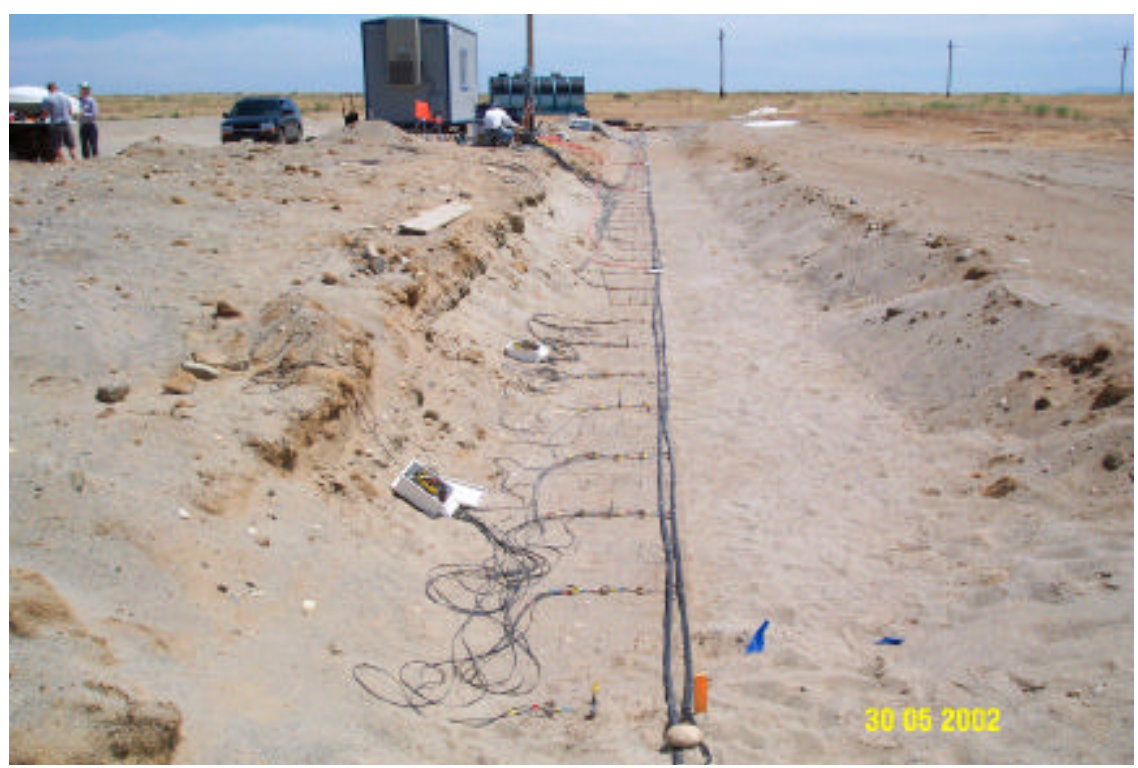

Figure 2.6. The FIELD SITE During Instrumentation Looking in an Easterly Direction Along the Transect. The TDR Probes were installed at 50-cm (20-in.) spacing, but measurements were made at 1.0-m (3.3-in.) spacing. Intermediate probes were used for High Resolution Resistivity Measurements. Multipurpose TDR (TDR + tensiometer) were installed on a 2.0-m (6.6-ft) spacing. A 16-channel TDR multiplexer is shown in the foreground at the left.

Water was applied at three rates, $0.1,0.01$, and $0.001 \mathrm{~K}_{\mathrm{s}}$, which for a sand matrix was equivalent to $10^{-3}$, $10^{-4}$, and $10^{-5} \mathrm{~cm} \mathrm{~s}^{-1}$. Irrigation started with the lowest rate and proceeded until steady-state-flow conditions were attained in the profile. At each flux, a direct measure of a $K(\theta)$ and $\psi(\theta)$ provided one point on the wetting curve. During wetting, the soil profile was monitored for $\theta, \psi$, and $\mathrm{W}$ at $1-\mathrm{h}$ intervals. Net infiltration rates were measured using a miniature tipping-bucket buried under the drip line. Measurements were also made during the subsequent drainage phase to provide data for the drainage branch of $\psi(\theta)$. At steady state, the tensiometers were converted over to suction lysimeters and used to collect water samples for tracer analysis. Water and tracer fronts were monitored using a combination of TDR, neutron probe, surface and cross-borehole radar, and high-resolution resistivity (HRR). The flux was incremented to the higher level after solution samples and TDR impedance measurements confirmed that the tracer had been leached from the profile. The boundary conditions applied during the course of the experiments are described below.

\subsubsection{Boundary Conditions}

Two infiltration experiments were conducted under constant-flux surface-boundary conditions. Water application started on May 14, 2002, with calibration of the irrigation system at a site about $50 \mathrm{~m}$ north of the plot. The irrigation system was moved into place on May 31, 2002, and water application started at an average rate of $243 \mathrm{~L} \mathrm{day}^{-1}$ (64 gpd) on June 1, 2002, for the first experiment. By June 25, 2002, a total of 16,644 L (4,397 gal) had been added and, based on TDR measurements of water content, the system was determined to be at steady state. At this time, a tracer solution consisting of $1.0 \mathrm{~g} \mathrm{~L}^{-1}$ potassium bromide and $7.5 \mathrm{~g} \mathrm{~L}^{-1}$ sodium thiosulfate was applied at the same rate as the irrigation water over a period 
of 3 days, starting on June 25, 2002. Household bleach (6\% sodium hypochlorite) was added at a rate of $260 \mathrm{ppm}$ to the irrigation tank and $120 \mathrm{ppm}$ to the main water tank to minimize the growth of algae and minimize plugging of the drip emitters. Problems with the pump system led to termination of irrigation over the weekend of July 26, 2002, after adding 24,018 L (6,345 gal) of water. Irrigation resumed on July 28 at a similar rate and continued for another 12 days, applying a total volume $28,558 \mathrm{~L}$ (7,544 gal) through August 7, 2002 (Figure 2.7).

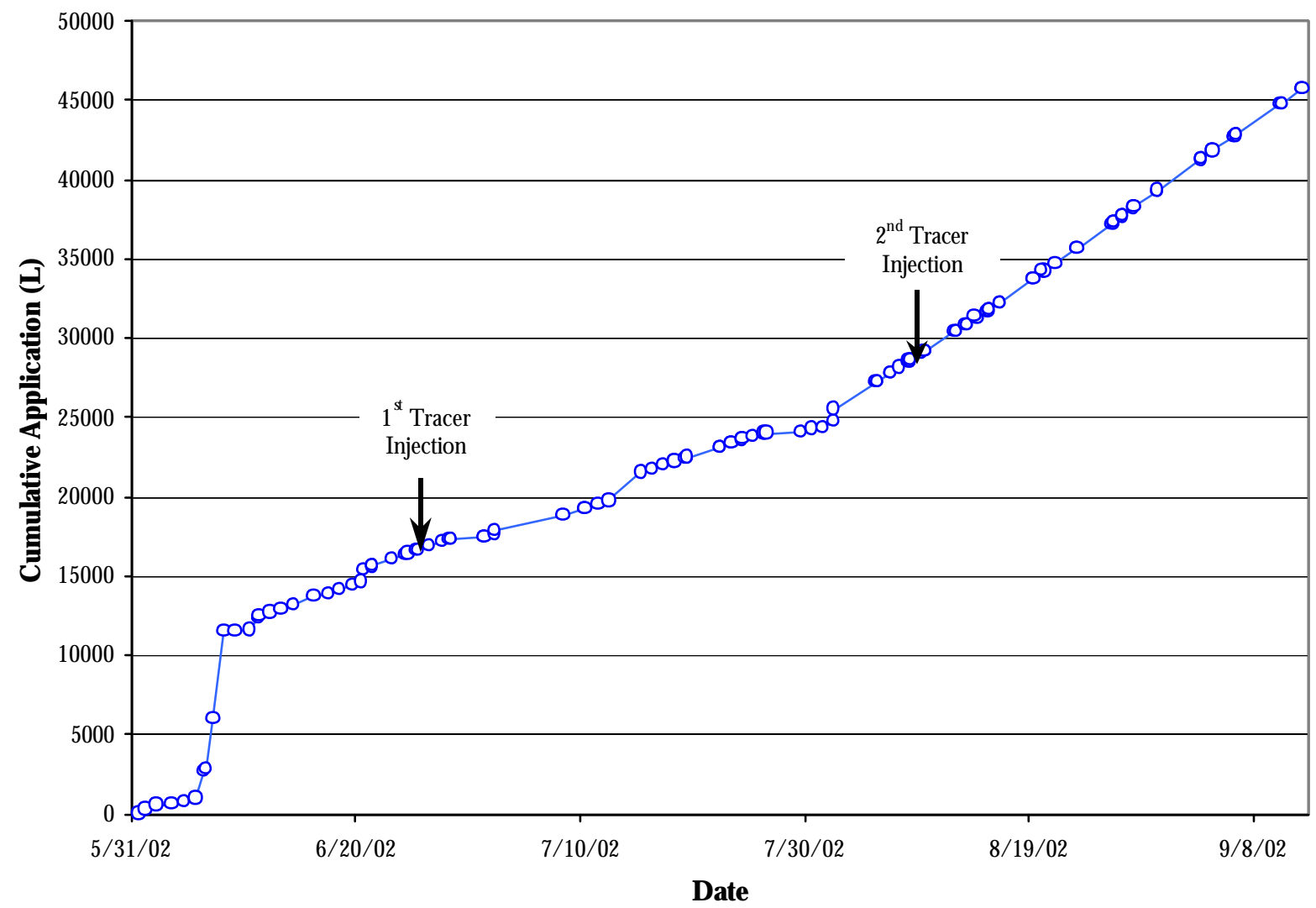

Figure 2.7. Cumulative Volume of Water Applied During the FY 2002 Field Experiment. The tracer injections are indicated by the arrows.

On July 31, 2002, the irrigation rate was increased to $485 \mathrm{~L} \mathrm{day}^{-1}$ (128.1 gpd) for the second injection experiment. The plot reached steady-state conditions on August 8, 2002, at which time the irrigation source was switched from the water tank to the tracer tank. For this second experiment, the tracer consisted of $1.0 \mathrm{~g} \mathrm{~L}^{-1}$ potassium bromide, $10.0 \mathrm{~g} \mathrm{~L}^{-1}$ sodium thiosulfate, and $1.3 \mathrm{~g} \mathrm{~L}^{-1}$ of Deuterium. In addition, sodium hypochlorite, from commercial bleach, was added to the main water tank at $116 \mathrm{ppm}$ to control algal growth. The injection protocol was similar to the first experiment, except that injection occurred over a period of 2 days. Details of the timing of the boundary conditions are summarized in Tables 2.1 and 2.2. 
Table 2.1. Schedule for the First FY 2002 Infiltration Experiment

\begin{tabular}{|c|c|c|c|c|c|}
\hline Date 2002 & Action & $\begin{array}{c}\text { Neutron } \\
\text { Probe } \\
\end{array}$ & $\begin{array}{c}\text { GPR } \\
\text { survey }\end{array}$ & XBR & Solution Samples \\
\hline $29 \mathrm{Apr}$ & trench excavation & & & & \\
\hline 29-Apr & pre-injection site walk down & & & & \\
\hline 10-May & baseline loggings & & & $\mathrm{X}$ & \\
\hline 14-May & baseline logging & & $\mathrm{X}$ & & \\
\hline 21-May & baseline logging & & $\mathrm{X}$ & & \\
\hline 31-May & drip lines placed and covered & $\mathrm{X}$ & & & \\
\hline 31-May & start water injection & & & & \\
\hline 3-Jun & monitor profile & & $\mathrm{X}$ & & \\
\hline 6-Jun & monitor profile & $\mathrm{X}$ & $\mathrm{X}$ & $\mathrm{X}$ & \\
\hline 10-Jun & monitor profile & $\mathrm{X}$ & & & \\
\hline 13-Jun & monitor profile & $\mathrm{X}$ & $\mathrm{X}$ & & \\
\hline 20-Jun & monitor profile & $\mathrm{X}$ & & & \\
\hline 20-Jun & collect samples & & & & $\mathrm{X}$ \\
\hline 24-Jun & collect samples & $\mathrm{X}$ & $\mathrm{X}$ & $\mathrm{X}$ & $\mathrm{X}$ \\
\hline 25-Jun & inject tracer-noon & & & & \\
\hline 26-Jun & collect samples & & & & $\mathrm{X}$ \\
\hline 27-Jun & collect samples & & $\mathrm{X}$ & & $\mathrm{X}$ \\
\hline 28-Jun & stop tracer & $\mathrm{X}$ & & & $\mathrm{X}$ \\
\hline 29-Jun & collect sample & & & & $\mathrm{X}$ \\
\hline 30-Jun & collect sample & & & & $\mathrm{X}$ \\
\hline 1-Jul & collect samples & $\mathrm{X}$ & & & $\mathrm{X}$ \\
\hline 2-Jul & collect samples & & & & $\mathrm{X}$ \\
\hline 3-Jul & collect sample & & & & $\mathrm{X}$ \\
\hline 5-Jul & collect samples & & & & $\mathrm{X}$ \\
\hline 8-Jul & collect sample & $\mathrm{X}$ & & & $\mathrm{X}$ \\
\hline 10-Jul & collect sample & & & & $\mathrm{X}$ \\
\hline 12-Jul & collect sample & & & & $\mathrm{X}$ \\
\hline 15-Jul & collect samples & $\mathrm{X}$ & & & $\mathrm{X}$ \\
\hline 18-Jul & collect sample & & & & $\mathrm{X}$ \\
\hline 22-Jul & collect samples & $\mathrm{X}$ & & & $\mathrm{X}$ \\
\hline 25-Jul & collect sample & & & & $\mathrm{X}$ \\
\hline 29-Jul & monitor & $\mathrm{X}$ & $\mathrm{X}$ & & \\
\hline
\end{tabular}

\subsection{Monitoring Methods}

Monitoring infrastructure at the site was limited to eight PVC access tubes installed by cone penetrometer in FY 2001. Given the objectives of this study, we focused on established, near-surface monitoring techniques to provide realtime measurements of the variables of interest. A selection of nine technologies resulted from a screening process and included neutron moisture logging, tensiometry/suction lysimetry, cross borehole radar (XBR), surface radar, and HRR. For monitoring transport behavior, a suite of tracers, including natural isotopes, was injected at specified intervals. The details of each of the nine methods selected are summarized in Table 2.3. 
Table 2.2. Schedule for the Second FY 2002 Infiltration Experiment

\begin{tabular}{|c|c|c|c|c|c|}
\hline 31-Jul & Adjust flow rate (2X) & & & & \\
\hline 2-Aug & Check on flow rate & & & & \\
\hline 5-Aug & confirm flow rate & $\mathrm{X}$ & & & \\
\hline 7-Aug & collect sample & & & & $\mathrm{X}$ \\
\hline 8-Aug & start $2^{\text {nd }}$ injection & $\mathrm{X}$ & & & $\mathrm{X}$ \\
\hline 9-Aug & stop tracer injection & & & & $\mathrm{X}$ \\
\hline 10-Aug & collect samples & & & & $\mathrm{X}$ \\
\hline 11-Aug & collect samples & & & & $\mathrm{X}$ \\
\hline 12-Aug & collect sample & $\mathrm{X}$ & $\mathrm{X}$ & & $\mathrm{X}$ \\
\hline 13-Aug & collect sample & & & & $\mathrm{X}$ \\
\hline 14-Aug & collect sample & & & & $\mathrm{X}$ \\
\hline 15-Aug & collect sample & & & & $\mathrm{X}$ \\
\hline 16-Aug & collect sample & & & & $\mathrm{X}$ \\
\hline 19-Aug & collect sample & & & & $\mathrm{X}$ \\
\hline 20-Aug & monitor & $\mathrm{X}$ & & & \\
\hline 21-Aug & collect samples & & & & $\mathrm{X}$ \\
\hline 23-Aug & collect samples & & & & $\bar{X}$ \\
\hline 26-Aug & collect samples & $\mathrm{X}$ & & & $\mathrm{X}$ \\
\hline 28-Aug & collect samples & & & & $\mathrm{X}$ \\
\hline 30-Aug & collect samples & & & & $\mathrm{X}$ \\
\hline 4-Sep & collect samples & $\mathrm{X}$ & $\mathrm{X}$ & $\mathrm{X}$ & $\mathrm{X}$ \\
\hline 6-Sep & collect samples & & & & $\mathrm{X}$ \\
\hline 12-Sep & terminate test & & & & \\
\hline
\end{tabular}

\subsubsection{Time Domain Reflectometry}

Time-domain reflectometry was chosen for automated measurement of soil water content and for tracking solute movement. Following the introduction of this technique for simultaneous measurements of water content and solute concentrations (Ward and Kachanoski 1989), ${ }^{(a)}$ it is now routinely used for monitoring transport experiments at Hanford. ${ }^{(a)}$ With this method, the TDR is used to monitor changes in electromagnetic (EM) travel times along the length of the waveguide from which the dielectric constant and water content are calculated according to the method of Topp et al (1980). Simultaneous recording of the waveforms permits calculation of the reflection coefficient from which the impedance is inferred. Bulk electrical conductivity is determined from the impedance and solute mass flux calculated according to the method of Kachanoski et al (1992). Using the method described by Baumgartner et al. (1994), the TDR technique was coupled with tensiometry to allow measurement of $\psi$ in the same monitoring volume.

(a) AL Ward, RE Clayton, and JC Ritter. 1998. Hanford Low-Activity Tank Waste Performance Assessment Activity: Determination of In Situ Hydraulic Parameters of the Hanford Surface Sediments. A letter report for activity S1W03490 submitted to the Lockheed Martin Hanford Company. 
Table 2.3. Characterization and Monitoring Technologies Selected for FY-2002 Field Tests

\begin{tabular}{|c|c|c|c|c|}
\hline Method & Application & $\begin{array}{c}\text { Properties } \\
\text { Measured/Derived }\end{array}$ & Resolution & Status \\
\hline Neutron-Neutron & $\begin{array}{l}\text { Moisture content, } \\
\text { porosity (saturated), } \\
\text { identification of } \\
\text { aquitards, lithology }\end{array}$ & $\begin{array}{l}\text { Hydrogen } \\
\text { concentration }\end{array}$ & $\leq 10 \mathrm{~cm}$ & $\begin{array}{l}\text { Provides precise measure of hydrogen concentration. } \\
\text { Multiple detector systems are borehole compensated. } \\
\text { Epithermal systems are less affected by lithologic } \\
\text { variation than thermal systems. }\end{array}$ \\
\hline $\begin{array}{l}\text { Cross Borehole } \\
\text { Radar }\end{array}$ & $\begin{array}{l}\text { Moisture distribution, } \\
\text { lithology, soil } \\
\text { disturbances, buried } \\
\text { materials }\end{array}$ & Dielectric permittivity & $\begin{array}{l}5-60 \mathrm{~cm} \\
\text { depending } \\
\text { on } \\
\text { frequency }\end{array}$ & $\begin{array}{l}\text { Depth of penetration may be quite limited }(<30 \mathrm{~cm}) \text { if } \\
\text { the formation is electrically conductive; it can be as high } \\
\text { as } 9 \mathrm{~m} \text { in non-conductive formations. Measures } \\
\text { continuous vertical profile. Interpretation may be } \\
\text { difficult in complex situations. }\end{array}$ \\
\hline $\begin{array}{l}\text { Time Domain } \\
\text { Reflectometry }\end{array}$ & & & & \\
\hline $\begin{array}{l}\text { Tensiometry/ } \\
\text { Suction } \\
\text { Lysimetry }\end{array}$ & $\begin{array}{l}\text { Derivation of matric } \\
\text { potential; water } \\
\text { content, hydraulic } \\
\text { conductivity; pore- } \\
\text { water samples }\end{array}$ & $\begin{array}{l}\text { Matric potential } \\
\text { Collect pore-water } \\
\text { samples for chemical } \\
\text { analysis }\end{array}$ & Point & $\begin{array}{l}\text { Established technology with traditional methods. } \\
\text { Advanced tensiometers/lysimeters now being applied in } \\
\text { boreholes and at environmental scales. }\end{array}$ \\
\hline $\begin{array}{l}\text { Electrical } \\
\text { Resistivity } \\
\text { Tomography }\end{array}$ & $\begin{array}{l}\text { Monitor changes in } \\
\text { bulk resistivity }\end{array}$ & $\begin{array}{l}\text { DC electrical } \\
\text { resistivity }\end{array}$ & $\geq 1 \mathrm{~m}$ & $\begin{array}{l}\text { Continuous monitoring of resistivity in either a plane or a } \\
\text { volume. Requires the installation of a series of } \\
\text { electrodes in at least two monitoring wells. Now } \\
\text { commercially available. }\end{array}$ \\
\hline
\end{tabular}


The TDR probes were multiplexed to a Tektronix 1502B reflectometer using Dynamax multiplexers. Data acquisition was controlled by computer using the U.S. Department of Agriculture (USDA)developed TDR software, TACQ. Shortly after installation, initial measurements of water content and bulk electrical conductivity were made. The TDR system was divided into two blocks to reduce the total sampling time and allow the capture of short-term transients. Each block included a computer, a TDR unit, and the associated multiplexers. In general, TDR measurements were made at 1-h intervals.

\subsubsection{Neutron Moisture Logging}

Neutron probes are used routinely to monitor field water contents at the Hanford Site (e.g., Ward and Gee 1997; Fayer et al. 1999; DOE 1999). Details of this technique and measurement procedure are described in Ward and Gee (2001). The probe used in this study was Campbell Pacific Hydroprobe, with a $50 \mathrm{mCi}$ americium-241 and beryllium source. Use of the neutron probe requires cased access tubes, which, in this study, were made of PVC. Locations of the access tubes are shown in Figure 2.5. The tubes were installed by cone penetrometer to depths ranging from 5 to $8 \mathrm{~m}$ (16 to $26 \mathrm{ft}$ ) in May 2001. The installation procedure and the initial logging results are described by Murray et al. (2001). The numbering system used in this experiment and the relation to the system used by Murray et al (2001) are also shown in Figure 2.5. For each measurement, the probe was initialized, a standard shield count, $\mathrm{C}_{\mathrm{s}}$, was recorded, and the probe was lowered into a vertical access tube. Fifteen-second neutron counts in the soil, $\mathrm{C}$, were made while pulling the probe back to the surface. Probe counts in the soil were converted to a count ratio, $C R=C / C_{s}$, and subsequently converted to water content, $\theta$, using a function derived from a field calibration experiment. The calibration procedure and results are described in a subsequent section.

\subsubsection{Cross Borehole Radar}

Cross borehole radar measurements provide information about the porous medium between two boreholes. Like TDR, the radar technique measures the travel time of EM waves in the soil from which the permittivity and water content are inferred. A major difference, however, is a larger scale interrogated by XBR and the requirement for access tubes. The primary information obtained is the variation of dielectric properties of the subsurface between the access tubes. Also inferred is the lithology and information-related characteristic of the soil texture. In this case, fine-textured materials, such as those comprising the dike, can be expected to delay EM times and attenuate the transmitted radar pulse. The velocity and amplitude of the data are recorded as a function of time to give a series of data in the time domain. Numerous rays are typically measured, and the data are usually collected in a tomographic mode, which are then inverted to provide a tomogram of either velocity or attenuation properties. Arrival times and pulse amplitudes are measured and analyzed in the time domain using tomographic processing techniques. However, the data are often reduced to the frequency domain to infer attributes of the data indicative of various subsurface properties. The data can also be collected in a more rapid fashion in just a limited cross-well configuration. The data can also be processed to give reflection images in stratigraphic sequences. Cross borehole measurements were made in six access tubes shown in Figure 2.5 according to the schedule described in Table 2.2.

\subsubsection{Surface Ground Penetrating Radar}

There is a gap in support between the typical localscale measurement and scale of practical interest for field-scale modeling, which is often much larger. GPR, which provides non-invasive measurement of 
EM travel times, can provide information of subsurface characteristics and water content from the subcentimeter scale to the kilometer scale. The depth of interrogation is a function of antennae frequency with the lower frequency antennae giving greater depths of penetration. For this study, antennas with center frequencies of 200 and $450 \mathrm{MHz}$ were chosen to monitor wetting-front migration. Surface GPR measurements were made in two modes (1) reflection (Figure 2.8a) and (2) common midpoint (CMP) (Figure 2.8b). In the reflection mode, the transmitter-to-receiver spacing is kept constant as they are moved along the transect. In the CMP mode, the common midpoint is the midway between the two antennas and therefore remains fixed as the antennas are moved apart. Measurements started with 0.1-m $(0.33-\mathrm{ft})$ antenna separation with subsequent increases of about $0.1 \mathrm{~m}(0.33 \mathrm{ft})$ (each antenna is moved $0.05 \mathrm{~m}[1.6 \mathrm{ft}]$ away from the other) about their common midpoint to a maximum of $2 \mathrm{~m}(6.6 \mathrm{ft})$.
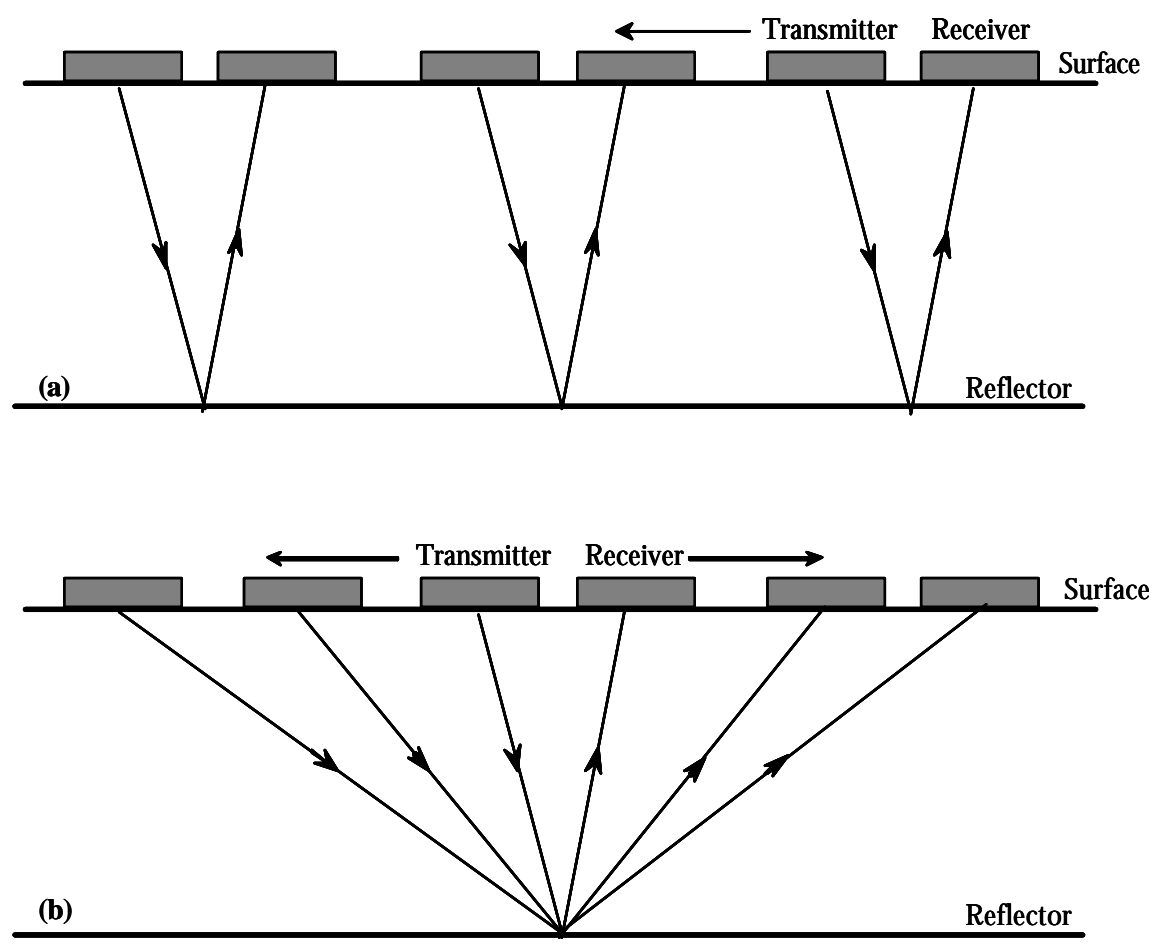

Figure 2.8. Illustration of the Acquisition Modes Used for Surface GPR Operation: (a) Reflection Mode: Antennas Are Kept at a Fixed Spacing as they Are Moved Along the Transect; (b) Common Midpoint: the Common Midpoint Is the Midpoint Between the Transmitter and Receiver that Remains Fixed as they Are Moved Apart

Because the depth to the different interfaces is quite variable and generally unknown a priori, the velocity of the ground wave is best determined by CMP measurements to allow calculation of the propagation velocity at the site. Given the heterogeneity at the site, it was expected that this would require separate CMP measurements in the sand-dominated matrix and on the dike.

Each field campaign consisted of common offset profiles and CMPs. Measurements were typically made in a west-to-east direction (left to right in Figure 2.5). The common offset profiles were collected parallel to the drip line and within the shallow trench excavated for this line. Two lines were typically collected for each frequency with the following parameters. In the first profile, data were collected at $450 \mathrm{MHz}$ at a 5-cm (2-in.) interval while in the second profile, data were collected at $225 \mathrm{MHz}$ with a 10-cm (4-in.) 
spacing. The first profile was collected parallel to the drip line with an 80-cm (31.5-in.) spacing between the center of the antenna and the line source. The second profile was also measured parallel to the line source, but at a distance of $30 \mathrm{~cm}$ (12 in.) between the center of the antenna and the line source. The CMPs were made at $450 \mathrm{MHz}$ and typically followed the common offset profiles with measurements at $\mathrm{x}=8$ and $20 \mathrm{~m}$ ( 26 and $65.6 \mathrm{ft}$ ) along the transect The radar data were collected as a measurement of signal amplitude versus time, and conversion to permittivity and water content required knowledge of the ground-wave velocity. Calculation of $\theta$ was a three-step process. The data were processed using a combination of ground-wave analysis and normal moveout (NMO) analysis of the reflections (Yilmaz 1987, p. 526).

First, the velocities of the air and ground waves to depth $\mathrm{L}$ were calculated simply as v=L.t ${ }^{-1}$ (Figure 2.9). The apparent dielectric permittivity was calculated from the air and ground wave travel-time picks as follows (Husiman et al. 2001):

$$
\kappa=\left[\frac{c\left(t_{\text {ground }}-t_{\text {air }}\right)+x}{x}\right]^{2}
$$

where $\quad c=$ EM velocity in air

$x=$ antenna separation $(3.5 \mathrm{~m})$

$\mathrm{t}_{\text {ground }}=$ arrival time of the ground wave

$t_{\text {air }}=$ arrival time of the air wave.

In the final step, $\kappa$ was converted to a mean water content, $\bar{\theta}$, over the sampling depth using the $\theta(\kappa)$ derived by Topp et al. (1980). Water storage over the GPR sampling depth, L, was calculated simply as $\bar{\theta} \mathrm{L}$. The penetration depth of the ground wave decreases with increasing antenna frequency, $\mathrm{f}$, and increasing $\theta$, which is determined from the wavelength of the ground wave, $\lambda$ (Du and Rummel 1994). The penetration depth was expected to vary between $0.5 \lambda$ and $\lambda$ with $\lambda=\mathrm{c} /\left(\mathrm{f} \cdot \kappa^{1 / 2}\right)$.

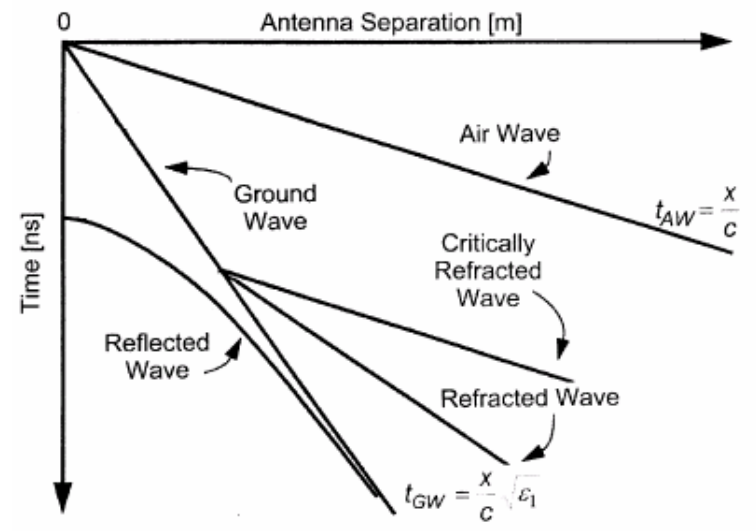

\section{Figure 2.9. Schematic of CMP Sounding-Ray Paths and Idealized Event Arrival Time Versus Antenna Spacing}

The first survey was conducted on May 14, 2002, with a GSSI SIR10A Model 5106 GPR system. The $300-\mathrm{MHz}$ antenna was attached to a 40-m (131-ft) antenna cable and was pulled by hand. Data were collected as discrete points with a point collected every $5 \mathrm{~cm}(2 \mathrm{in}$.$) in a 150 \mathrm{~ns}$ window. The sample rate 
was 512 samples per scan in 16 BIT format. The data gain was fixed at $10 \mathrm{db}$, and filtering was via a low-pass filter 2/50 and a high-pass filter 2/4. Data were collected in two 60-m (197-ft) sections starting at the west end of the transect and moving east (Figure 2.10). There was no data stacking. Subsequent surveys were conducted with a PulseEKKO ${ }^{\mathrm{TM}} 1000$ GPR system using a $200 \mathrm{~V}$ transmitter (Sensors and Software, Mississauga, Ontario, Canada) with two sets of antennae with center frequencies of 225 and $450 \mathrm{MHz}$.

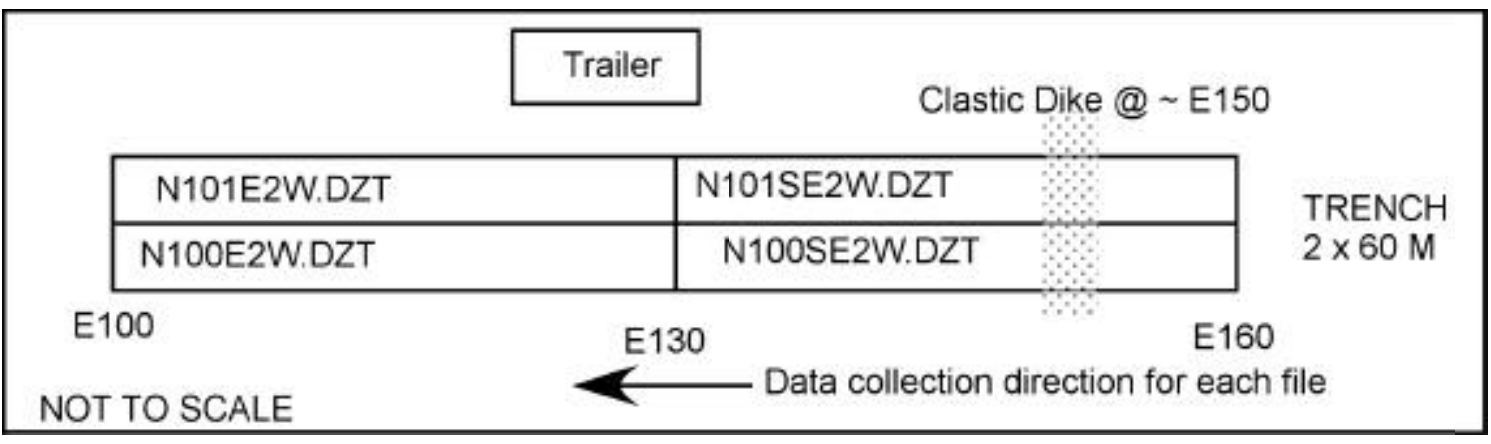

Figure 2.10. Schematic of Transect Showing Direction of Data Collection with Surface GPR

\subsubsection{Tensiometers}

Tensiometers are water-filled porous cups placed in contact with soils to measure matric potential (Cassel and Klute 1986). The water pressure inside the porous cup is subsequently monitored with a pressure gauge or electronic transducer and related directly to the matric potential of the soil water. The tensiometers were designed to facilitate easy conversion to suction lysimeters for collecting pore-water samples after tracer application. Tensiometers were constructed from a 3/8-in. i.d. stainless steel tube and a $1 / 2$-in.-long sintered steel (Motts). Welding a conical piece of stainless steel in place closed the distal end of the cup. The cup assembly was welded to the steel tube to form a steel tensiometer. The tip of the cone was later ground flat to reduce confocal effects when used with TDR. Tensiometers were soaked in a solution of alcohol for $24 \mathrm{~h}$ to remove hydrophilic residues and then rinsed in copious amounts of distilled water. Tensiometers were installed to depths of 0.4 and $0.8 \mathrm{~m}(1.3$ and $2.6 \mathrm{ft})$ at 2-m (6.6-ft) intervals along the transect (Figure 2.5). To make measurements of matric potential, the tubes were filled with de-aired water, and the tops of the tubes were closed with a cap assembly, which was clamped in place with a hose clamp. A temperature-compensated pressure transducer was installed on each tensiometer for automated measurements (Figure 2.11). Transducers were multiplexed with Campbell Scientific AM416 multiplexers and controlled by a Campbell CR10 datalogger. Measurements were made at 60-s intervals and averaged over 30 -min intervals for recording.

\subsubsection{Suction Lysimetry and Tracer Methods}

The tracers used in the first experiment consisted of $1.0 \mathrm{~g} \mathrm{~L}^{-1}$ potassiu m bromide, and $7.5 \mathrm{~g} \mathrm{~L}^{-1}$ sodium thiosulfate and was applied over a 3-day period starting June 25, 2002. Household bleach (6\% sodium hypochlorite) was added at a rate of $260 \mathrm{ppm}$ in the small tank and $120 \mathrm{ppm}$ in the main tank to control algal growth. In the second experiment, the tracer consisted of $1.0 \mathrm{~g} \mathrm{~L}^{-1}$ potassium bromide, $10.0 \mathrm{~g} \mathrm{~L}^{-1}$ sodium thiosulfate, and $1.3 \mathrm{~g} \mathrm{~L}^{-1}$ of Deuterium. Deuterium was added a means of detecting and quantifying preferential flow. Household bleach was added at a rate of $116 \mathrm{ppm}$ to the main water tank in this case. In both experiments, tracer salts were dissolved in river water in a separate tank plumbed into 
the pump system (Figure 2.5). Tracer distributions were determined from pore-water samples obtained from the suction lysimeters and analyzed by auto analyzer. The interest of this study was non-reactive transport, so the analysis was limited to anions in the two experiments in addition to deuterium in the second experiment.

Tracers were typically applied after steady-state flow conditions were attained. Following the achievement of steady-state flow conditions, water in the tensiometers was removed, and the transducer and cap assembly were replaced with a rubber septum. The septum was fitted with two spaghetti tubes, one for evacuating the tube and one for recovering the pore-water sample. A schematic of the sampler and the associated plumbing is shown in Figure 2.12.

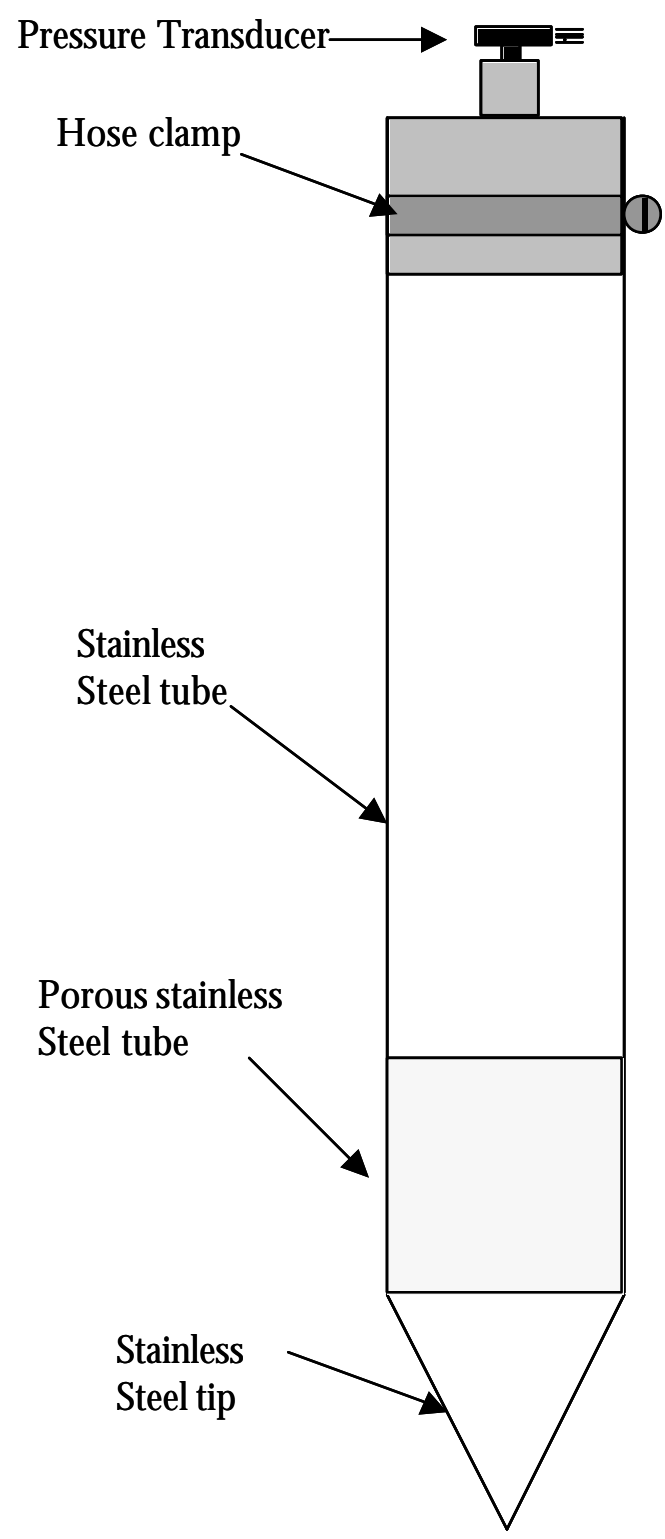

Figure 2.11. Schematic of Tensiometer and Wiring for Automated Matric Potential Measurements 


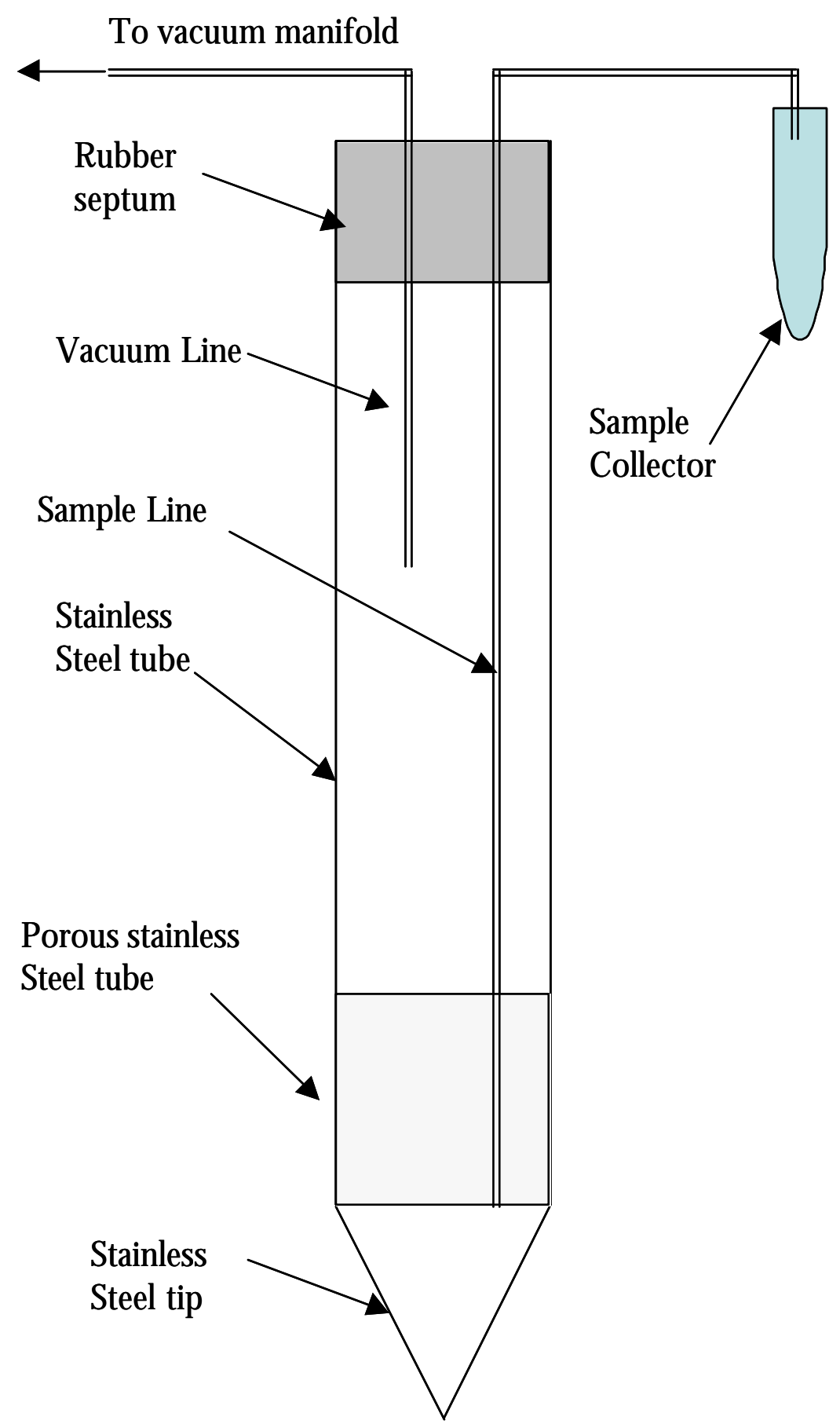

Figure 2.12. Schematic of Stainless Steel Suction Lysimeter/Tensiometer and Vacuum System Used for Collecting Water Samples 
Pore-water sampling was accomplished through the use of a manifold system and a 12-V vacuum pump. Each lysimeter was connected to a central vacuum line on the manifold via a $15-\mathrm{cm}$ (6-in.) vacuum line (Figure 2.12). The central vacuum line was connected directly to the pump. To collect a sample, the sample tube was first closed and the system evacuated by running the pump for 30 to $60 \mathrm{~min}$. After evacuation, a vaccutainer blood-collection tube (anti-coagulant free) was attached to the collection tube, and valve A was opened to allow equilibration with atmospheric pressure. The increase in pressure in the lysimeter coupled with the small vacuum in the collection tube forced the water sample out of the lysimeter into the collection tube. The sequence of steps to assure sample collection is described below.

1. Make sure that gray rubber stoppers are covering the needles (the needles where the sample vial will be connected). It will snap into place over the lip on the green plastic.

2. Turn on the pump and adjust the bleed valve so that the pressure is between 17 and 20 . The two ends of the tubing will read approximately 13.

3. Let the pump run for $1 \mathrm{~h}$.

4. Label the sample vials. Labeling: Location - Depth - date (e.g., 0-80-629 for $0 \mathrm{~m} 80 \mathrm{~cm}$ on June 29, 2002).

5. Turn off the pump and open the valve so that the pressure starts to return to atmospheric.

6. Pull off the gray stoppers and put them in a zip-lock bag for later. Put new labeled vials on the needles.

7. Most vials will fill in seconds.

8. Remove samples and put in order in tray. For vials that are almost full, use the $10-\mathrm{mL}$ vials to suck the remaining water from the tensiometer. The used $10-\mathrm{mL}$ vials can be discarded.

9. Put the gray stoppers back on the needles.

10. Record the estimated volumes of vials in the laboratory record book (LRB).

11. Take the samples to Sigma 5 for analysis.

In the event that insufficient sample $(<5 \mathrm{~mL})$ was collected, the collection tubes were left in place for an additional 5 to 10 min after which steps 8 through 11 were completed. Samples were labeled to include the distance along the transect, the depth, and the sampling date, e.g., 5-80-629 for a sample from $5 \mathrm{~m}$ (16.4 ft) along the transect at $80 \mathrm{~cm}$ (31.5 in.) on June 29, 2002. The sampling schedule was determined by modeling the injection with a goal of adequately describing the peak and collecting at least 15 wellspaced samples per location to assure adequate description of the breakthrough curve.

Tracer concentrations were measured on the pore-water samples using ion chromatography at Pacific Northwest National Laboratory (PNNL). Data were analyzed to locate the center of mass (time or depth) and the variance about the mean for each sampling location. The resulting data were used to generate flux-concentration curves. Resident breakthrough curves were also developed using TDR-measured electrical conductivity. Tracer-breakthrough curves were fitted to a simple 2-D advection and 2-D dispersion model to quantify the transport velocity and the transverse and longitudinal dispersion coefficients for the conservative tracers. To evaluate the parameters without making assumptions about the transport model, data were also analyzed using moment time analysis. 


\subsection{Modeling the Experiment}

Before the experiment, distributions of moisture beneath the line source were predicted using the analytical solution described by Zhang et al. (2000). The solution is coupled to the steady-state solutions for constant flux from a line source described by Phillip (1971), which was expressed in terms of a matric-flux potential:

$$
\phi(y, z)=\frac{q}{\pi} e^{\frac{\alpha z}{2}}\left[K_{0}\left(\frac{\alpha}{2} \sqrt{y^{2}+z^{2}}\right)-\frac{\alpha}{2} e^{\frac{\alpha z}{2}} \int_{z}^{\infty} e^{-\frac{\alpha z}{2}} K_{0}\left(\frac{\alpha}{2} \sqrt{y^{2}+z^{2}}\right) d z\right]
$$

where $\quad y=$ horizontal distance, perpendicular to the line source

$\mathrm{z}=$ vertical distance from the source (positive downward)

$\alpha=$ inverse macroscopic capillary length $\left(\mathrm{m}^{-1}\right)$

$\mathrm{K}_{\mathrm{s}}=$ saturated hydraulic conductivity $\left(\mathrm{m} \mathrm{s}^{-1}\right)$

$\mathrm{q}=$ source strength $\left(\mathrm{m}^{3} \mathrm{~s}^{-1} \mathrm{~m}^{-1}\right)$

$\mathrm{K}_{0}=$ modified Bessel function of the second type of order zero

At the source, $y=0$, and Eq. [1] simplifies to

$$
\phi(z)=\frac{q}{\pi} e^{\frac{\alpha z}{2}}\left[\left(1+\frac{\alpha}{2} z\right) K_{0}\left(\frac{\alpha}{2} z\right)-\frac{\alpha}{2} z K_{1}\left(\frac{\alpha}{2} z\right)\right]
$$

where $\mathrm{K}_{1}$ is a modified Bessel function of the second type of order one. Assuming that the unsaturated hydraulic conductivity function is log linear and decreases with decreasing matric potential, $\psi$, (Gardner 1958), $\psi$ is defined as:

$$
\psi(\mathrm{x}, \mathrm{z})=\frac{1}{\alpha} \ln \left[\frac{\alpha}{\mathrm{K}_{\mathrm{s}}} \phi(\mathrm{x}, \mathrm{z})\right]
$$

Calculation of the water content from the matric potential is accomplished by invoking the Russo-Gardner relationship between $\theta$ and $\psi$ proposed by Russo (1988):

$$
\theta(\psi)=\theta_{\mathrm{r}}+\left(\theta_{\mathrm{s}}-\theta_{\mathrm{r}}\right)\left[\mathrm{e}^{0.5 \alpha \psi}(1-0.5 \alpha \psi)\right]^{\frac{2}{2+\mathrm{m}}}
$$

where $\theta_{\mathrm{s}}$ is the saturated soil water content, $\theta_{\mathrm{r}}$ is the residual soil water content, and $\mathrm{m}$ is a constant equal to 0.5 in this study. Zhang et al. (2000) used these relationships to describe the spatial distribution of $\psi(\mathrm{y}, \mathrm{z})$ under a line source as

$$
\psi(\mathrm{x}, \mathrm{z})=\frac{1}{\alpha} \ln \left\{\left[\frac{\alpha}{\pi} \frac{\mathrm{q}}{\mathrm{K}_{\mathrm{s}}} \mathrm{e}^{\frac{\alpha \mathrm{z}}{2}}\left[\mathrm{~K}_{0}\left(\frac{\alpha}{2} \sqrt{\mathrm{y}^{2}+\mathrm{z}^{2}}\right)-\frac{\alpha}{2} \mathrm{e}^{\frac{\alpha \mathrm{z}}{2}} \int_{\mathrm{z}}^{\infty} \mathrm{e}^{-\frac{\alpha \mathrm{z}}{2}} \mathrm{~K}_{0}\left(\frac{\alpha}{2} \sqrt{\mathrm{y}^{2}+\mathrm{z}^{2}}\right) \mathrm{dz}\right]\right]\right\}
$$

with

$$
\psi_{0}(\mathrm{z})=\frac{1}{\alpha} \ln \left\{\frac{\alpha}{\mathrm{K}_{\mathrm{s}}} \frac{\mathrm{q}}{\pi} \mathrm{e}^{\frac{\alpha \mathrm{z}}{2}}\left[\left(1+\frac{\alpha \mathrm{Z}}{2}\right) \mathrm{K}_{0}\left(\frac{\alpha \mathrm{Z}}{2}\right)-\frac{\alpha \mathrm{Z}}{2} \mathrm{~K}_{1}\left(\frac{\alpha \mathrm{Z}}{2}\right)\right]\right\}, \text { if } \mathrm{x}=0
$$


The steady-state water storage, $\mathrm{W}(\mathrm{m})$, from the soil surface to $\mathrm{z}=\mathrm{L}$ below a surface-line source at steady state is given by $\mathrm{W}(\mathrm{L})=\bar{\theta} \cdot \mathrm{L}$, with $\bar{\theta}$ being the average soil water content, or

$$
W(y, L)=\theta_{r} L+\left(\theta_{s}-\theta_{r}\right) \int_{0}^{L}\left[e^{(0.5 \alpha \psi(y, z))}(1-0.5 \alpha \psi(y, z))\right]^{p .8} d z
$$

Similarly, solute travel time from the surface to $z=z^{*}$ directly below the line source $(y=0)$ is given by (Zhang et al. 2000)

$$
\mathrm{T}\left(\mathrm{z}^{*}\right)=\frac{2 \mathrm{p}}{\mathrm{aq}} \int_{0}^{\mathrm{z}^{*}} \frac{?_{\mathrm{r}}+\left(?_{\mathrm{s}}-?_{\mathrm{r}}\right)\left[\mathrm{e}^{\left(0.5 \mathrm{a} 0_{0}(\mathrm{z})\right)}\left(1-0.5 \mathrm{a} \cdot{ }_{0}(\mathrm{z})\right)\right]^{0.8}}{\mathrm{e}^{\frac{\mathrm{az}}{2}} \mathrm{~K}_{1}\left(\frac{\mathrm{az}}{2}\right)} \mathrm{dz}
$$

Equations (2.2) to (2.6) were used to predict the distribution pressure head, soil-water content, and soilwater storage at steady state under a surface-line source. Steady-state distributions of $\psi(\mathrm{x}, \mathrm{z})$ and $\theta(\mathrm{x}, \mathrm{z})$ were generated using Eq. (2.6) to develop the monitoring protocol. Steady-state $\theta(x, z)$ and the irrigation rate were used to determine the expected dilution ratios and pore-water velocities and to optimize tracer input and sampling protocol to assure the capture of the peak tracer concentration. The goal was to obtain about 15 to 20 pore water samples over the length of each injection. Tracer breakthrough curves for the expected steady-state $\theta(\mathrm{x}, \mathrm{z})$ were predicted using the analytical solution to the CDE. Transport in a homogeneous medium while assuming two-dimensional (2-D) advection and 2-D dispersion is described by:

$$
\frac{\partial C}{\partial t}=D_{L} \frac{\partial^{2} C}{\partial z^{2}}-v_{z} \frac{\partial C}{\partial z}+D_{T} \frac{\partial^{2} C}{\partial y^{2}}-v_{y} \frac{\partial C}{\partial y}
$$

$$
\text { where } \quad \begin{aligned}
\mathrm{C} & =\text { solute concentration }\left[\mathrm{M} \mathrm{L}^{-3}\right] \\
\mathrm{t} & =\text { time }[\mathrm{T}] \\
\mathrm{D}_{\mathrm{L}} \text { and } \mathrm{D}_{\mathrm{T}} & =\text { longitudinal and transverse dispersion coefficients }\left[\mathrm{L}^{2}\right], \text { respectively } \\
\mathrm{V} & =\text { pore water velocity }\left[\mathrm{L} \mathrm{t}^{-1}\right] \\
\mathrm{y} & =\text { horizontal distance, perpendicular to the line source } \\
\mathrm{Z} & =\text { vertical distance from the source }
\end{aligned}
$$

The solution domain is a half plane with y $=0$ and the other boundaries at infinity. Leij et al. (1991) have presented solutions for this and similar problems in terms of $\mathrm{C}(\mathrm{y}, \mathrm{z})$. A linear relation is assumed between the dispersion coefficient and velocity, i.e., $\mathrm{D}=\mathrm{D}_{\mathrm{o}}+\lambda \mathrm{v}$, where $\lambda$ is the dispersivity and $\mathrm{D}_{\mathrm{o}}$ is the molecular diffusion coefficient. The model was parameterized using a mean value of $\lambda_{\mathrm{L}}=0.2 \mathrm{~m}$ $(0.66 \mathrm{ft})$ reported for near-surface layers at Hanford. ${ }^{\text {(a) }}$ Pore-water velocities were derived from the ratio of source strength to the simulated $\theta(\mathrm{y}, \mathrm{z})$ distributions described above.

(a) AL Ward, RE Clayton, and JC Ritter. 1998. Hanford Low-Activity Tank Waste Performance Assessment Activity: Determination of In Situ Hydraulic Parameters of the Hanford Surface Sediments. A letter report for activity S1W03490 submitted to the Lockheed Martin Hanford Company. 


\subsection{Results}

This section summarizes the results of the FY 2002 field tests and also reports on progress related to developing a more robust conceptual model of vadose-zone transport for the Hanford Site. The latter activities included an innovative approach for measuring localscale hydraulic conductivity and its anisotropy, development of a new conceptual modelfor state-dependent anisotropy, continued work on parameter scaling, and three-dimensional (3-D) inverse modeling of unsaturated flow. The results of the FY 2002 are first summarized, starting with modeling results used to optimize the design of the experiment.

\subsection{Premodeling the Experiment}

Figure 3.1a shows the steady-state distribution of $\theta(\mathrm{y}, \mathrm{z})$ while $\psi(\mathrm{y}, \mathrm{z})$ is shown in Figure 3.1b. These distributions were predicted by Eq. (2.6) for a line source of strength $10^{-6} \mathrm{~m}^{2} \mathrm{~s}^{-1}$ located at $(\mathrm{y}, \mathrm{z})=(0,0)$. The matric potential clearly decreases (becomes more negative) with increasing distance from the line source for all depths. However, for any given distance $y>0$ from the source, $\psi(y, z)$ increases with depth to a maximum and then decreases as z continues to increase. As expected, the maximum value of $\psi(\mathrm{y}, \mathrm{z})$ is at the source. The extent of the saturated region near the source is considered to be the region through which infiltration occurs and is useful for calculating the flux density, $\mathbf{J}_{\mathrm{w}}$. Predicted $\psi(\mathrm{y}, \mathrm{z})$ are well within the range of tensiometer performance, suggesting the potential for determining $K(\psi)$ and for collecting water samples for tracer analysis. Steady state $\theta(y, z)$ is shown in Figure $3.1 \mathrm{~b}$ and reflects the distribution of $\psi(y, z)$. Simulations were repeated for the three expected values of source strength to assure that the required monitoring and sampling could be accomplished.
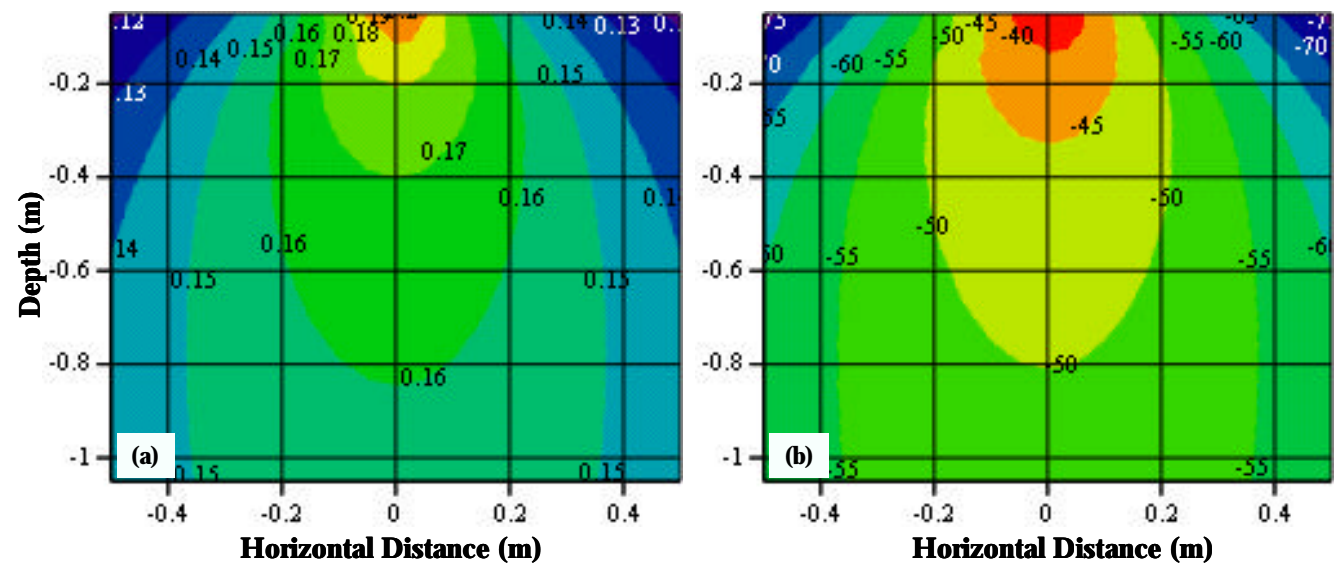

Figure 3.1. Schematic of Stainless Steel Suction Lysimeter/Tensiometer and Vacuum System Used for Collecting Water Samples

In the field experiment, probe installation started at $3 \mathrm{~cm}$ from the line source; therefore, profiles of $\theta(\mathrm{y}, \mathrm{z})$ and $\psi(y, z)$ must be adjusted to account for this offset. 
Figure 3.2 shows the predicted $\theta(\mathrm{z})$ profiles at the expected locations for the 1-, 0.8-, 0.4, and 0.2-m (3.3-, 2.6-, 1.3-, and 0.66-ft) probes. Recall that the probes are spaced $0.15 \mathrm{~m}(0.5 \mathrm{ft})$ apart, perpendicular to the source. The water content is highest near the source (1-m and 0.8-m probes) and decreases with depth and distance from the line source.

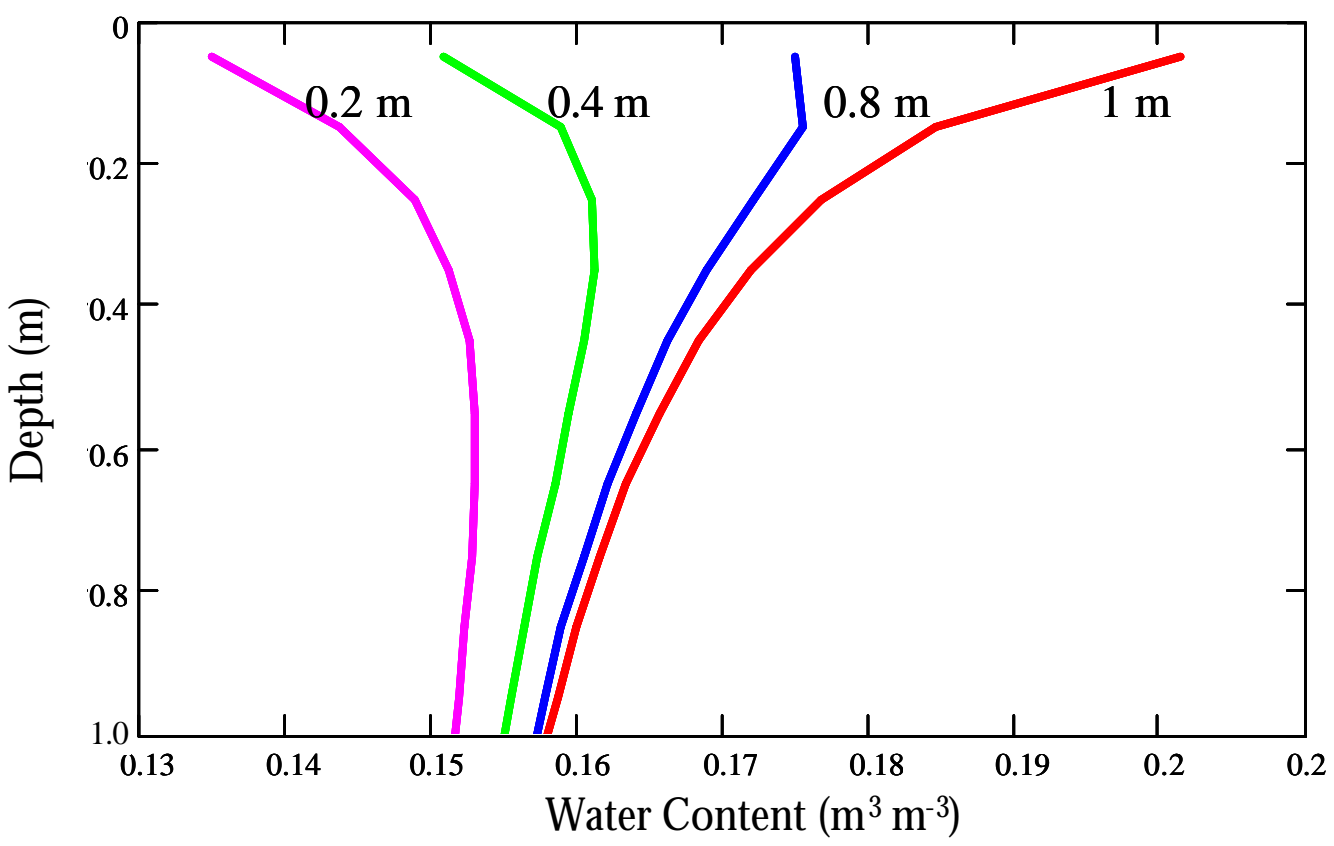

Figure 3.2. Predicted Water Content Profiles at 0.15-m (0.5-ft) Increments from the Line Source

However, at greater distances from the source, the $\theta(\mathrm{z})$, there is an initial increase followed by a decrease.. This is consistent with the shape of the wetting front shown in Figure 3.1. Given that the TDR probe reports a mean value, $\bar{?}_{\mathrm{L}}$, averaged over probe length, $\mathrm{L}$, a comparison of $\bar{?}_{\mathrm{L}}$ for different probe locations is needed to estimate mean travel time with the steady-state solution to the CDE. Mean values were calculated in a two-step procedure. First, the $\theta(\mathrm{y}, \mathrm{z})$ was integrated over depth $\mathrm{L}$ to determine the water storage, $\mathrm{W}$. The mean water content was then calculated by dividing $\mathrm{W}$ by $\mathrm{L}$. Predicted $\mathrm{W}$ and $\bar{?}_{\mathrm{L}}$ are shown in Table 3.1. As can be expected, the mean water content decreases with distance from the line source.

Table 3.1. Predicted Water Storage and $\bar{?}_{\mathrm{L}}$ for Different Probe Lengths

\begin{tabular}{||c|c|c|c||}
\hline $\mathbf{L}(\mathbf{m})$ & $\mathbf{y}(\mathbf{m})$ & $\mathbf{W}(\mathbf{m m})$ & $\bar{?}_{\mathrm{L}}\left(\mathbf{m}^{\mathbf{3}} \mathbf{m}^{\mathbf{- 3}}\right)$ \\
\hline 1.0 & 0.05 & 169.5 & 0.170 \\
\hline 0.8 & 0.20 & 127.6 & 0.159 \\
\hline 0.4 & 0.35 & 56.4 & 0.141 \\
\hline 0.2 & 0.50 & 24.2 & 0.121 \\
\hline
\end{tabular}


Figure 3.3 shows predicted flux-concentration breakthrough curves at $0.8-$ and $0.4 \mathrm{~m}$ (2.6- and $1.3-\mathrm{ft})$ depths. Because of the decrease in $\bar{?}_{\mathrm{L}}$ with distance from the source, travel time shows an inverse square dependence with distance and travel time varies accordingly. The tracer appears sooner at the $0.8-\mathrm{m}$ (2.6-ft) depth, and the travel time to $0.4 \mathrm{~m}(1.3 \mathrm{ft})$ is longer. This apparent contradiction is due to the 2-D flow field and the 2-D nature of the advective and dispersive fields. Although the peak traveltimes are quite similar, the amount of dispersion mean travel times is quite different. This type of information was used to optimize the sampling protocol to assure the capture of the peak concentration.

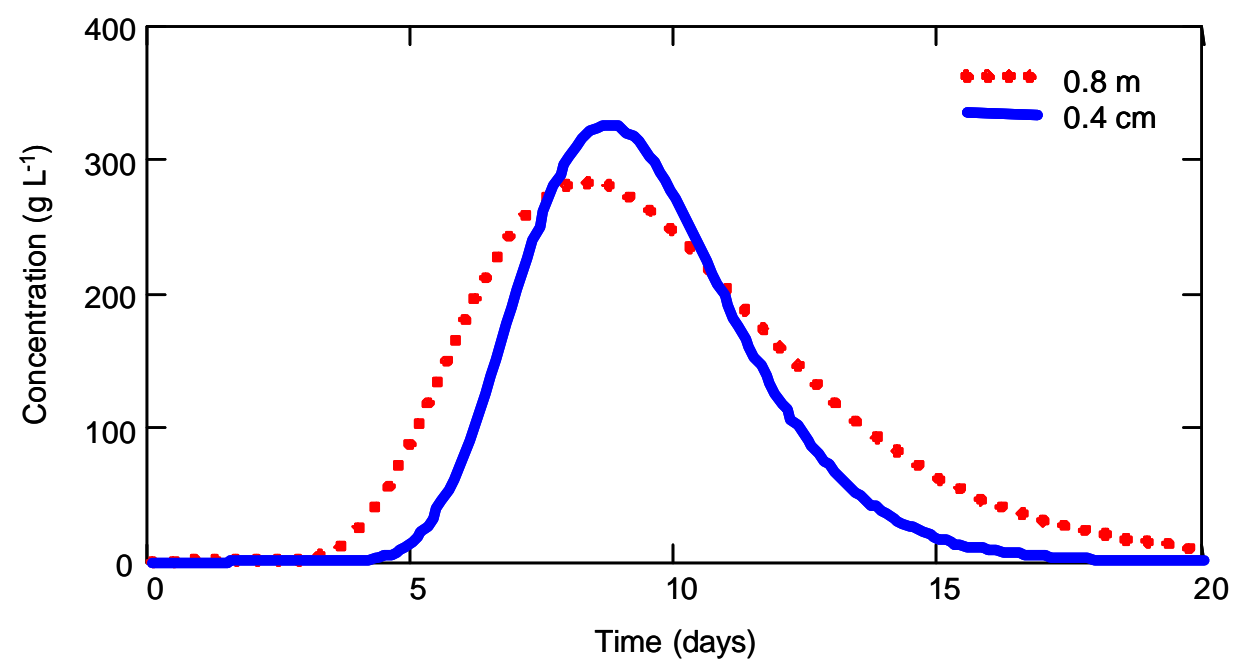

Figure 3.3. Predicted Flux Concentrations of a Conservative Tracer at Locations $(y, z)=(0.15,0.8)$ and $(0.30,0.4)$. Note the longer travel time to the $0.4-\mathrm{m}(1.3-\mathrm{ft})$ depth. This is due to the inverse square dependence of travel time with distance from the source.

\subsection{Neutron Probe Data Summary}

The neutron moisture gauge (hydroprobe) was used as the standard for distributions of soil water content, $\theta$, in this study. The instrument used in this study was a Campbell Pacific Nuclear (CPN) neutron hydroprobe (Model 503 DR), serial number H30083414. Proper calibration of the neutron probe and subsequent verification is critical to successful use. Probes are factory calibrated and typically show a linear relationship between probe counts and volumetric moisture content. However, the factory calibration is not always appropriate for field use, especially in fine-textured soil, given that soils are inherently heterogeneous. Although this probe has been calibrated for site use, the use of PVC access tubes instead of the standard aluminum tubes dictated the need for a new calibration curve.

\subsubsection{Calibration}

Probe calibration was conducted in the field at the experimental site at the Army Loop Road dike excavation. Calibration measurements were made in 2-in.-diameter schedule 40 PVC tubes installed by cone penetrometer in May 2001. Measurements were made at 10-cm (4-in.) increments from the surface to a depth of at $66 \mathrm{~cm}$ (26 in.). Undisturbed soil samples were taken in thin-walled aluminum (5-cm [2-in.]-o.d., 10-cm [4-in.]-long) cores at 15-cm (6-in.) increments in the lower sand unit near Cone 
Penetrometer Technology (CPT) Tube \#1. These cores provided information at the lower end of the moisture scale. A 2-m (6.6-ft.)-diameter ring was then installed around the access tube, and water was added to increase the moisture content. Sampling was repeated to obtain neutron count data at the higher water content. A final set of cores was collected near CPT Tube \#8 where sampling focused on the effect of the fine-textured lens. Cores were analyzed to determine bulk density and water content. Neutronprobe readings were taken at the same depths at which the samples were taken.

Figure 3.4a shows a plot of $\theta$ as a function of count ratio, the ratio of hydroprobe counts in the soil, $\mathrm{C}$, to shield counts, $\mathrm{C}_{\mathrm{s}}$, collected in the two field campaigns. All measurements in the 0 - to 10 -cm (0- to 4-in.) range were removed before analysis.

The relationship is clearly curvilinear and is best described by the power function

$$
?=0.3735 \mathrm{CR}^{1.8756}
$$

The coefficient of determination $\left(\mathrm{r}^{2}\right)$ for the power function is 0.85 , compared to 0.65 for a linear model. Given the relatively poor fit and knowledge that the site is composed of two distinct soil types (sand matrix and fine-textured composites in the dike), the data were analyzed as two distinct populations to investigate the need for separate calibration curves. There are two main factors contributing to the hydroprobe response: variability in mineralogic al composition and variability in water-content distributions, typically due to variability in physical and hydraulic properties. Both sources of heterogeneity can affect probe response, particularly in measuring vertical profiles of water content, and it has been suggested that different calibration curves may be needed for different textures. Variations of a few percent for most elements encountered in soils rarely cause variations in $\theta$ of more than $0.015 \mathrm{~m}^{3} \mathrm{~m}^{-3}$.

Extensive excavation at the site shows a 15- to 30-cm (6- to 12-in.) fine-textured layer at a depth of $3 \mathrm{~m}$

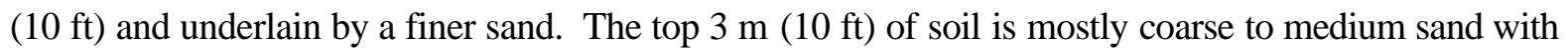
thin fine-textured lenses (Dike images). The fine-textured layer contains $25 \%$ silt-sized particles, $10 \%$ sand, and $65 \%$ clay-sized particles. The bulk density, determined by the clod method, was $1.8 \mathrm{~g} \mathrm{~m}^{-3}$. Experimental investigations on a variety of soils have established that, in addition to the moisture content of the soil, the probe reading depends mainly on dry bulk density with chemical composition being of less importance. Figure $3.4 \mathrm{~b}$ shows a significant improvement in the quality of the fit when the data are separated into two populations. There was no significant difference between linear and power function models for the data collected in the sand matrix. The data were described equally well with a linear model

$$
?=0.3416 \mathrm{CR}-0.0566
$$

with a coefficient of determination of 0.93 and the power function model

$$
?=0.2858 \mathrm{CR}{ }^{1.41}
$$

with a coefficient of determination of 0.97 . The power function is perhaps more meaningful as it suggests a count rate of zero for $\theta=0$. Given the limited number of data points, the choice of calibration functions cannot be finalized, and it is planned that calibration will continue in the next set of experiments. 
Nevertheless, for the purpose of this report, the relationship shown in Figure 3.4a and described by the power function described by Eq. (3.1) are used to illustrate the data collected during the field tests.
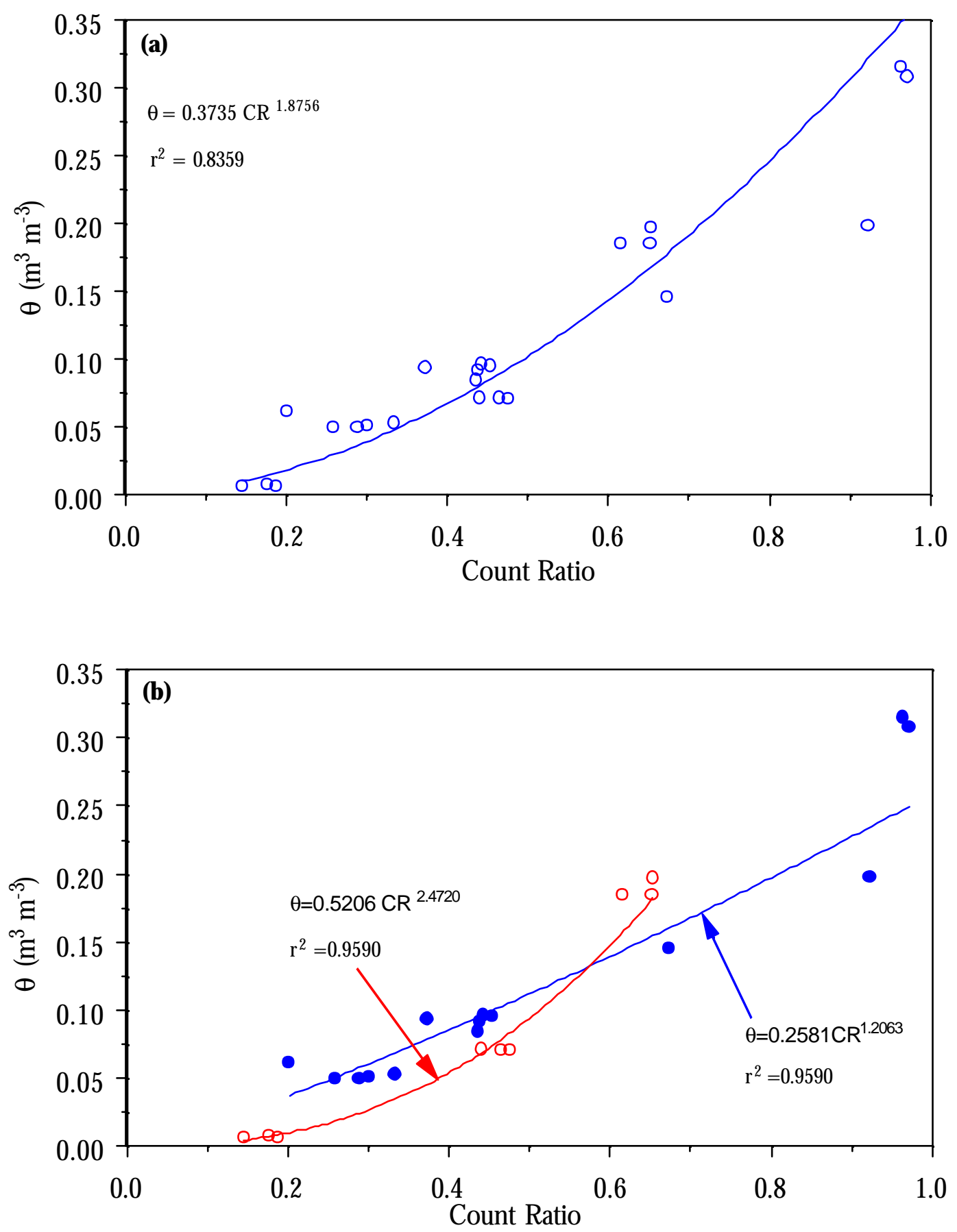

Figure 3.4. Calibration Relations for the Neutron Probe in PVC Tubes at the FY 2002 Field Site (a) a Single Calibration Curve for a Composite Data Set from both Calibration Experiments (b) Separate Curves the Fine and Coarse-Textured Soils 


\subsubsection{Water-Content Distributions}

Figure 3.5 shows examples of water-content profiles derived from neutron-probe measurements in access tubes CPT 6 and CPT 7 during the FY 2002 infiltration tests. Both access tubes are located west of the dike (Figure 2.5) but show very different profiles. In the profiles nearest to the line source (Figure 3.5a), the wetting front remained in the top $1 \mathrm{~m}(3.3 \mathrm{ft})$ for the duration of the experiment, showing only small increases in $\theta(\mathrm{z})$. The increase in $\theta$ within a limited region is consistent with the expected behavior of the wetting front emanating from a line source in a homogeneous medium. However, the removal of the top $1 \mathrm{~m}(3.3 \mathrm{ft})$ of soil of the transect before the experiment suggests that this region may be a finer textured soil underlain by a coarser sediment, as will be discussed later. In contrast, Figure 3.5b shows a more complex profile. The observed water content increased to a maximum of $0.20 \mathrm{~m}^{3} \mathrm{~m}^{-3}$ in the top $1 \mathrm{~m}$ ( $3.3 \mathrm{ft}$ ), compared to $0.30 \mathrm{~m}^{3} \mathrm{~m}^{-3}$ in Tube CPT-6. In addition, there is a significant increase in $\theta$ in the 1to 2-m (3.3- to 6.6-ft) depth interval. This feature is likely a reflection of subsurface heterogeneity. Measurements on this tube in an earlier infiltration experiment suggest the presence of a fine-textured lens at this depth. Such a structure would lead to the preferential lateral movement of moisture and an increase in $\theta$ in this region.
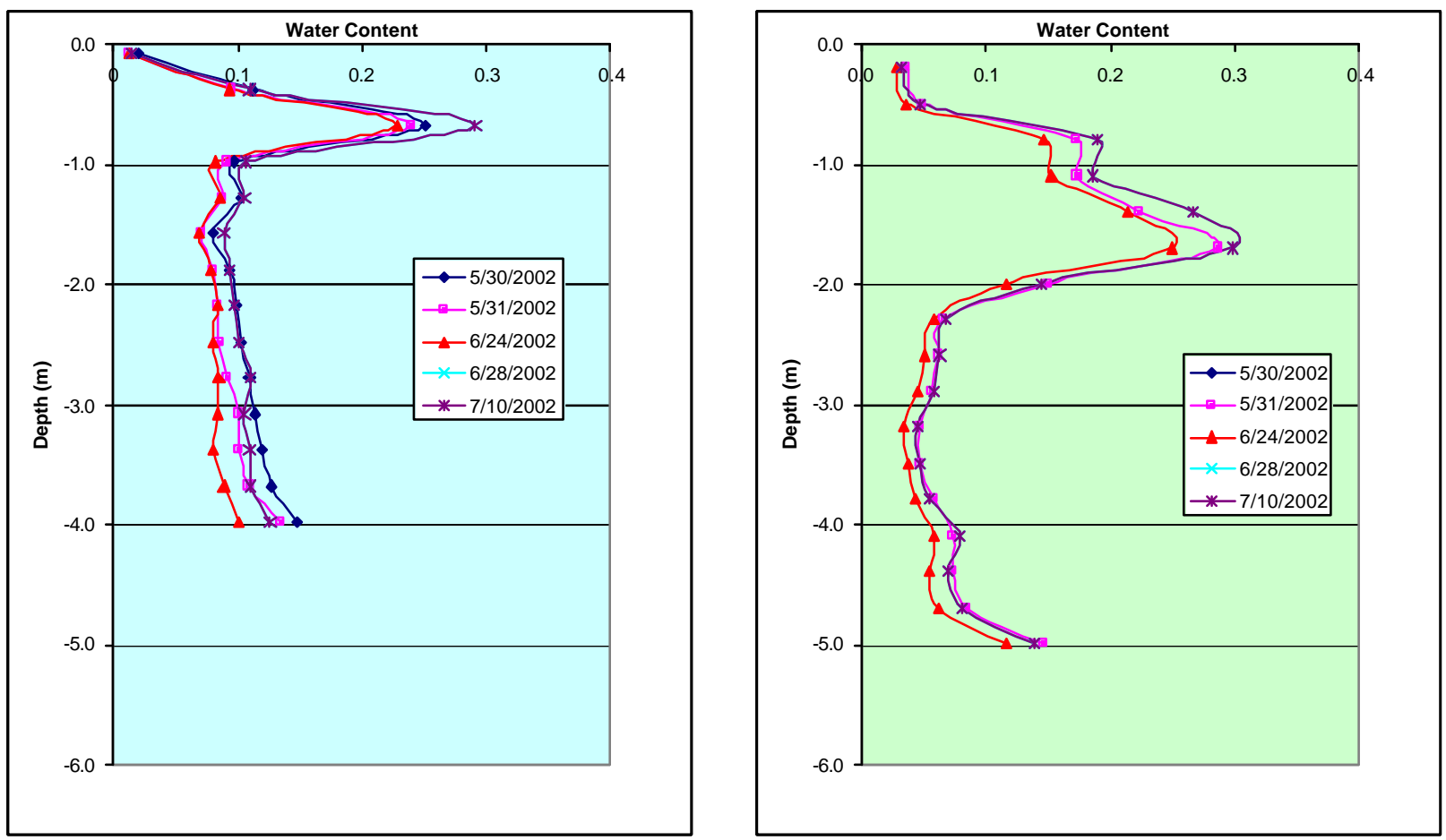

\section{Figure 3.5. Water Content Profiles Measured During the FY 2002 Infiltration Experiments (a) Tube 1 (CPT6) (b) Tube 4 (CPT7)}

Figure 3.6 shows water-content profiles resulting from the FY 2001 infiltration experiment at a site slightly north of the current test plot. The similarities between the two experiments are limited to the fact that both were conducted under constant flux conditions. The major difference is that the FY 2002 experiment used a line source while a constant flux was applied over the entire surface of the FY 2001 experiment; thus, the subsurface flow regimes were somewhat different. Figure 3.6a clearly shows the 
impact of subsurface heterogeneity, particularly layering, on the movement of the wetting front. On the west side of the dike where a sill was observed, there is a steady increase in $\theta$ in the 0.5- to 1.5-m (1.6- to 5 -ft) depth in terval with time with minimal changes beyond this depth. However, as $\theta$ increased to $0.20 \mathrm{~m}^{3} \mathrm{~m}^{-3}$, a sudden increase in $\theta$ in the underlying layer was detected. This phenomenon is identical to that observed with capillary breaks in which a fine-textured layer must reach near saturation before water penetrates into an underlying coarser layer. The relatively low moisture content at which breakthrough occurs in this case suggests that the difference in particle-size distribution may not be very great, but is certainly large enough to cause a low enough permeability in the underlying layer and induce preferential flow in the lateral direction. A similar phenomenon, although to a much lesser extent, is observed east of the dike (Figure 3.6b). Although there is no evidence of a sill on this side of the dike, there is a very clear increase in $\theta$ in the 0.5 - to $1.5-\mathrm{m}$ (1.6- to 5-ft) depth intervalbefore similar changes occur deeper in the profile. The water content at which breakthrough occurs is also much lower $\left(0.10 \mathrm{~m}^{3} \mathrm{~m}^{-3}\right)$, suggesting an even smaller difference in particle-size distributions. Excavations north of CPT-2 show mostly homogeneous sand, except for small-scale heterogeneities (Figure 2.2a,b), compared to the sill west of the dike (Figure 3.7). This sill is about $0.25 \mathrm{~m}(0.8 \mathrm{ft})$ thick, and although its lateral extent is uncertain, it appears to be influencing flow from the line source, which is more than $3 \mathrm{~m} \mathrm{(10} \mathrm{ft)} \mathrm{away.}$
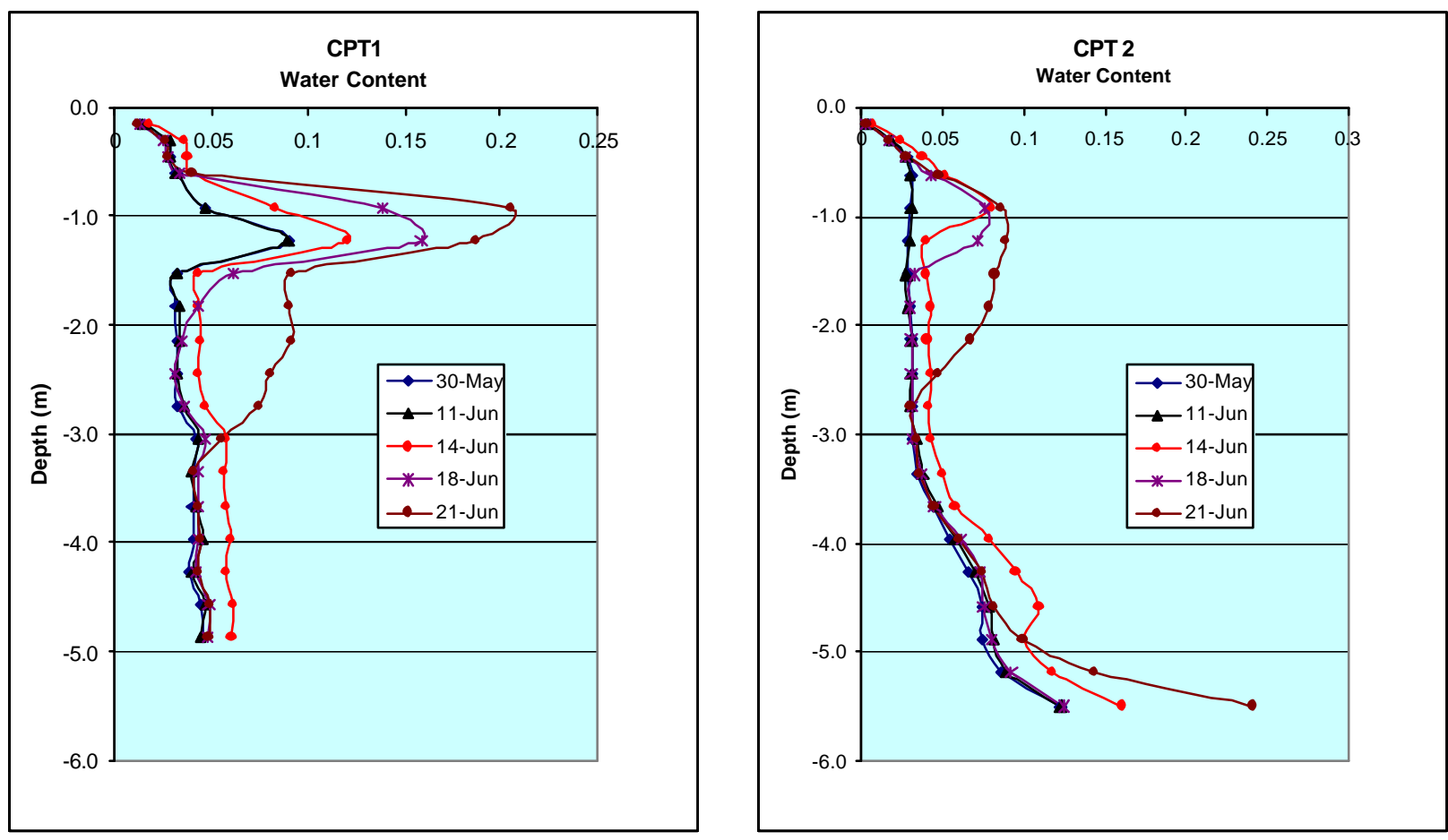

Figure 3.6. Water Content Profiles Measured During the FY 2001 Infiltration Experiments (a) Tube CPT-1 and (b) Tube CPT-2 


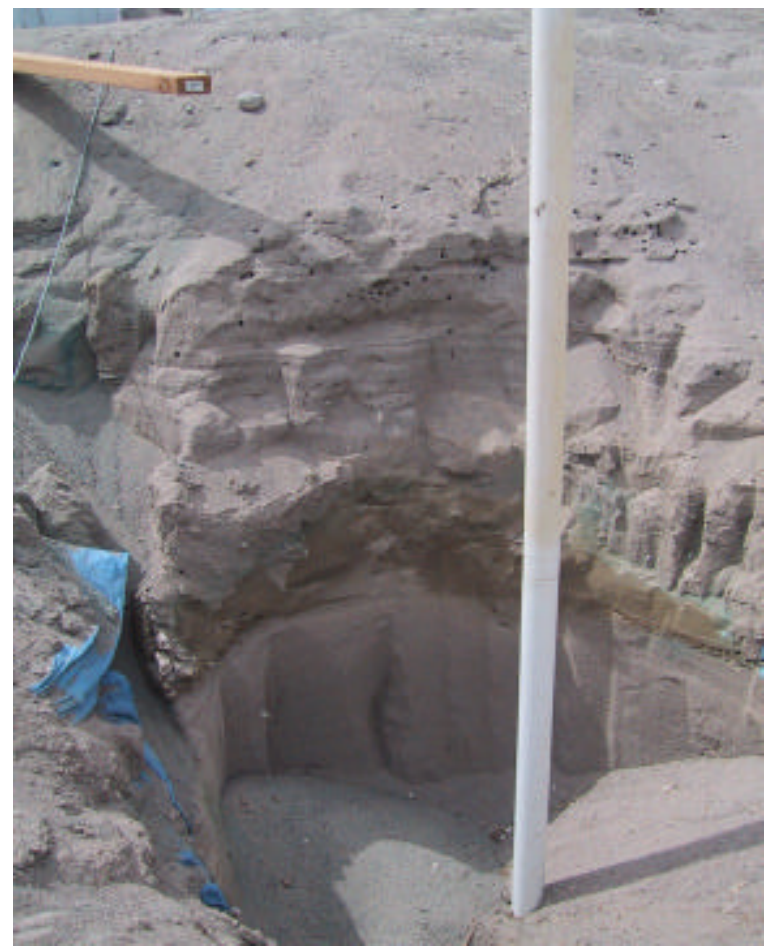

Figure 3.7. Wet Sill Observed West of the Dike and Adjacent to CPT-8 (Tube \#5)

These results coupled with information about the subsurface stratification obtained from excavations, real-time TDR moisture measurements, and surface GPR will be invaluable in validating the improved conceptual model for flow anisotropy.

\subsection{Tensiometer Data Summary}

During the FY 2002 test, tensiometers were installed at 2-m (6.6-ft) intervals along the transect to depths of 0.4 and $0.8 \mathrm{~m} \mathrm{(1.3} \mathrm{and} 2.6 \mathrm{ft})$ for measuring matric potential, $\psi$. Simultaneous transient measurements of $\psi$ and $\theta$ were intended to provide in situ measurements of the $\psi(\theta)$ relationship. However, a variety of problems resulted in data of questionable quality. Figure 3.8 shows steady-state distributions of $\psi(x, y)$ at 0.4 and $0.8 \mathrm{~m}$ (1.3 and $2.6 \mathrm{ft})$ during the first experiment. In general, the trend in $\psi(\mathrm{x}, \mathrm{y})$ is consistent with those predicted by Eq. 2.6. Values at the 0.8-m (2.6-ft) depth are larger (less negative) that at the $0.4 \mathrm{~m}$ (1.3-ft) depth. However, the absolute values as well as the temporal and spatial trends are questionable, primarily for two reasons. These are best explored in a plot that shows the temporal variations in $\psi(\mathrm{x}, \mathrm{y})$

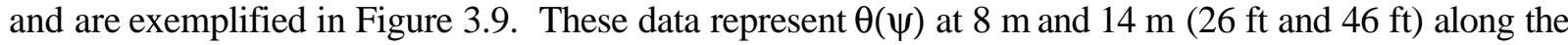
transect during the first experiment. At $8 \mathrm{~m}(26 \mathrm{ft})$ (Figure 3.9), tensiometers were in the dike material, and measured water contents showed this region to be somewhat wetter than at other locations. While the $0.4-\mathrm{m}(1.3-\mathrm{ft})$ data show a realistic trend in $\theta(\psi)$, i.e., a decrease in $\psi$ with decreasing $\theta$, such a trend is not evident from the $0.8-\mathrm{m}(2.6-\mathrm{ft})$ measurements. At $14 \mathrm{~m}(46 \mathrm{ft})$, the large change in $\theta$ for such a small change in $\psi$ is also suspect. It is possible that some of the error in $\psi$ may be due to the pressure transducers. Although the transducers were temperature compensated, they appear to have been 

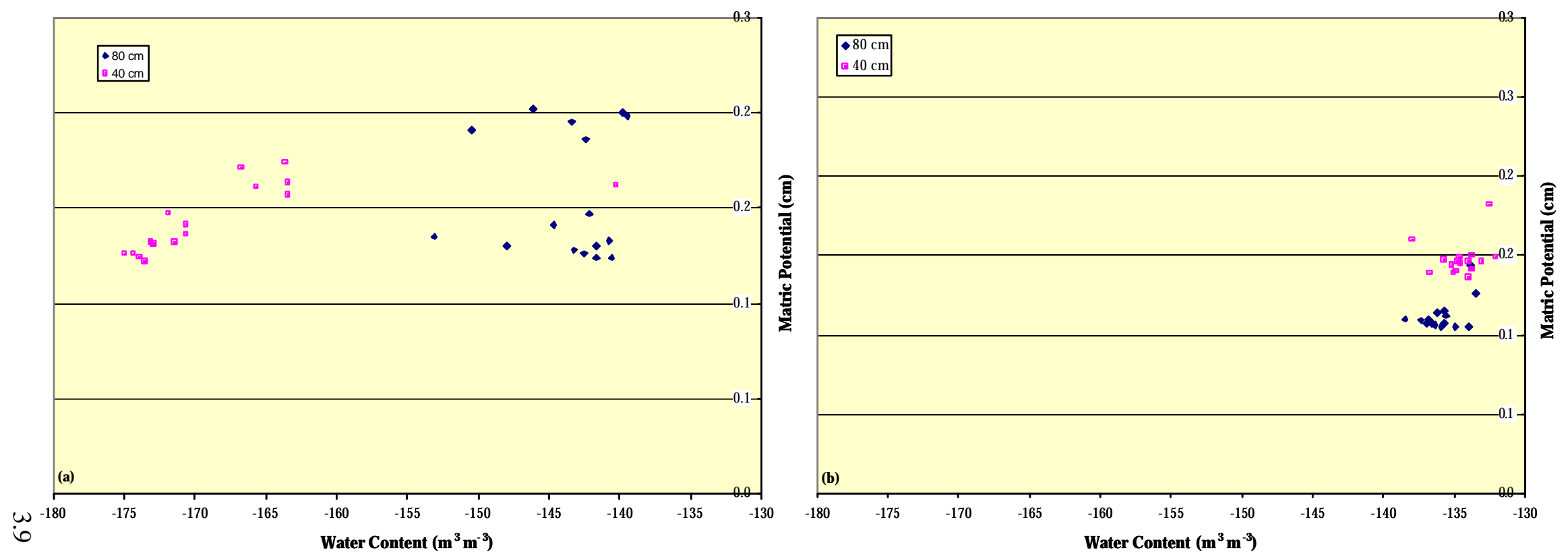

Figure 3.8. Measured Water Content-Matric Potential Relationships from Experiment 1, (a) at $8 \mathrm{~m} \mathrm{(26.3} \mathrm{ft)} \mathrm{Along} \mathrm{the}$ Transect, (b) $14 \mathrm{~m}$ (46 ft) Along the Transect 


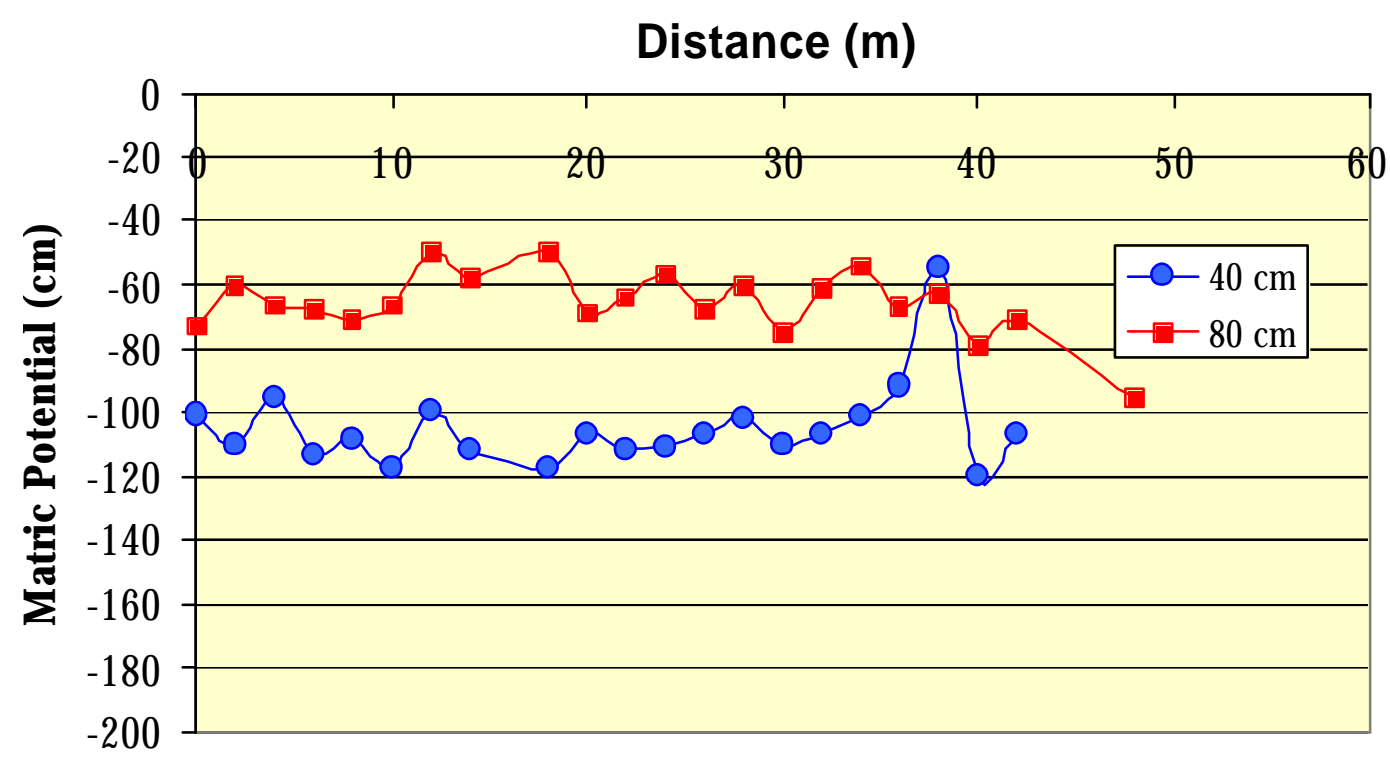

Figure 3.9. Steady-State Matric Potentials Along the Transect in Experiment 1

adversely affected by diurnal temperature fluctuations. Secondly, close examination of the data suggest that the tensiometers may have leaked at various times during the experiment due to failing seals at the proximal end. These two factors may be responsible for the absence of expected temporal and spatial trend differences and the failure to observe differences due to textural differences. Work on modifications of the instruments for the next set of experiments is currently in progress.

\subsection{Surface Ground Penetrating Radar}

Figure 3.10 shows the baseline common offset profile collected parallel to the line source on May 21, 2002 , using the GSSI system with a 300-MHz antenna. Data were acquired every $5 \mathrm{~cm} \mathrm{(2} \mathrm{in.)} \mathrm{at} \mathrm{a}$ distance of $0.8 \mathrm{~m}(2.6 \mathrm{ft})$ between the mid point of the antenna and the 1.0-m (3.3-ft) TDR probes. Data acquisition started at the northwestern end of the transect, and the resulting data were of reasonably high quality as can be seen in Figure 3.10.

Data of similar quality were collected for the duration of the experiment and were used to identify a variety of reflectors. The arrival times to these reflectors vary from 10 to 20 -ns in the baseline, but changed as the experiment progressed. Arrival times showed a gradual increase with time, indicative of an increase in moisture, as well as a decrease in the signatto-noise ratio as the cumulative volume of injected water increased.

High conductivity in the dike increased the dielectric loss of the signal resulting in reduced strength of the reflections, as can be seen near $\mathrm{x}=52 \mathrm{~m}(170 \mathrm{ft})$. The most obvious effect of the dike itself is the diffractions observed near the surface and a loss of coherence in the underlying reflector. The diffractions often define the edges of the dikes. They also disrupted or weakened the continuity of underlying reflections. Several coherent reflections are obvious from the data. In the upper $1 \mathrm{~m}(3.3 \mathrm{ft})$ on the south side of the transect, a rising event is seen from 2 to $10 \mathrm{~m}(6.6$ to $33 \mathrm{ft})$. This is one of the strongest reflectors at the site and can be clearly seen between 7 and 15 ns initially curving upward and then dipping downward as the distance along the transect increases. This reflector could be a bounding surface 
separating two different units or could very well be the sill observed near the dike in CPT Tubes CPT 7 and 8. Additional strong reflections are also easily observed from this profile, but will require sampling to confirm this. The absence of coherent reflection events in the overlying sections suggests that these reflections may be related to facies.

Travel times to the reflectors were used to calculate water contents at various spatial locations. Calculating water contents required information of the ground-wave velocities, and this was obtained from the common midpoint profiles. A typical CMP dataset is presented in Figure 3.11.

CMP measurements were made with 450-MHz antennas, starting with an antenna separation of $0.26 \mathrm{~m}$ $(0.9 \mathrm{ft})$ and with subsequent measurements being in $0.02-\mathrm{m}(0.066-\mathrm{ft})$ increments (i.e., the transmitting antenna and receiving antenna each moved $1 \mathrm{~cm}[0.4 \mathrm{in}]$.$) . The 225-\mathrm{MHz}$ antennas started with an antenna separation of $0.26 \mathrm{~m}(85 \mathrm{ft})$, and they were moved away from one another in steps of $0.04 \mathrm{~cm}$ (0.016 in.). The CMPs allowed unambiguous determination of the air and direct ground-wave arrivals as well as other reflections (Figure 3.11). The move-out (i.e., wavelet slope) of each of these arrivals allowed definition of the velocity of the arrival, or in the case of a reflector, the average velocity of the overlying sediments.

Figure 3.12 shows an example of changes in $\theta_{v}$ computed from changes in travel time. The notation used in the legend for each plot refers to the date of acquisition and the reflector under consideration (e.g., 66_red1 represents the $\theta_{\mathrm{v}}$ calculated for reflector "red1" on 06/06/02). Recall that the baseline value of $\theta_{\mathrm{v}}$ was 0.129 and that it was assumed to be constant along the entire length of the profile. For this reason, it is only included on the first of the eight graphs. For the most part, each of the plots of $\theta_{\mathrm{v}}$ as a function of time exhibits the same general trend. As expected, the changes in moisture content were iterative with increases in $\theta_{v}$ of approximately 0.05 or five percent per 3-week interval. Data from some reflectors suggest wetting over the first weeks of the experiment followed by a cycling of drying then wetting then drying. This may be due to inconsistent picking of travel times as it is not supported by the neutron-probe measurements. These data undoubtedly show that surface GPR can be used to monitor wetting-front migration in a non-invasive fashion. However, the limited depth of investigation of $450-\mathrm{MHz}$ data antennas suggests that more work is necessary to optimize the antenna frequencies for the next set of experiments.

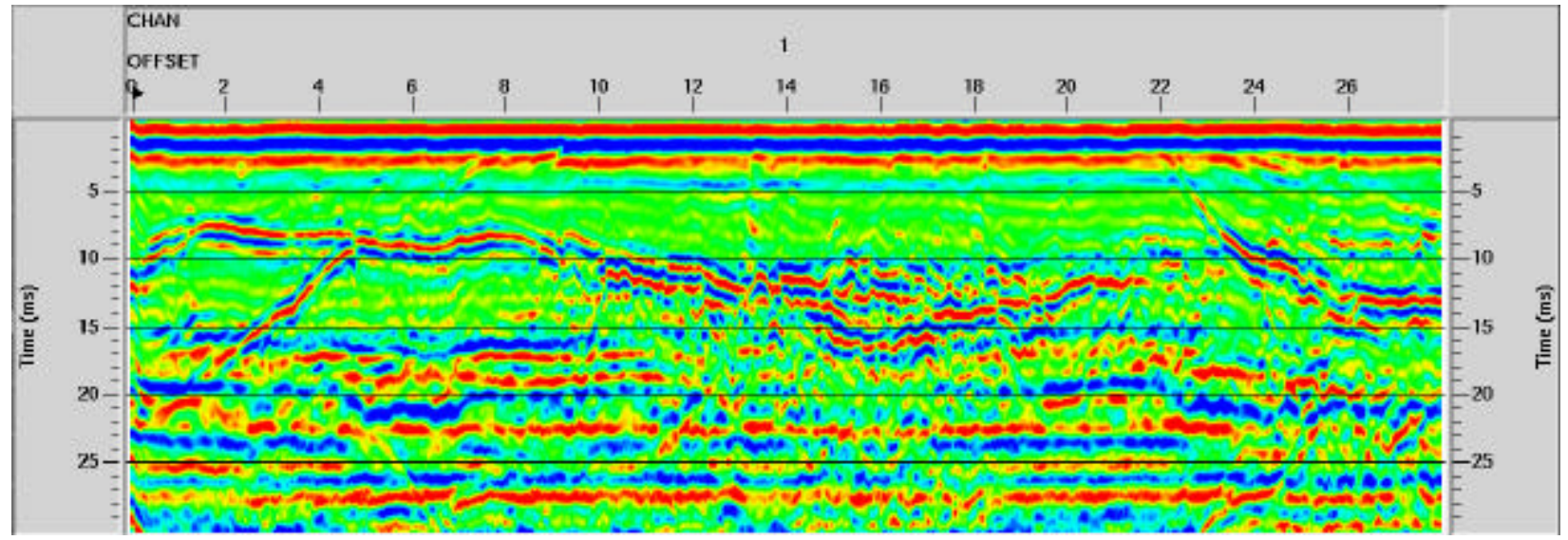

Figure 3.10. Common Offset GPR Data Collected $0.8 \mathrm{~m}(0.26 \mathrm{ft})$ from the Line Source on May 21, 2002 


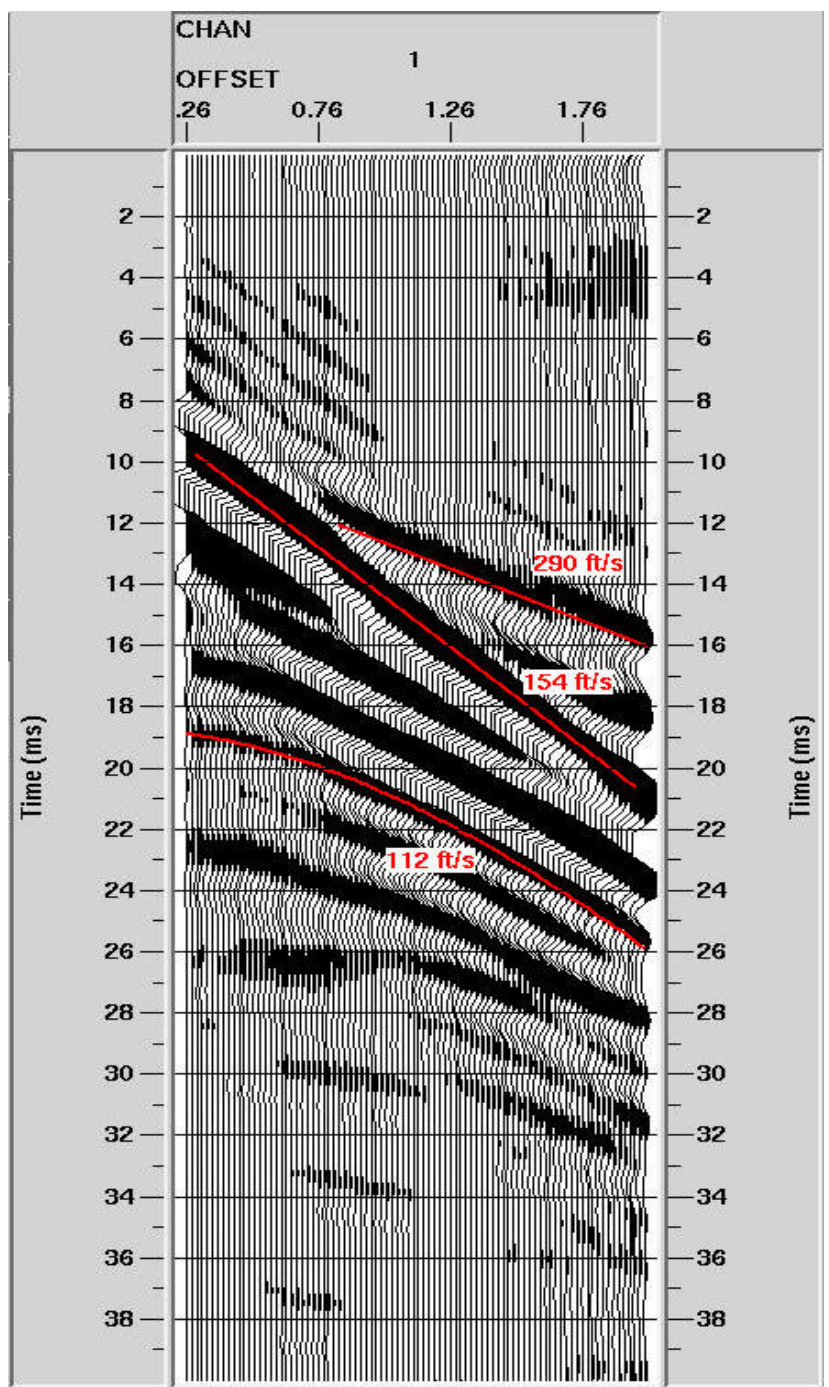

Figure 3.11. Example of Common Mid-Point Data with Arrivals Labeled

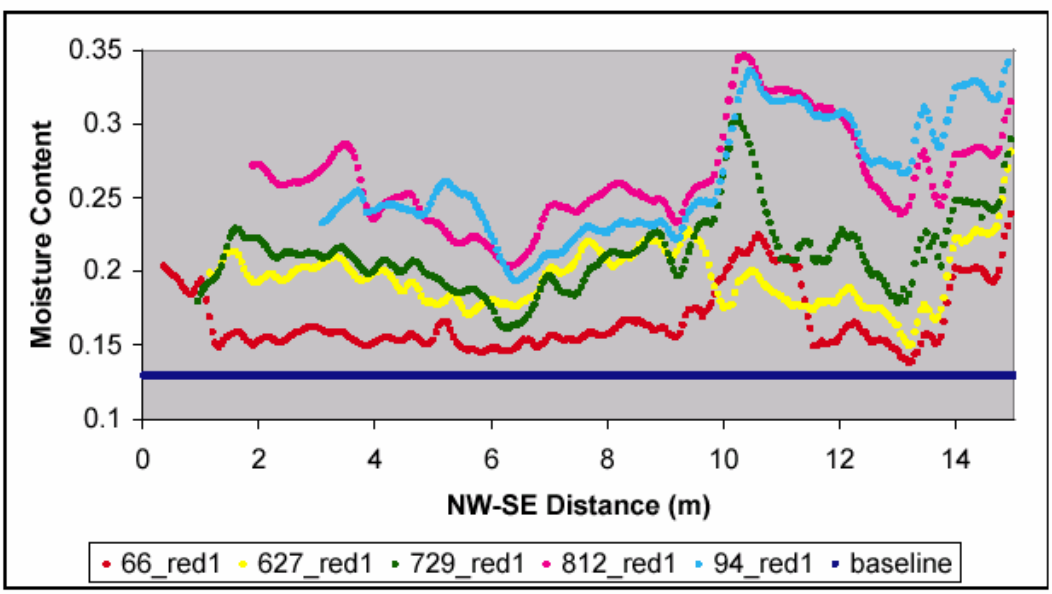

Figure 3.12. Change in $\theta_{\mathrm{v}}$ of Sediment Overlying Reflector "red9" over 3-Month Period 
The velocity of a given reflector determined using the CMP data is then used to determine the depth to a given reflector using the recorded two-way travel time from transmitter to reflector to receiver. Given sufficient CMP locations along the length of the common offset profile, the velocity as a function of depth for a variety of reflectors can be assessed. Unfortunately, the CMPs were not measured at the expected 2-m (6.6-ft) interval and the locations chosen for this investigation yielded only one or two usable reflectors. These occurred only for the location 40-m (131-ft) from the profile starting point. As can be seen in Figure 3.12, the most prominent reflector occurs at roughly 19-ns and has a velocity of $0.112-\mathrm{m} / \mathrm{ns}$. The other two reflectors are marked with their velocities and represent, from top to bottom, the direct airwave arrival $(0.290-\mathrm{m} / \mathrm{ns} \approx 0.3-\mathrm{m} / \mathrm{ns})$ and the ground-wave arrival $(0.154-\mathrm{m} / \mathrm{ns})$.

It should be noted that the accuracy of these data depends on a number of factors, particularly acquisition methodology and the picking of travel times. With respect to the acquisition methodology, it became clear early on that the start and stop positions of the profiles were not being exactly repeated. This becomes clear when looking at the $\theta_{\mathrm{v}}$ data presented above. The prominent peaks and troughs evident in data collected during one visit are phase-shifted from those occurring at later dates. As these peaks and troughs likely represent "fixed" stratigraphic effects, they would not be expected to change their lateral position over the course of the experiment. So the only plausible explanation is that the start/stop position of the GPR unit was slightly variable over the course of the investigation and that perhaps some data points were skipped due to a variety of causes during operation. This does not diminish the overall utility of the methodology; it merely forces the data to be interpreted a bit more qualitatively. In other words, a given position (e.g., $23.5 \mathrm{~m}[77 \mathrm{ft}]$ from the start) may not correspond precisely each time to the corresponding TDR (or similar) measurement. With respect to the accuracy of the travel time picking, it is helpful to consider the following example. From experience, it appears likely that the accuracy of the picks is on the order of \pm 0.5 -ns. If one then uses this to assess the accuracy of the computed $\theta_{v}$ values, then it can be found that the error in $\theta_{v}$ is \pm 0.0188 . Smoothing and averaging the travel time picks probably assures better accuracy (or at least improved repeatability) of the data, and assuming the error is reduced to \pm 0.2 -ns, the corresponding error in $\theta_{\mathrm{v}}$ is \pm 0.0075 .

\subsection{Cross-Hole Ground Penetrating Radar}

Figure 3.13 shows the base- and post-infiltration velocity tomograms derived from cross-hole measurements. Several characteristics of the tomograms remain constant throughout the infiltration experiment. Tomograms 5-4 and 4-3 (i.e., the tomograms formed by well pairs 5-4 and 4-3) showed relatively uniform velocity to a depth of $6.0 \mathrm{~m}(20 \mathrm{ft})$ with a value of about $0.14 \mathrm{~m} \mathrm{~ns}^{-1}$. Tomograms $1-2$ and 2-8 show significantly decreased velocity in the upper $2 \mathrm{~m}(6.6 \mathrm{ft})$ relative to the lower regions. The tomograms traversing the clastic dike (3-1 and 8-5) show significant reductions in velocity relative to the surrounding tomograms. However, the velocities are not consistent with those in the neighboring tomograms. This could be due to the higher moisture content of the dike or its electrical properties.

A well-known limitation in crosshole tomography methods lies in their inability to resolve structures that (1) extend vertically above and below the plane of tomography, but (2) have lateral boundaries located between the two vertically oriented boreholes. In other words, if no rays can pass around an object (above or below), then the horizontal thickness and the velocity of the structure cannot be estimated from standard crosshole measurement techniques. For the case of a low-velocity vertical structure with unknown horizontal thickness and unknown velocity, for example, an overall decrease in velocity is smeared across the velocity tomogram. If, however, the true velocity profile is known on both sides of the vertical structure (say, from neighboring tomograms), and if estimates of the dike thickness are known, then the velocity of the vertical structure can still be estimated. 
Both planes formed between well pairs 1-3 and 8-5 encompass the clastic dike, as seen through an outcropping at the surface. The dike is presumed to be a vertical structure extending from below the tomogram up to the ground surface, and it is suspected to contain fine materials with potentially high water-retention capacity. The tomograms for these well pairs do not show coherent structure in the vicinity of the dike. Rather, these tomograms show an overall decreased velocity relative to the neighboring tomograms, those that do not intersect the clastic dike. Furthermore, the average velocity value is lower in well pair 1-3 than in well pair 8-5. This is consistent with the fact that the drip line is closer to well pair 1-3, making this a potentially wetter region with a lower GPR velocity. Tomogramvelocity distributions were converted to the dielectric constant through the procedure already described. This allowed the distributions of moisture content, as shown in Figure 3.14, to be calculated and compared with neutron-probe data. A low-velocity region is seen during all times, before and after infiltration, near the surface between well pairs 1-2 and 2-8, suggesting pre-existing elevated moisture content. Regardless, changes in moisture content are observed in this region as infiltration proceeds.

Figure 3.14 shows the changes from a) Base to Post 1, b) Post 1 to Post 2, c) Post 2 to Post 3, and d) Base to Post 3. Changes in moisture content are relatively constant through much of the region (between $\pm 2 \%$ ). However, there are notable exceptions. For example, the tomogram straddling the clastic dike nearest to the drip line (well pair 1-3) shows significant wetting (dark blue) in the upper region from Post 1 to Post 2-although, as previously mentioned, it is expected that horizontal smearing due to the moist dike (low velocity vertical structure) occurs. Interestingly, slight drying (yellow to red) appears to occur from Post 2 to Post 3 in this same region. Similarly, wetting is also seen in the upper regions of the 1-2 and 2-8 well-pair tomograms from Post 1 to Post 2, followed by slight drying in the same regions from Post 2 to Post 3. Signific ant overall wetting (light blue) is seen from Base to Post 3 in the tomogram corresponding to well pair 4-3. The relevant neutron data are shown for each well alongside the tomograms.

It is important to note that the moisture content range shown is only from $-5 \%$ to $+5 \%$, and through most of the tomograms, changes of only $\pm 2 \%$ are seen. Since this is assumed to approach the accuracy limit of crosshole measurements, then the GPR-inferred changes in moisture content are assumed minimal.

Neutron-probe data were also collected for most of the wells at the different GPR survey times; these data were calibrated giving moisture-content profiles for the regions surrounding the boreholes. In this way, the neutron-probe data may be used to constrain interpretations offered by the GPR crosshole measurements.

Considering Wells 3, 4, and 5, one sees that before the onset of infiltration, the moisture content in Well 3 is roughly constant (ranging between 0.05 and 0.10 ) above the depth of $4.0 \mathrm{~m}(13 \mathrm{ft}$ ), below which the moisture content slightly increases. After the onset of infiltration (after NP2, for reference), increases in moisture content to 0.15 and higher are evident, while the region above $2.0 \mathrm{~m}(6.6 \mathrm{ft})$ remains at the lower moisture content (0.05-0.10). Wells 4 and 5 show similar behavior to Well 3 before infiltration: nearly constant moisture content values (ranging between 0.05 and 0.1 ) are seen to a depth of about $4.0 \mathrm{~m}$ $(13 \mathrm{ft})$, and the moisture content is higher below this depth. These observations suggest that the following flow phenomenon is occurring on the eastern side of the clastic dike: during the infiltration experiment, a predominantly vertically (though somewhat laterally) migrating plume of water developed and reached Well 3 at a depth of about $2.0 \mathrm{~m}(6.6 \mathrm{ft}$ ) but did not reach Wells 4 or 5 (probably since they were located further from the water source than was Well 3). 

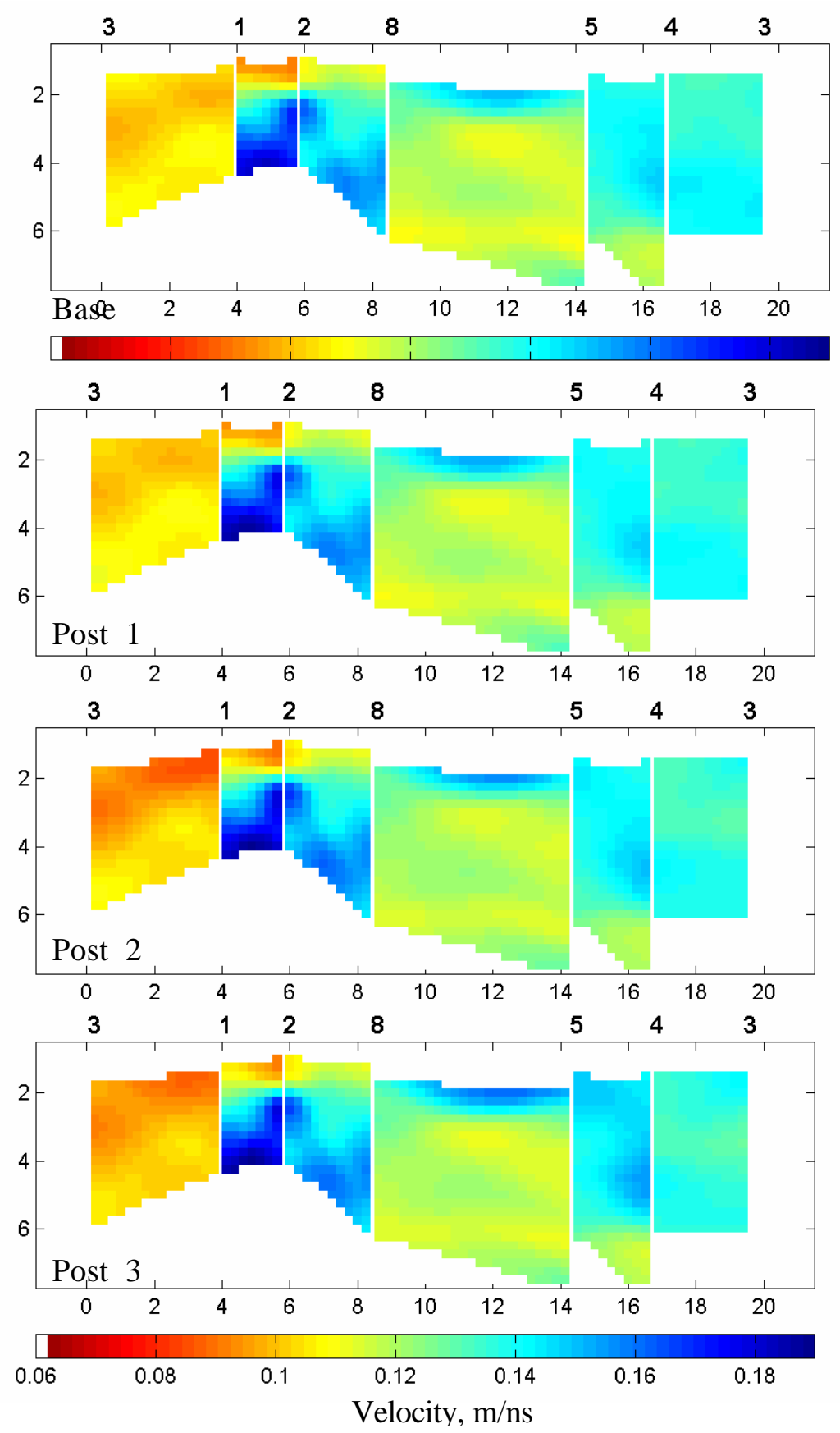

Figure 3.13. Crosshole Velocity Tomograms (a) Before and (b-d) During Infiltration Experiment 
a)

b)

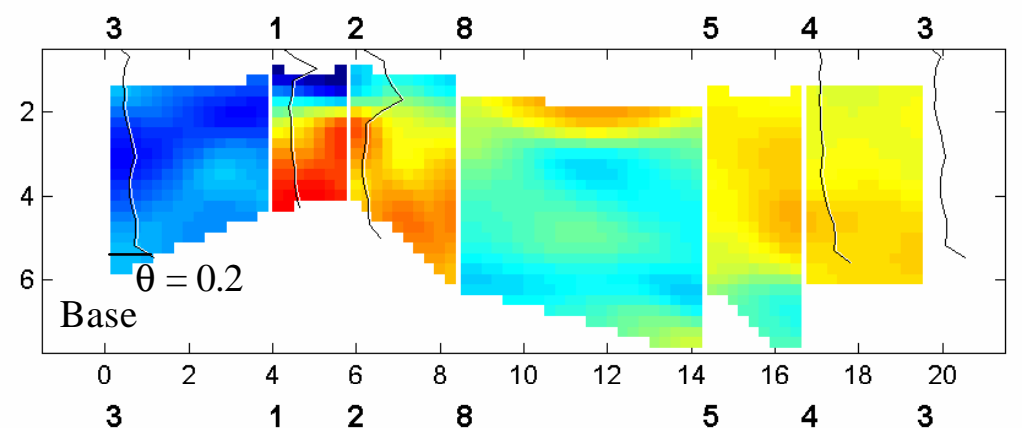

c)
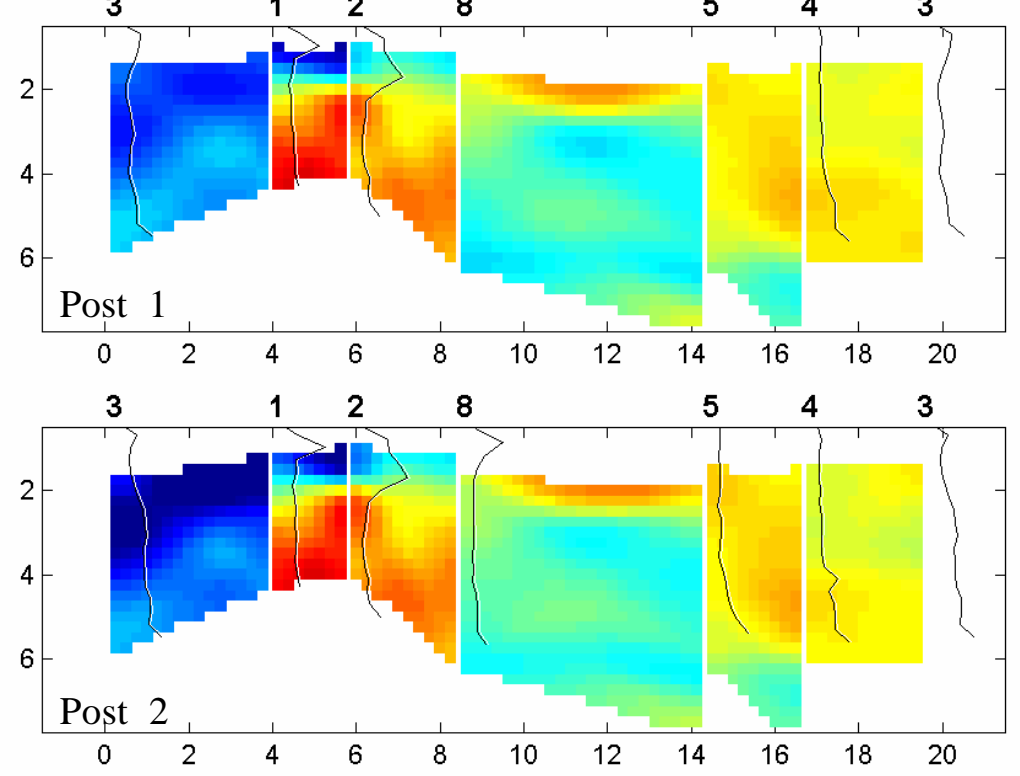

d)

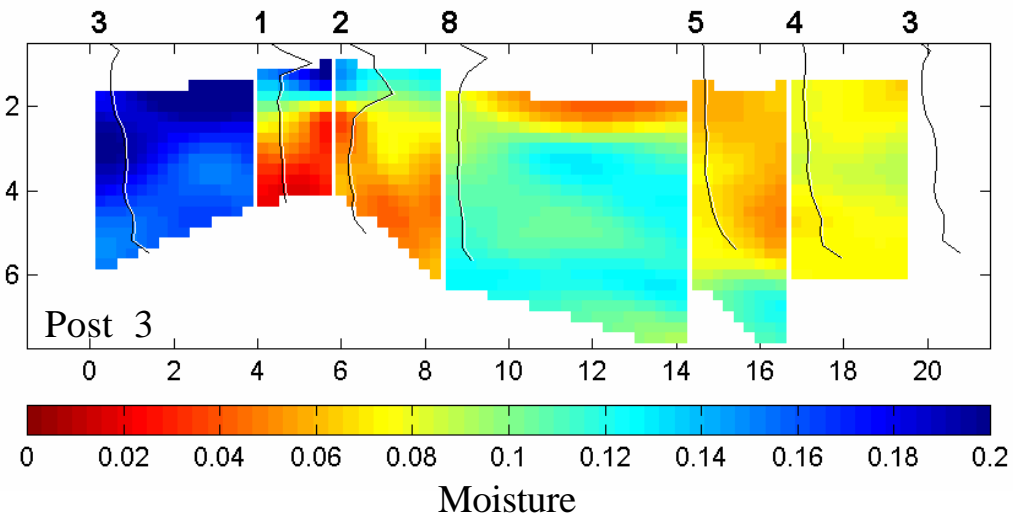

Figure 3.14. Comparison of Moisture Content Derived from GPR TraverTime Tomography and Neutron-Probe Measurements 


\subsection{Hydraulic Properties and Correlation Structure}

The experiment was designed to permit determination of the correlation structure of the hydraulic properties. Although the analysis of the data is incomplete, an example of this structure is illustrated with the analysis of steady-state water content measured by the 1-m (3.3-ft)-long TDR probes. The distribution of water content averaged over the 1-m (3.3-ft) depth is shown in Figure 3.15. In general, $\theta$ ranged between 0.10 and $0.15 \mathrm{~m}^{3} \mathrm{~m}^{-3}$ along the transect, except at the location of the main dike. On the dike, $\theta$ increased to over $0.25 \mathrm{~m}^{3} \mathrm{~m}^{-3}$. Not only was the water content higher on the dike, but there was increased wicking away from the line source. The elevated water contents recorded with TDR are consistent with those observed by neutron probe and cross-hole radar. Under constant flux conditions, this elevated water content could result in a reduced pore-water velocity on the dike relative to the sand matrix if piston displacement is assumed. These results are also invaluable for calculating the spatial distribution of unsaturated hydraulic conductivity and the slope of the log linear hydraulic conductivity function.

Although sedimentary units typically show a great degree of spatial variability, they also tend to show a distinct, directional correlation, which is thought to be related to depositional processes. This variability has also been shown to affect transport processes. To quantify the degree of spatial variability and determine the spatial correlation length scale, we used the geostatistical theory of regionalized variables. In this approach, a value of a parameter $Z($ e.g., $\theta, \psi)$ measured at a given location is considered a single realization taken from a probability distribution. The set of such values measured at different locations is then treated as a spatial array of random values. Application of the theory is based on the assumption that $Z$ is spatially stationary so that (1) each location is described by the same probability distribution, $\mathrm{f}(\mathrm{Z} ; \mathrm{x}, \mathrm{y})$ and (2) spatial covariance depends only on the separation between the measurements and not on the absolute location. Discrete TDR measurements of $\theta$ were used to construct semivariograms for the pre-injection condition as well as throughout the course of the experiment. The semivariogram is used to identify the spatial correlation structure and the correlation lengths (the distance at which a plateau in variance is reached) for each principle direction. The equation used to relate the directional correlation length for properties measured over an increasing spatial scale is

$$
\gamma(h)=\left(\frac{1}{2 N(h)}\right)_{j=1}^{N(h)}\left[Z_{j}(x+h)-Z_{j}(x)\right]^{2}
$$

where the sum is taken over the set of all measured pairs of values a distance $h$ apart; $h$ is the separation distance, $\mathrm{N}(\mathrm{h})$ is the number of measurement pairs separated by distance $\mathrm{h}$; and $Z(\mathrm{x})$ is the value at position $\mathrm{x}$.

Figure 3.16 shows an example omni-directional variogram using the data shown in Figure 3.15. There is no clear sill, in fact, the variogram shows some oscillation, an indication that $\theta$ may be a cyclical property. This might be expected at locations of fine-textured layers in a coarse host matrix such as silt lenses or polygon boundaries of the dike. Although no attempt has been made to model the variogram, it appears that a hole-effect model, that takes this phenomenon into account, must be considered. 


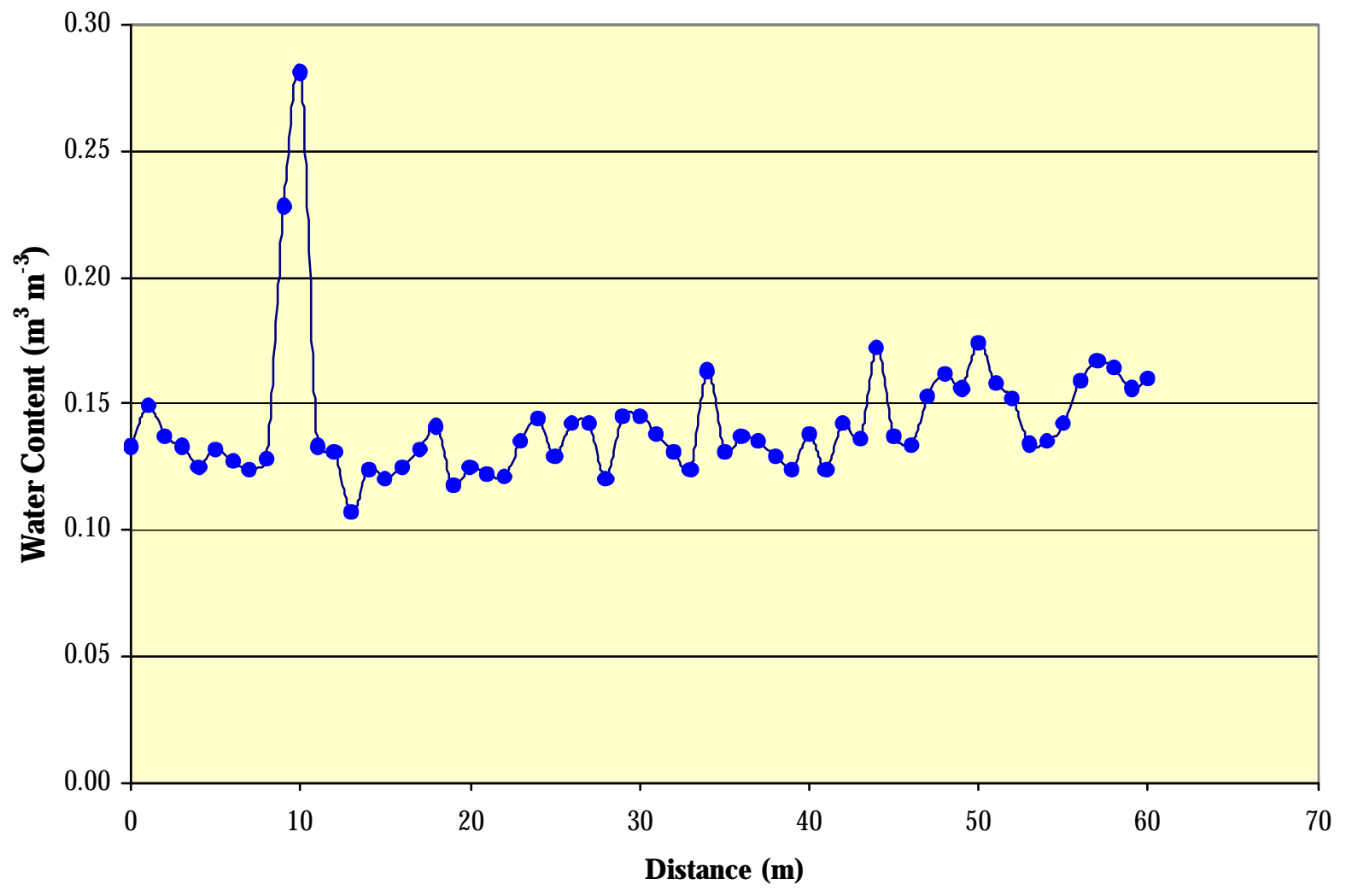

Figure 3.15. Spatial Distribution of Steady-State Water Content Measured with 1-m (3.3-ft)-long TDR Probes. The dike is located around $8 \mathrm{~m}(26 \mathrm{ft})$.

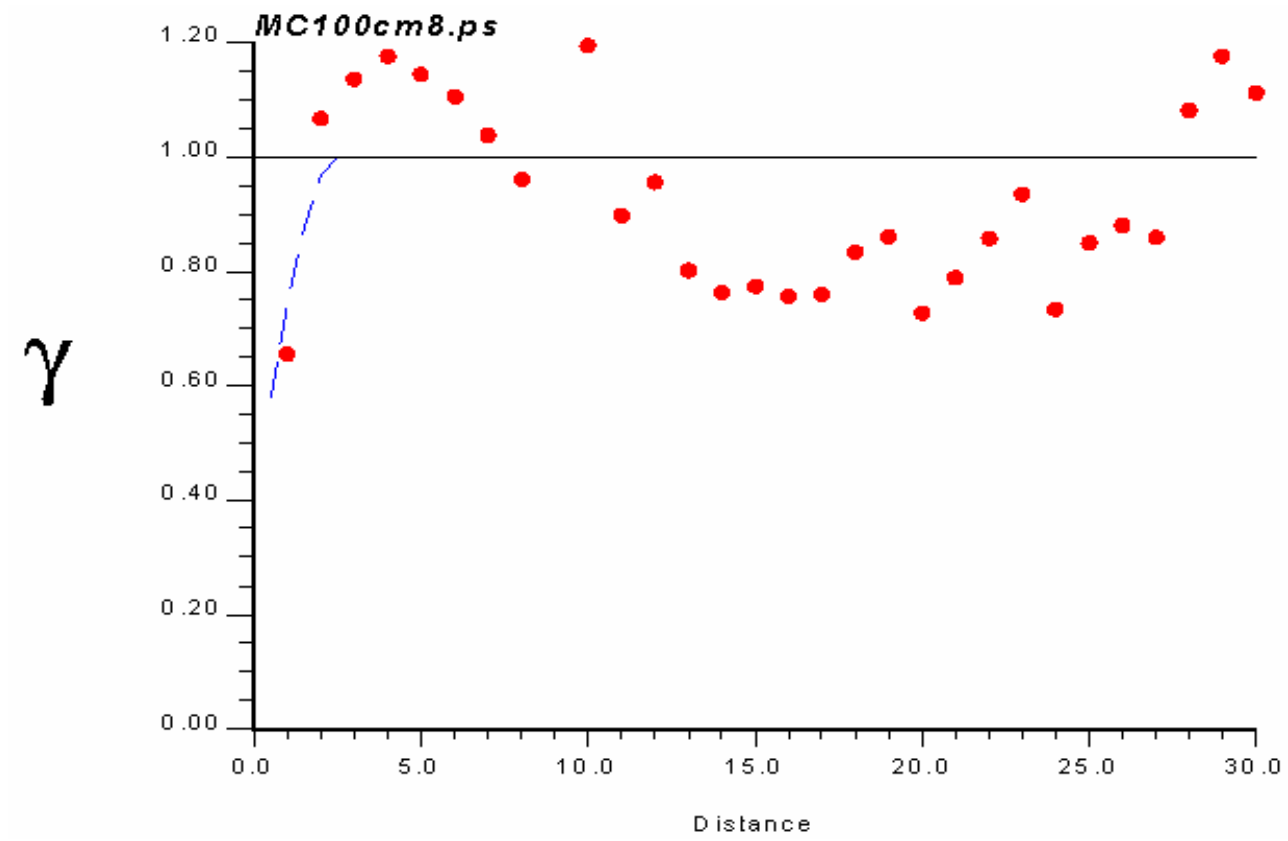

Figure 3.16. Experimental Variogram for Steady-State Water Content Measured with 1-m (3.3-ft)-long TDR Probes 
A more striking observation is the large nugget effect. The nugget effect is the vertical discontinuity at the origin, i.e., the intercept of $\gamma$. For a separation distance of zero, (i.e., samples that are at exactly the same location), the average squared differences are zero. It is clear however, that the variogram did not converge to zero as the separation distance decreased. This nugget effect suggests that there are scale variations occurring at a scale smaller than the probe spacing. Recall that although probes were installed at $0.5-\mathrm{m}$ (1.6-ft) spacing, measurements were made at a L-m (3.3-ft) spacing. The contribution of the short-scale variation will be determined from the variogram analysis of the GPR data, which were acquired at $0.05-\mathrm{m}(0.16-\mathrm{ft})$ intervals. In the next infiltration tests, all of the TDR probes will be used at the reduced spacing. As data analysis continues, variogram modeling will be completed and the ranges determined for the different hydraulic properties.

\subsection{Transport Measurements}

In a 2-D convective-dispersive mixing regime, the dispersion of a solute plume can be described by the $\mathrm{CDE}$, a longitudinal dispersion coefficient, $\mathrm{D}_{\mathrm{L}}$, which quantifies the dispersion in the direction of flow, and a transverse dispersion coefficient, $\mathrm{D}_{\mathrm{T}}$, which describes dispersion perpendicular to the flow direction. Compared to the amount of information published about $\mathrm{D}_{\mathrm{L}}$, there are very few reports of $\mathrm{D}_{\mathrm{T}}$ measurements in the literature, and such information is virtually non existent for Hanford. Quantitative information about the two dispersion coefficients was obtained by calibrating the CDE to the displacement experiments. For the purpose of this report, parameter estimation is limited to fitting the CDE under the assumption of a uniform moisture-content distribution to the depth of observation, and time-moment analysis. Based on the expected $\theta(\mathrm{y}, \mathrm{z})$ distribution (Figures 3.1, 3.2), the assumption of uniform $\theta(y, z)$ is somewhat limiting, but a more detailed analysis is not possible until the necessary modifications to the inverse model have been completed.

\subsubsection{Multi-component Transport}

Multi-component transport processes can be expected to play an important role in subsurface transport at Hanford. Therefore, the investigation of fate-and-transport behavior and its dependence on soil properties is critical to our understanding future migration. Under ideal conditions, it should be possible to predict transport behavior purely from the relevant physical and chemical parameters, using available mechanistic models for the chemical interactions and knowledge of the soil constituents. A variety of models exists for the adsorption of ions by soil components, but predictions with these models are unlikely to be perfect because of the variability in the chemical reactivity of soil components. Nevertheless, they can provide useful insight into transport behavior and its dependence on soil properties, provided that multi-component transport can be observed. The experiment was designed to provide some information on multi-component transport through the use of a mixture of tracers. In this study, a tracer consisting of potassium bromide, sodium thiosulfate, and deuterium oxide was injected. Tracer samples were analyzed for the bromide, thiosulfate, and sulfate ions. Figure 3.17 shows a typical plot of flux concentration, derived from pore-water samples of the applied tracers versus time. 


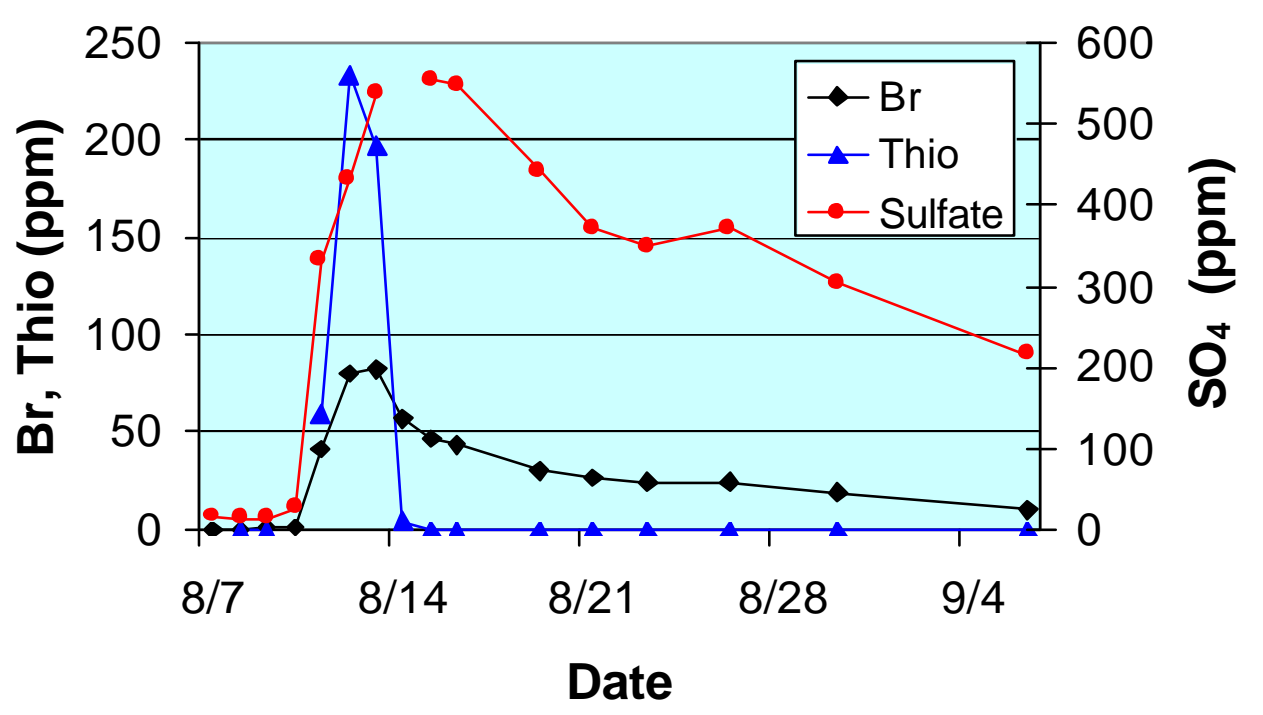

Figure 3.17. Example of Multi-Component Flux Concentration Breakthrough Curves at $x=24 \mathrm{~m}(78 \mathrm{ft})$

Except for $\mathrm{S}_{2} \mathrm{O}_{3}^{2-}$, the breakthrough curves are asymmetric with a steep rising limb and a slower decline. This shape is consistent with that of flux concentration curves. The three anions all show a similar initial increase in concentration but differences in the arrival time of the peak. The thiosulfate anion appears to have the shortest arrival time, followed by bromide and then sulfate. Although it is too early to into the analysis to offer an expla nation for the differences between $\mathrm{S}_{2} \mathrm{O}_{3}^{2-}$ and $\mathrm{Br}^{-}$, a likely explanation is anion exclusion. This phenomenon has been observed during the FY 2000 and FY 2001 experiments at the Sisson and Lu site and has been attributed to the difference in transport velocities of anions of similar charge due to differences in size. The difference in shape of the $\mathrm{S}_{2} \mathrm{O}_{3}^{2-}$ is likely due to oxidation to $\mathrm{SO}_{4}^{2-}$. This hypothesis is supported by the later breakthrough of $\mathrm{SO}_{4}^{2-}$ and the much slower decline in concentration over time, compared to $\mathrm{Br}^{-}$, a trend that was observed over most of the transect.

These data will be useful for providing insight into multicomponent transport behavior and its dependence on soil properties. Sulfate is a common anion in aquatic and soil systems and influences ion adsorption and surface chemistry of mineral oxides. It also plays a major role in elemental cycles in acidmine drainage. The transformations of sulfur and its compounds resemble those of nitrogen in many ways, and the requirements of the soil for the reactions to proceed are similar. Field observations for such a system are superior to laboratory measurements as it would be very difficult to determine the dependencies experimentally. One complication in modeling these data, however, may lie in the fact that transformations are also microbially mediated. For example, thiobacilli will oxidize thiosulfate in exothermic reactions as follows (Stevenson 1986, pp.285-320):

$\mathrm{Na}_{2} \mathrm{~S}_{2} \mathrm{O}_{2}+\mathrm{O}_{2}+\mathrm{HOH}------>\mathrm{Na}_{2} \mathrm{SO}_{4}+\mathrm{H}_{2} \mathrm{SO}_{4}$

and for tetrathionate 
$2 \mathrm{Na}_{2} \mathrm{~S}_{4} \mathrm{O}_{6}+7 \mathrm{O}_{2}+6 \mathrm{HOH}----->2 \mathrm{Na}_{2} \mathrm{SO}_{4}+6 \mathrm{H}_{2} \mathrm{SO}_{4}$

Therefore, a succession of species takes place as the $\mathrm{pH}$ of the soil is lowered by the production of sulfate. Organisms that produce hydrogen sulfide from the reduction of thiosulfate are easily detected. $\mathrm{The}_{2} \mathrm{~S}$ reacts with iron in the medium to produce ferrous sulfide, a black precipitate; thus, core samples from the site should confirm whether these mechanisms are active.

As data analysis proceeds, we will investigate to what extent a multi-component mechanistic interaction model, coupled with a 2-D convection, 2-D dispersion transport model is able to predict the combined transport of sulfate and $\mathrm{pH}$ changes in the field system.

\subsubsection{Flux-Averaged Versus Volume-Averaged Concentrations}

Figure 3.18 shows examples of tracer breakthrough curves derived from suction lysimeter measurements and TDR electrical-conductivity measurements. Although TDR measurements were made on an hourly basis, the data are reported on a fixed 24-h basis to avoid errors induced by the temperature effects on electrical-conductivity measurements. The data shown represent two different concentrations. The suction lysimeter measurements represent flux-averaged concentrations, $\mathrm{C}_{\mathrm{F}}$, while the TDR measurements represent volume-averaged or resident concentrations, $\mathrm{C}_{\mathrm{R}}$. The most striking observation is asymmetry in the breakthrough curves. This asymmetry is typical of fractured or aggregated media and generally results in residence-time estimates and dispersion estimates different from those predicted for symmetric distributions. Another difference is in the amount of spreading or dispersion about the mean. Under certain limiting conditions, i.e., low dispersivities, solutions to the CDE yield symmetric spatial and temporal distributions of concentration. As the apparent dispersivity increases, the discrepancy between $C_{F}$ and $C_{R}$ increases (Kreft and Zuber 1978).

In this case, the discrepancy between $C_{F}$ and $C_{R}$ may also be due to a failure to account for electrical neutrality of the system in this preliminary analysis. The oxidation of thiosulfate to sulfate and the retardation of primary cations relative to mobile anions could result in an apparent increase in dispersion and, hence, longer tails on the $\mathrm{C}_{\mathrm{R}}$ breakthrough curves relative to $\mathrm{C}_{\mathrm{F}}$. The overall effect is a delay in complete breakthrough of electrical conductivity when retardation of the principle tracer cation occurs. It can be expected that after an appropriate ele ctrical neutrality model and a method to handle retardation are incorporated, the TDR-measured curves should reflect the exact chemical equilibrium between the influent and effluent solutions. Electricalconductivity measurements with TDR clearly provide a rapid estimate of solute concentration useful for evaluating tracer breakthrough (Ward et al. 1994). The characteristics of the electrical-conductivity curve clearly depend on the localscale water flux, the retardation factor, the species of cation and anion in the tracer, and the cation initially occupying the exchange complex. It is possible that these measurements may be useful for indicating the extent of chemical equilibrium and retardation and the estimation of reactivity coefficients when compared to simultaneous measurements of flux concentrations. However, before such analyses can be completed, we need to refine our method for correcting for the effects of temperature on the electrical-conductivity measurements. In addition, a method to account for the requirement of electrical neutrality in the solution must be developed and incorporated. 

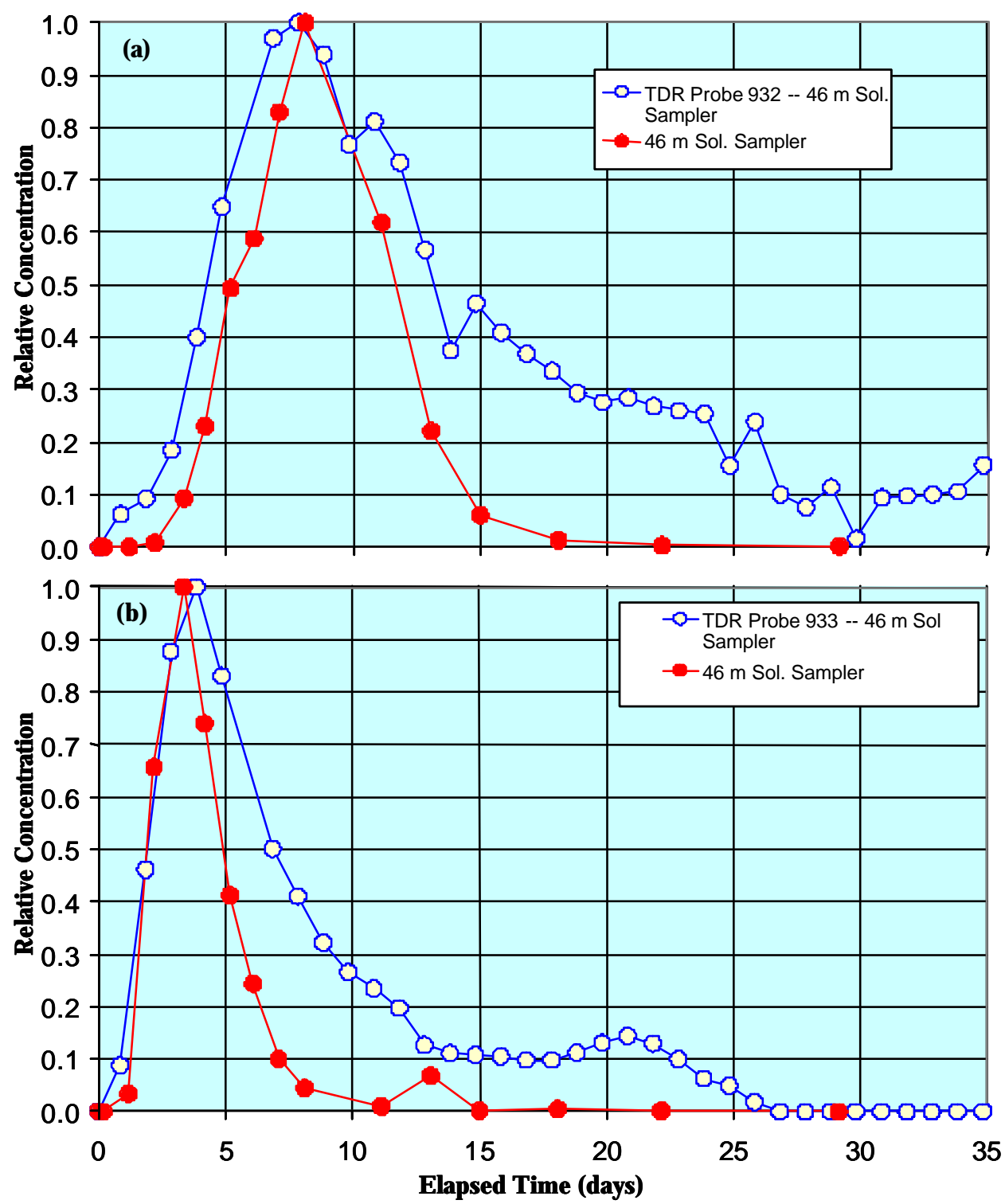

Figure 3.18. Comparison of Flux Concentrations Derived from Pore Water Samples of Br- and Resident Concentrations Derived from TDR Measurements at $x=46 \mathrm{~m}$ (151 ft), (a) a Depth of $0.4 \mathrm{~m}(1.3 \mathrm{ft}),(\mathrm{y}, \mathrm{z})=(0.30,0.40)$, and $(\mathrm{b})$ a Depth of $0.80 \mathrm{~m}(2.6 \mathrm{ft})$, $(\mathbf{y}, \mathbf{z})=(0.15,0.80)$.

The interpretation of breakthrough curves derived from suction lysimeters is a little less certain. Depending on the degree to which the sampling procedure disrupts the local flow pattern, sampled concentrations may represent resident concentrations or flux concentrations or a combination of the two (Parker and van Genuchten 1984). Nevertheless, it has been shown (Kreft and Zuber 1986) that the first time moments of the flux-averaged concentrations still represent the mean residence time of the tracer.

Information about transport through the vadose zone at Hanford is typically derived from well logs, which correspond to volume-averaged or resident concentrations, $\mathrm{C}_{\mathrm{R}}$, and water samples form the water table, which correspond to flux-averaged concentrations, $\mathrm{C}_{\mathrm{F}}$. It is clear that these two types of information must 
be interpreted differently, but when done correctly, can provide invaluable information about vadose-zone transport processes.

\subsubsection{Multi-Region Transport}

Figure 3.19 compares flux concentration curves from the samples located in the sand matrix $(\mathrm{x}=20 \mathrm{~m}$ [65.6 ft] $)$ and in the dike ( $\mathrm{x}=8 \mathrm{~m}[26.2 \mathrm{ft}])$. The most striking difference is the large amount of asymmetry observed with the dike measurements. There is a rapid early breakthrough, followed by a decline in concentration and a later increase. In this secondary mobilization of tracer, concentrations remained relatively high through the end on sample collection, never returning to background. Such asymmetry is typical of fractured or aggregated media and is a reflection of some portion of the pore space being bypassed. Under such conditions, there can be expected to be a large discrepancy between flux-averaged and volume-averaged concentrations. Thus, flux-averaged concentrations from the water table will provide little insight into the amount of contaminant remaining in the vadose zone.

Because the traditional form of the $\mathrm{CDE}$ moves at a fixed velocity with symmetric dispersion occurring about the mean, attempts to fit the dike date results in an over estimation of dispersivity. To correct for the obvious discrepancies, it will be necessary to introduce a bicontinuum model with "mobile" and "immobile" pore regions to account for the two main regions that appear to control transport.

\subsubsection{Transport Properties}

It is not possible to obtain analytical solutions to the CDE except in the case of the semi-infinite medium. Thus, in this preliminary analysis, transport properties were estimated based on the assumption of a homogeneous, semi-infinite medium at the localscale. In addition, the results of a time-moment analysis are presented, given that such an analysis is appropriate for a multillayered system in the absence of a correct transport model. The parameters in Table 3.2 represent the local-scale values derived from this analysis. There is need for caution in the interpretation of the spatially averaged transport parameters. While the resident concentrations can be easily averaged to obtain the field-scale values, simple averages of the flux concentrations are not physically meaningful (Parker and van Genuchten 1984). Physically meaningful flux-averaged flux concentrations require weighting of the local concentrations by the localscale hydraulic fluxes so that the transformation of the CDE remains valid. Local-scale fluxes have not been determined at this stage, but can be easily calculated from the local-scale changes in water storage derived from TDR measurements. 


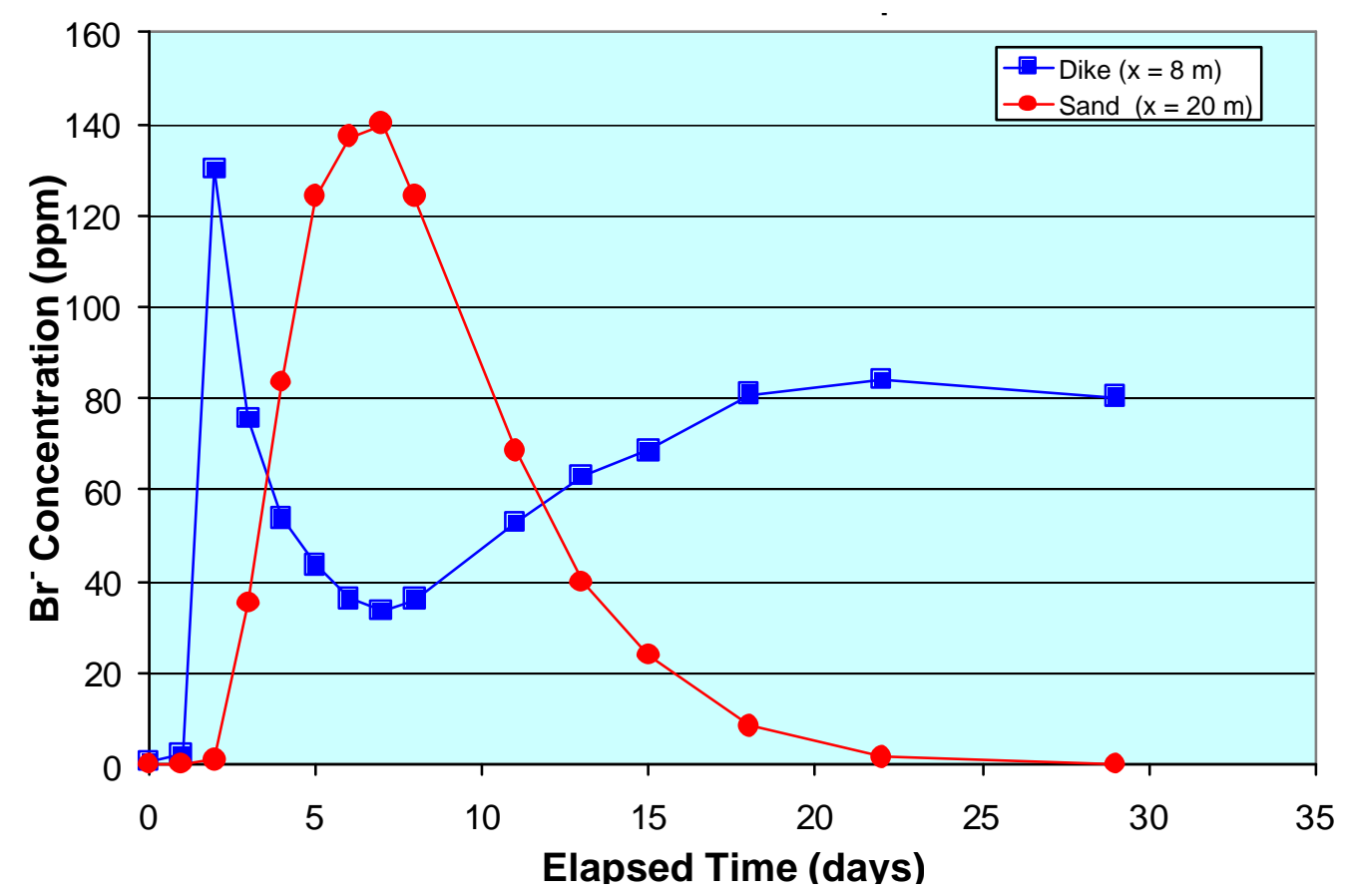

Figure 3.19. Comparison of Flux Concentrations Derived from Pore Water Samples of Br- at $0.8 \mathrm{~m}(2.6 \mathrm{ft})$ in the Sand Matric $(x=20 \mathrm{~m}[65.6 \mathrm{ft}])$ and Dike $(x=8 \mathrm{~m}[26 \mathrm{ft}])$. The breakthrough curve (BTC) from the dike shows evidence of multi-region transport, likely due to the small-scale heterogeneities within the dike.

\subsection{Measurement of Hydraulic Conductivity and its Anisotropy}

A number of methods are available for estimating and measuring hydraulic conductivity. It is well known that $\mathrm{K}$ is a second-rank tensor, and a variety of tests have shown that natural soils are anisotropic. In these soils, horizontal $\left(\mathrm{K}_{\mathrm{x}}\right)$ is generally larger than the vertical $\left(\mathrm{K}_{\mathrm{z}}\right)$ conductivity. However, none of the

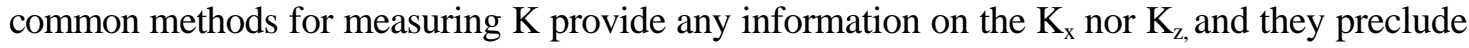
quantification of anisotropy or directional differences in K. Disk infiltrometers have become quite popular for rapid measurements of K (Zhang 1997). More recently, mini-disk infiltrometers have been adopted for rapid field measurements (1997). This infiltrometer is typically used in the field in a vertical orientation (Figure 3.20a) 


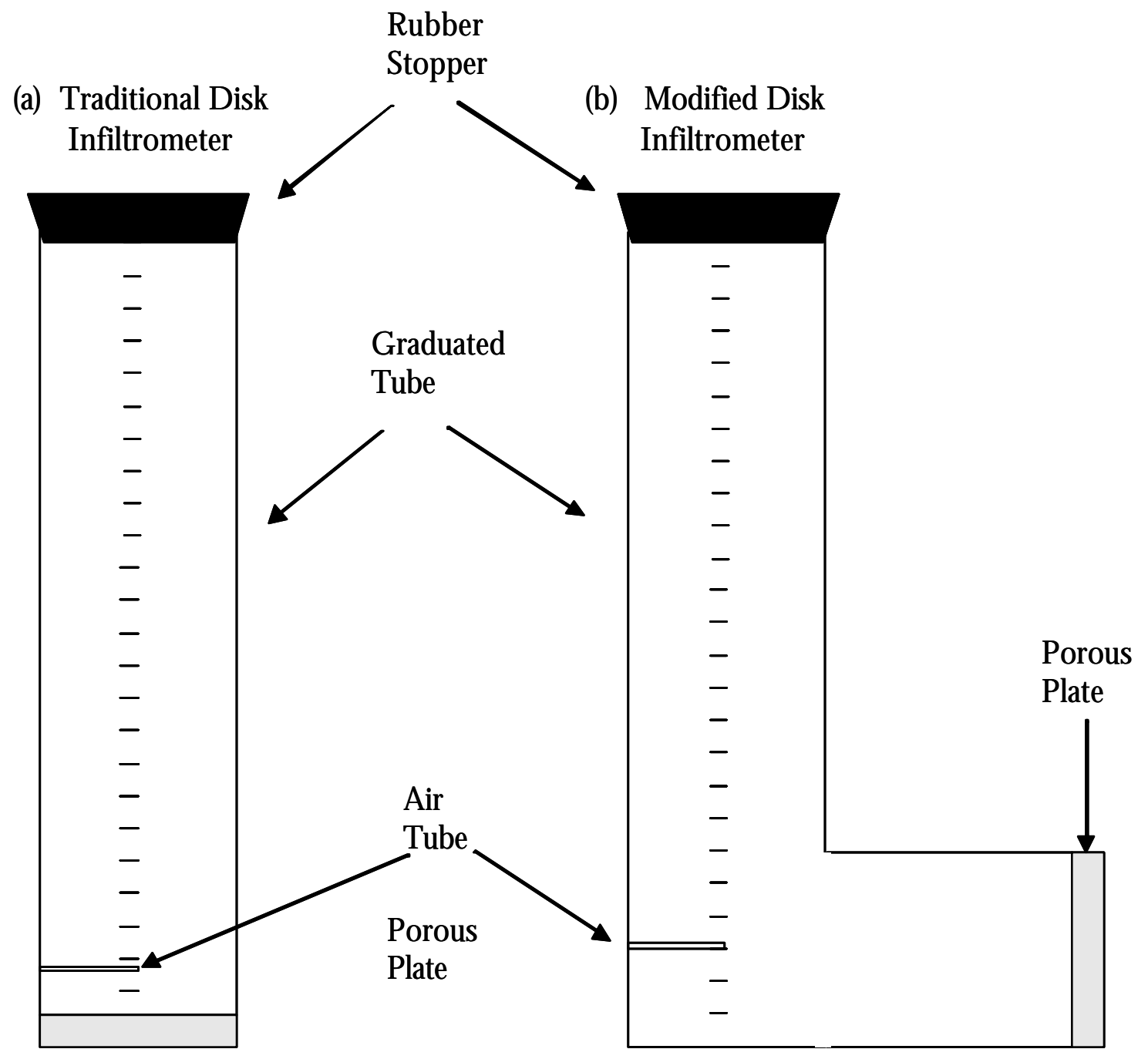

Figure 3.20. Schematic of Mini Disk-Infiltrometer (a) Conventional Design for Effective Vertical K, (b) Modified Design for Effective Horizontal K 
Table 3.2. Fitted Transport Parameters for the First Experiment

\begin{tabular}{|c|c|c|c|c|c|c|c|c|c|c|c|c|c|c|}
\hline \multirow{2}{*}{\begin{tabular}{||l|} 
Analysis \\
\end{tabular}} & \multirow[b]{2}{*}{ Parameter } & \multicolumn{13}{|c|}{ "Horizontal Distance (m) } \\
\hline & & 0.0 & 2.0 & 4.0 & 6.0 & 8.0 & 10.0 & 12.0 & 14.0 & 16.0 & 18.0 & 20.0 & 22.0 & 24.0 \\
\hline \multirow[t]{4}{*}{ 1-D CDE } & $v\left(m d^{1}\right)$ & 0.114 & 0.083 & 0.073 & 0.062 & 0.082 & NA & 0.033 & 0.031 & NA & NA & 0.076 & 0.082 & 0.129 \\
\hline & $D\left(m^{2} d^{-1}\right)$ & 0.008 & \begin{tabular}{|l|}
0.004 \\
\end{tabular} & 0.003 & 0.000 & 0.005 & NA & 0.000 & 0.000 & NA & $\mathrm{NA}$ & 0.002 & 0.005 & 0.007 \\
\hline & $\lambda(\mathbf{m})$ & 0.068 & \begin{tabular}{|l|}
0.047 \\
\end{tabular} & 0.040 & 0.003 & 0.057 & NA & 0.010 & 0.014 & NA & NA & 0.030 & 0.066 & 0.058 \\
\hline & $\mathbf{T}_{\text {mean }}(\mathrm{d})$ & 7.018 & \begin{tabular}{|l|}
9.639 \\
\end{tabular} & 10.959 & 12.903 & 9.756 & $\mathrm{NA}$ & 24.242 & 25.806 & NA & $\mathrm{NA}$ & 10.526 & 9.756 & 6.202 \\
\hline \multirow[t]{2}{*}{ CLT } & $\sigma$ & 0.406 & 0.338 & 0.311 & 0.091 & 0.397 & $\mathrm{NA}$ & 0.157 & 0.186 & NA & $\mathrm{NA}$ & 0.272 & 0.395 & 0.370 \\
\hline & $\mu$ & 5.782 & 6.126 & 6.255 & 6.465 & 6.149 & NA & 7.100 & 7.155 & NA & NA & 6.233 & 6.105 & 5.666 \\
\hline \multirow[t]{4}{*}{ Moments } & $T_{\text {mean }}(d)$ & 6.349 & \begin{tabular}{|l|}
9.195 \\
\end{tabular} & 12.903 & 13.559 & 14.545 & $\mathrm{NA}$ & 23.529 & 22.222 & NA & $\overline{\mathrm{NA}}$ & 10.667 & 9.412 & 6.349 \\
\hline & $\mathrm{v}$ (m/day) & 0.126 & \begin{tabular}{|l|}
0.087 \\
\end{tabular} & 0.062 & 0.059 & 0.055 & NA & 0.034 & 0.036 & NA & NA & \begin{tabular}{|l|}
0.075 \\
\end{tabular} & 0.085 & 0.126 \\
\hline & $D\left(m^{2} d^{-1}\right)$ & 0.008 & \begin{tabular}{|l|}
0.003 \\
\end{tabular} & 0.005 & 0.002 & 0.006 & NA & 0.000 & 0.001 & NA & NA & 0.002 & 0.005 & 0.010 \\
\hline & $\lambda(\mathbf{m})$ & 0.066 & \begin{tabular}{|l|}
0.036 \\
\end{tabular} & 0.083 & 0.039 & 0.101 & NA & 0.007 & 0.027 & NA & $\mathrm{NA}$ & 0.032 & 0.055 & 0.081 \\
\hline \multirow[t]{7}{*}{ 2-D CDE } & $V_{z}\left(m^{d^{1}}\right)$ & 0.117 & 0.088 & 0.078 & 0.071 & 0.114 & $\overline{\mathrm{NA}}$ & 0.034 & 0.001 & NA & $\mathrm{NA}$ & 0.083 & \begin{tabular}{l|l|}
0.090 \\
\end{tabular} & 0.139 \\
\hline & $V_{y}\left(m^{1} d^{1}\right)$ & 0.024 & \begin{tabular}{|l|}
0.016 \\
\end{tabular} & 0.014 & 0.007 & 0.012 & NA & 0.000 & 0.003 & NA & NA & 0.014 & 0.017 & 0.026 \\
\hline & $D_{z}\left(m^{2} d^{-1}\right)$ & 0.016 & 0.008 & 0.005 & 0.000 & 0.020 & NA & 0.000 & 0.109 & NA & $\mathrm{NA}$ & 0.005 & 0.011 & 0.019 \\
\hline & $D_{y}\left(m^{2} d^{-1}\right)$ & 0.001 & 0.000 & 0.000 & 0.000 & 0.000 & NA & 0.000 & 0.000 & NA & NA & 0.000 & 0.000 & 0.000 \\
\hline & $\lambda_{\mathbf{z}}(\mathrm{m})$ & 0.137 & \begin{tabular}{|l|}
0.091 \\
\end{tabular} & 0.064 & 0.005 & 0.175 & $\mathrm{NA}$ & 0.011 & 101.77 & $\mathrm{NA}$ & $\mathrm{NA}$ & 0.059 & 0.122 & 0.137 \\
\hline & $\lambda_{\mathbf{y}}(\mathrm{m})$ & 0.026 & \begin{tabular}{|l|}
0.019 \\
\end{tabular} & 0.020 & 0.004 & 0.025 & NA & 5.049 & 0.024 & NA & $\mathrm{NA}$ & 0.012 & 0.021 & 0.018 \\
\hline & & \multicolumn{13}{|c|}{ Horizontal Distance (m) } \\
\hline Analysis & Parar & 26.0 & 28.0 & 30.0 & 32.0 & 34.0 & 36.0 & 38.0 & 40.0 & 42.0 & 44.0 & 46.0 & 48.0 & 50.0 \\
\hline \multirow[t]{4}{*}{ 1-D CDE } & $v\left(m d^{1}\right)$ & 0.135 & 0.023 & 0.174 & 0.032 & 0.062 & 0.062 & 0.091 & 0.193 & 0.093 & 0.135 & 0.206 & 0.283 & $\overline{\mathrm{NA}}$ \\
\hline & $D\left(m^{2} d^{-1}\right)$ & 0.006 & 0.007 & 0.005 & 0.001 & 0.008 & 0.003 & 0.003 & 0.010 & 0.014 & 0.007 & 0.013 & 0.006 & $\overline{\mathrm{NA}}$ \\
\hline & $\lambda(\mathbf{m})$ & 0.045 & 0.302 & 0.029 & 0.034 & 0.129 & 0.047 & 0.030 & 0.052 & 0.151 & 0.055 & 0.063 & 0.020 & $\overline{\mathrm{NA}}$ \\
\hline & $T_{\text {mean }}(d)$ & 5.926 & 34.783 & 4.598 & 25.000 & 12.903 & 12.903 & 8.791 & 4.145 & 8.602 & 5.926 & 3.883 & 2.827 & $\overline{\mathrm{NA}}$ \\
\hline \multirow[t]{2}{*}{ CLT } & $\sigma$ & 0.329 & \begin{tabular}{|l|}
0.869 \\
\end{tabular} & 0.268 & 0.370 & 0.579 & 0.339 & 0.271 & 0.352 & 0.569 & 0.363 & 0.387 & 0.224 & $\overline{\mathrm{NA}}$ \\
\hline & $\mu$ & 5.633 & 7.662 & 5.398 & 7.209 & 6.405 & 6.416 & 6.046 & 5.270 & 5.890 & 5.622 & 5.192 & 4.925 & $\overline{\mathrm{NA}}$ \\
\hline \multirow[t]{4}{*}{ Moments } & $\mathbf{T}_{\text {mean }}(\mathrm{d})$ & 7.339 & 19.512 & 5.479 & 21.053 & 12.308 & 11.940 & 8.989 & 5.195 & 8.000 & 6.250 & 4.211 & 2.787 & $\overline{\mathrm{NA}}$ \\
\hline & $\mathrm{v}$ (m/day) & 0.109 & \begin{tabular}{|l|}
0.041 \\
\end{tabular} & 0.146 & 0.038 & 0.065 & 0.067 & 0.089 & 0.154 & 0.100 & 0.128 & 0.190 & 0.287 & $\overline{\mathrm{NA}}$ \\
\hline & $D\left(m^{2} d^{-1}\right)$ & 0.019 & \begin{tabular}{|l|}
0.002 \\
\end{tabular} & 0.015 & 0.001 & 0.005 & 0.002 & 0.004 & 0.019 & 0.010 & 0.009 & 0.018 & 0.007 & $\overline{\mathrm{NA}}$ \\
\hline & $\lambda(\mathbf{m})$ & 0.172 & 0.056 & 0.103 & 0.029 & 0.078 & 0.035 & 0.040 & 0.126 & 0.098 & 0.071 & 0.094 & 0.026 & $\overline{\mathrm{NA}}$ \\
\hline \multirow[t]{6}{*}{ 2-D CDE } & $V_{z}\left(m d^{1}\right)$ & 0.131 & 0.011 & 0.169 & 0.024 & 0.085 & 0.066 & 0.090 & 0.241 & 0.214 & 0.144 & 0.231 & \begin{tabular}{l|l|}
0.464 \\
\end{tabular} & $\overline{\mathrm{NA}}$ \\
\hline & $V_{y}\left(m d^{1}\right)$ & 0.030 & 0.003 & 0.126 & 0.004 & 0.008 & 0.012 & 0.021 & 0.028 & 0.013 & 0.027 & 0.040 & 0.050 & $\overline{\mathrm{NA}}$ \\
\hline & $D_{z}\left(m^{2} d^{1}\right)$ & 0.011 & 0.008 & 0.005 & 0.006 & 0.021 & 0.003 & 0.003 & 0.019 & 0.089 & 0.016 & 0.030 & 0.067 & $\overline{\mathrm{NA}}$ \\
\hline & $D_{y}\left(m^{2} d^{-1}\right)$ & 0.001 & 0.001 & 0.018 & 0.000 & 0.001 & 0.002 & 0.001 & 0.001 & 0.001 & 0.001 & 0.001 & 0.000 & $\overline{\mathrm{NA}}$ \\
\hline & $\lambda_{\mathrm{z}}(\mathrm{m})$ & 0.084 & 0.733 & 0.032 & 0.248 & 0.247 & 0.050 & 0.038 & 0.079 & 0.416 & 0.111 & 0.130 & 0.144 & $\overline{\mathrm{NA}}$ \\
\hline & $\overline{\lambda_{y}(\mathrm{~m})}$ & 0.019 & 0.273 & 0.143 & 0.033 & 0.085 & 0.132 & 0.026 & 0.030 & 0.052 & 0.021 & 0.023 & 0.005 & $\overline{\mathrm{NA}}$ \\
\hline
\end{tabular}


Table 3.3. Fitted Transport Parameters for the Second Experiment

\begin{tabular}{|c|c|c|c|c|c|c|c|c|c|c|c|c|c|c|}
\hline & & \multicolumn{13}{|c|}{ Horizontal Distance (m) } \\
\hline Analysis & Parameter & 0.0 & 2.0 & 4.0 & 6.0 & 8.0 & 10.0 & 12.0 & 14.0 & 16.0 & 18.0 & 20.0 & 22.0 & 24.0 \\
\hline \multirow[t]{4}{*}{ 1-D CDE } & $\mathbf{v}\left(\mathbf{m ~ d} \mathbf{d}^{1}\right)$ & 0.266 & 0.040 & 0.042 & 0.051 & 0.151 & 0.008 & $\mathrm{NA}$ & 0.005 & 0.023 & 0.081 & 0.092 & 0.128 & 0.182 \\
\hline & $\mathbf{D}\left(\mathbf{m}^{2} \mathrm{~d}^{-1}\right)$ & 0.018 & 0.000 & 0.006 & 0.012 & \begin{tabular}{|l|}
0.029 \\
\end{tabular} & 0.043 & $\mathrm{NA}$ & 0.005 & 0.003 & 0.002 & 0.007 & 0.012 & 0.014 \\
\hline & $\lambda(\mathbf{m})$ & 0.068 & 0.005 & 0.138 & 0.235 & \begin{tabular}{|l|}
0.192 \\
\end{tabular} & 5.173 & NA & 1.029 & \begin{tabular}{|l|}
0.137 \\
\end{tabular} & 0.024 & 0.079 & 0.094 & 0.077 \\
\hline & $\mathbf{T}_{\text {mean }}(\mathbf{d})$ & 3.008 & 20.000 & 19.048 & 15.686 & 5.298 & 96.246 & NA & 156.89 & 34.783 & 9.877 & 8.696 & 6.250 & 4.396 \\
\hline \multirow[t]{2}{*}{ CLT } & $\sigma$ & 0.427 & 0.109 & 0.594 & 0.648 & 1.248 & 1.730 & $\mathrm{NA}$ & 0.857 & 0.407 & 0.242 & 0.429 & 0.458 & 0.426 \\
\hline & $\mu$ & 5.075 & 6.891 & 6.807 & 6.309 & 7.054 & 7.037 & NA & 7.901 & \begin{tabular}{|l|}
7.084 \\
\end{tabular} & 6.174 & 5.981 & 5.636 & 5.304 \\
\hline \multirow[t]{4}{*}{ Moments } & $\mathbf{T}_{\text {mean }}(\mathrm{d})$ & 3.828 & 20.000 & 17.021 & 14.286 & 16.327 & 11.940 & $\mathrm{NA}$ & 19.048 & 19.048 & 9.639 & 8.602 & 6.107 & 4.651 \\
\hline & $\mathrm{v}(\mathrm{m} / \mathrm{day})$ & 0.209 & 0.040 & 0.047 & 0.056 & \begin{tabular}{|l|}
0.049 \\
\end{tabular} & 0.067 & NA & 0.042 & \begin{tabular}{|l|}
0.042 \\
\end{tabular} & 0.083 & 0.093 & 0.131 & 0.172 \\
\hline & $D\left(m^{2} d^{-1}\right)$ & 0.025 & 0.000 & 0.003 & 0.006 & \begin{tabular}{|l|}
0.005 \\
\end{tabular} & 0.015 & NA & 0.002 & \begin{tabular}{|l|}
0.001 \\
\end{tabular} & 0.001 & 0.007 & 0.009 & 0.018 \\
\hline & $\lambda(\mathbf{m})$ & 0.118 & 0.007 & 0.061 & 0.114 & \begin{tabular}{|l|}
0.100 \\
\end{tabular} & 0.225 & $\mathrm{NA}$ & 0.045 & 0.023 & 0.018 & 0.070 & 0.072 & 0.105 \\
\hline \multirow[t]{7}{*}{ 2-D CDE } & $V_{z}\left(m d^{-1}\right)$ & 0.243 & 0.041 & 0.038 & 0.730 & 0.000 & 0.009 & $\mathrm{NA}$ & 0.009 & 0.021 & 0.084 & 0.098 & 0.143 & 0.199 \\
\hline & $V_{y}\left(m d^{1}\right)$ & 0.195 & 0.008 & 0.007 & 0.013 & \begin{tabular}{|l|}
0.000 \\
\end{tabular} & 0.002 & NA & 0.002 & \begin{tabular}{l|}
0.008 \\
\end{tabular} & 0.015 & 0.021 & 0.026 & 0.037 \\
\hline & $D_{z}\left(m^{2} d^{-1}\right)$ & 0.020 & 0.000 & 0.015 & 0.037 & \begin{tabular}{|l|}
0.091 \\
\end{tabular} & 0.179 & $\mathrm{NA}$ & 0.011 & \begin{tabular}{|l|}
0.031 \\
\end{tabular} & 0.003 & 0.010 & 0.013 & 0.018 \\
\hline & $D_{y}\left(m^{2} d^{-1}\right)$ & 0.256 & 0.259 & 0.001 & 0.001 & 0.003 & 0.004 & NA & 0.001 & \begin{tabular}{|l|l|}
0.000 \\
\end{tabular} & 0.000 & 0.001 & 0.008 & 0.003 \\
\hline & $\lambda_{z}$ & 0.082 & 0.005 & 0.395 & 0.051 & 1333 & 18.900 & NA & 1.161 & \begin{tabular}{|c|}
1.476 \\
\end{tabular} & 0.035 & 0.101 & 0.091 & \begin{tabular}{|l|l|}
0.090 \\
\end{tabular} \\
\hline & & 1.313 & 33.381 & 0.075 & 0.061 & 212.42 & 2.031 & $\mathrm{NA}$ & 0.247 & 0.005 & 0.014 & 0.061 & 0.309 & 0.090 \\
\hline & & \multicolumn{13}{|c|}{ Horizontal Distance (m) } \\
\hline Analysis & leter & 26.0 & 28.0 & 30.0 & 32.0 & 34.0 & 36.0 & 38.0 & 40.0 & 42.0 & 44.0 & 46.0 & 48.0 & 50.0 \\
\hline \multirow[t]{4}{*}{ 1-D CDE } & $v\left(m d^{1}\right)$ & 0.135 & 0.023 & 0.174 & 0.032 & 0.062 & 0.062 & 0.091 & 0.193 & 0.093 & 0.135 & 0.206 & 0.283 & NA \\
\hline & $D\left(m^{2} d^{-1}\right)$ & 0.006 & 0.007 & 0.005 & 0.001 & \begin{tabular}{|l|}
0.008 \\
\end{tabular} & 0.003 & 0.003 & 0.010 & 0.014 & 0.007 & 0.013 & 0.006 & NA \\
\hline & & 0.045 & 0.302 & 0.029 & 0.034 & \begin{tabular}{|l|}
0.129 \\
\end{tabular} & 0.047 & 0.030 & 0.052 & 0.151 & 0.055 & 0.063 & 0.020 & $\overline{\mathrm{NA}}$ \\
\hline & $\overline{T_{m}}$ & 5.926 & 34.783 & 4.598 & 25.000 & 3 & 12.903 & 8.791 & 45 & 602 & 5.926 & 3.883 & 2.827 & $\overline{\mathrm{NA}}$ \\
\hline \multirow[t]{2}{*}{ CLT } & 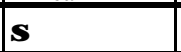 & 0.329 & 0.869 & 0.268 & 0.370 & \begin{tabular}{|l|}
0.579 \\
\end{tabular} & 0.339 & 0.271 & 0.352 & 0.569 & 0.363 & 0.387 & 0.224 & $\overline{\mathrm{NA}}$ \\
\hline & $\mu$ & 5.633 & 7.662 & 5.398 & 7.209 & 6.405 & 6.416 & 6.046 & 5.270 & 5.890 & 5.622 & 5.192 & 4.925 & NA \\
\hline \multirow[t]{4}{*}{ Moments } & $T_{\text {mean }}(d)$ & 7.339 & 19.512 & 5.479 & 21.053 & 12.308 & 11.940 & 8.989 & 5.195 & 8.000 & 6.250 & 4.211 & 2.787 & NA \\
\hline & $\mathrm{v}$ (m/day) & 0.109 & 0.041 & 0.146 & 38 & \begin{tabular}{|l|}
0.065 \\
\end{tabular} & 0.067 & 0.089 & 0.154 & 0.100 & 0.128 & 0.190 & 0.287 & $\overline{\mathrm{NA}}$ \\
\hline & $D\left(m^{2} d^{-1}\right)$ & 0.019 & 0.002 & 0.015 & 0.001 & 0.005 & 0.002 & 0.004 & 0.019 & 0.010 & 0.009 & 0.018 & 0.007 & NA \\
\hline & $\lambda(\mathbf{m})$ & 0.172 & 0.056 & 0.103 & 0.029 & 0.078 & 0.035 & 0.040 & 0.126 & 0.098 & 0.071 & 0.094 & 0.026 & NA \\
\hline \multirow[t]{6}{*}{ 2-D CDE } & $V_{z}\left(m d^{1}\right)$ & 0.131 & 0.011 & 0.169 & 0.024 & \begin{tabular}{|l|}
0.085 \\
\end{tabular} & 0.066 & 0.090 & 0.241 & 0.214 & 0.144 & 0.231 & 0.464 & $\overline{\mathrm{NA}}$ \\
\hline & $V_{y}\left(m d^{1}\right)$ & 0.030 & 0.003 & 0.126 & 0.004 & \begin{tabular}{|l|}
0.008 \\
\end{tabular} & 0.012 & 0.021 & 0.028 & \begin{tabular}{|l|}
0.013 \\
\end{tabular} & 0.027 & 0.040 & 0.050 & $\overline{\mathrm{NA}}$ \\
\hline & $D_{z}\left(m^{2} d^{1}\right)$ & 0.011 & 0.008 & 0.005 & 0.006 & \begin{tabular}{|l|}
0.021 \\
\end{tabular} & 0.003 & 0.003 & 0.019 & 0.089 & 0.016 & 0.030 & 0.067 & $\mathrm{NA}$ \\
\hline & $D_{y}\left(m^{2} d^{-1}\right)$ & 0.001 & 0.001 & 0.018 & 0.000 & 0.001 & 0.002 & 0.001 & 0.001 & 0.001 & 0.001 & 0.001 & 0.000 & NA \\
\hline & $\lambda_{\mathbf{z}}(\mathbf{m})$ & 0.084 & 0.733 & 0.032 & 0.248 & \begin{tabular}{|l|}
0.247 \\
\end{tabular} & 0.050 & 0.038 & 0.079 & 0.416 & 0.111 & 0.130 & 0.144 & $\overline{\mathrm{NA}}$ \\
\hline & $\lambda_{\mathrm{V}}(\mathrm{m})$ & 0.019 & 0.273 & 0.143 & 0.033 & 0.085 & 0.132 & 0.026 & 0.030 & \begin{tabular}{l|l|}
0.052 \\
\end{tabular} & 0.021 & 0.023 & 0.005 & NA \\
\hline
\end{tabular}

In this study, the traditional mini disk-infiltrometer was modified to allow measurements in a horizontal orientation. This modification would allow measurements on cut faces of outcrops, with the potential of providing in situ estimates of horizontal conductivity, $\mathrm{K}_{\mathrm{x}}$. The measurement procedure is similar to that proposed for the traditional infiltrometer. Immersing under water with the stopper removed fills the infiltrometer. The stopper is replaced under water and the infiltrometer removed, keeping the end with the stopper end upward. As with the traditional permeameter, a ring stand and clamp are used to keep the infiltrometer in place near the location of interest on the cut face after recording the water level. At time zero, the infiltrometer is moved into place, and then a volume of water in the tube is recorded at regular intervals. The cumulative volume infiltrated is recorded as a function of time. The cumulative water volume is converted to a depth by correcting for the starting volume and dividing by the area of the disk 
infiltrometer, in this case $7.92 \mathrm{~cm}^{2}$. Following the method of Zhang (1997), the depth of water is plotted as a function of the square root of time and fitted to a second degree polynomial with a zero intercept, i.e.,

$$
\mathrm{I}=\left(\mathrm{C}_{1}+\mathrm{C}_{2} \sqrt{\mathrm{t})}\right.
$$

The hydraulic conductivity is then computed from

$$
\mathrm{K}=\frac{\mathrm{C}_{1}}{\mathrm{~A}}
$$

where $\mathrm{A}$ is dependent on the value of the van Genuchten $\mathrm{n}$ parameter and is computed according to Zhang (1997). Figure 3.21 shows plots of cumulative infiltration as a function of the square root of time for different textures at the field site. Figure 3.21a shows the result for coarse sand, which appears to be essentially isotropic. This result is not too surprising, given that a coarse sand with well-rounded particles could be expected to show little difference in tortuosity or conductivity in different directions. This is confirmed by Figure 3.22, which shows that at an early time, the wetting front in the sand is quite isotropic. The effects of gravity at later time cause a deviation from isotropy. In contrast, the finetextured lens underlying the sand is strongly isotropic.

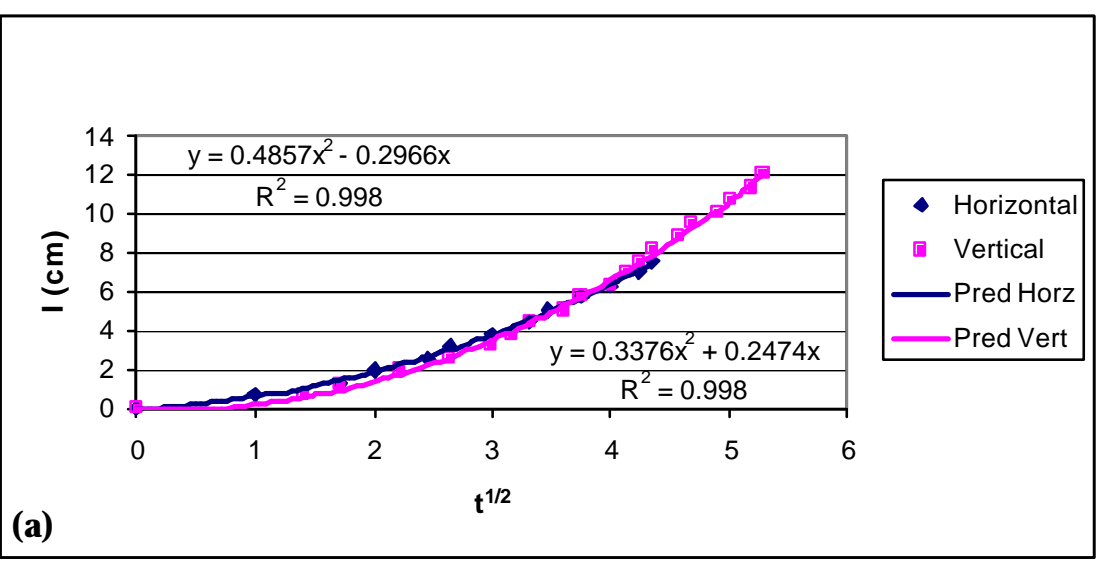

(a)

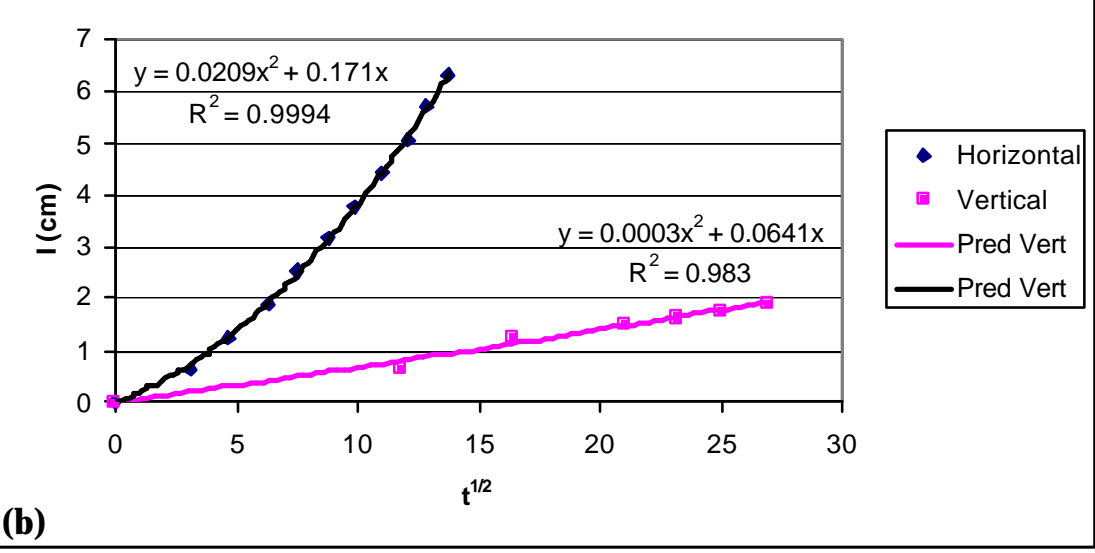

\section{Figure 3.21. Cumulative Infiltration Versus Square Root of Time (a) Sand Matrix, (b) Silt Lens Underlying Coarse Sand}




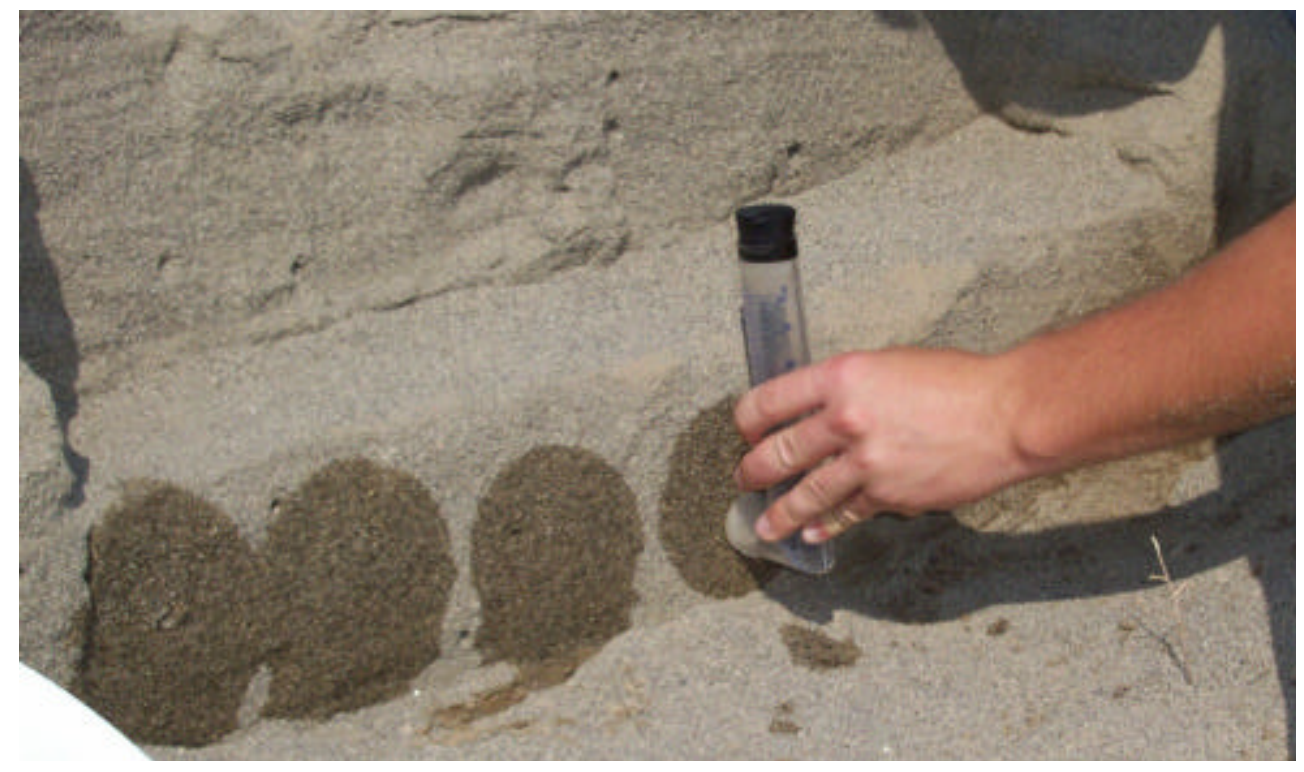

Figure 3.22. Wetting Fronts Resulting from Infiltration of Water from a Modified Disk Infiltrometer. The wetting fronts on the left are older and are beginning to show anisotropy due to the effects of gravity. The right-most wetting front is still quite isotropic. Note that the infiltrometer was put back in place for the picture but was not placed back in its original position at the center of the wetting front.

All measurements were made first in the vertical orientation, normal to bedding to get $\mathrm{K}_{\mathrm{z}}$, and then parallel to bedding to get $\mathrm{K}_{\mathrm{x}}$. Results show $\mathrm{K}_{\mathrm{z}}$ to be significantly lower than $\mathrm{K}_{\mathrm{x}}$ measured parallel to bedding on the silt lens. Table 3.4 summarizes $K_{x}$ and $K_{z}$ measured at different locations on the cut face.

A striking observation is that with the current analysis, measurements in the coarse sand from the test site appear to be mildly anisotropic, with A ratios near or slightly less than unity. The Buried Waste Test Facility (BWTF) sand, whose particle-size distributions show a greater percentage of fines, is slightly more anisotropic with $K_{x}=0.081 \mathrm{~cm} \mathrm{~s}^{-1}$, compared to a $K_{z}$ of $0.031 \mathrm{~cm} \mathrm{~s}^{-1}$, i.e., $A=2.59$. In contrast, the fine lens underlying coarser sediments at the field site shows $K_{x}=0.002 \mathrm{~cm} \mathrm{~s}^{-1}$, compared to a $K_{z}$ of $3.297 \cdot 10^{-5} \mathrm{~cm} \mathrm{~s}^{-1}$, i.e., $\mathrm{A}=69$. This anisotropy ratio is in the same magnitude as the value needed to explain the distribution of the $\mathrm{U}^{238}$ plume under BX-102 (Steve Yabusaki, personal communication). These results clearly suggest that measuring permeability distribution normal and parallel to foresets laminae is possible with a minipermeameter. However, some caution is needed for the interpretation of these data. The analysis conducted on the data from the modified infiltrometer is identical to that recommended for use with the traditional measurements, but some modifications may be necessary. For example, the traditional infiltrometer infiltrates water at a suction of $2 \mathrm{~cm}(0.8 \mathrm{in}$.), but because the porous plate of the modified infiltrometer is vertical, there will be a small head gradient from top to bottom such that the suction at infiltration is not everywhere equal to $2 \mathrm{~cm}(0.8 \mathrm{in}$.). The equation for cumulative infiltration is also somewhat empirical and based on the results of numerical simulations reported by Zhang (1997). Such an analysis has been performed for the traditional infiltrometer and confirms Zhang's findings. However, a similar analysis for the modified infiltrometer is still in progress. Early results suggest a need for a different method for calculating the A parameter used to derive $\mathrm{K}$ from the $\mathrm{C}$ coefficients. This work is in progress. 
Table 3.4. Vertical and Horizontal Hydraulic Conductivities Measured by Mini Infiltrometer and the Resulting Anisotropy Ratios. Horizontal measurements were conducted with a modified mini disk infiltrometer.

\begin{tabular}{||l|c|c|c||}
\hline \hline Soil Type & $\mathbf{K}_{\mathbf{z}}(\mathbf{c m} / \mathbf{s})$ & $\mathbf{K}_{\mathbf{x}}(\mathbf{c m} / \mathbf{s})$ & $\mathbf{A}\left(\mathbf{K}_{\mathbf{x}} / \mathbf{K}_{\mathbf{z}}\right)$ \\
\hline Coarse Sand & 0.092 & 0.131 & 1.43 \\
\hline Coarse Sand & 0.085 & 0.069 & 0.81 \\
\hline Coarse Sand & 0.087 & 0.073 & 0.84 \\
\hline Coarse Sand & 0.104 & 0.076 & 0.73 \\
\hline Coarse Sand & 0.090 & 0.063 & 0.70 \\
\hline Coarse Sand & 0.069 & 0.053 & 0.77 \\
\hline Coarse Sand & 0.043 & 0.019 & 0.44 \\
\hline Coarse Sand & 0.083 & 0.066 & 0.80 \\
\hline Coarse Sand & 0.081 & 0.059 & 0.73 \\
\hline Coarse Sand & 0.068 & 0.052 & 0.77 \\
\hline Coarse Sand & 0.069 & 0.053 & 0.77 \\
\hline Silt Lens Sand & $3.297 \cdot 10^{-5}$ & 0.002 & 69.67 \\
\hline Coarse Sand & 0.012 & 0.012 & 1.02 \\
\hline BWTF Soil & 0.031 & 0.081 & 2.59 \\
\hline \hline
\end{tabular}

Observations from the FY 2002 and previous experiments clearly show the effects of cross bedding on fluid flow. It is only from more general knowledge of the formation of the various cross-bedding types that we can design models of sedimentary structures that reflect the permeability distributions. It appears that in soils such as those at the FY 2002 sites, the important small-scale elements include bottomsets and foreset laminae with the bottomsets typically showing the lowest permeability. Measuring the permeability distributions parallel and normal to these elements, either through the use of cubic samples or with the mini infiltrometer, remains a top priority. Given the small sample size of the infiltrometer, however, it will be necessary to make a large number of measurements to gain insight into the true permeability distribution. Work will continue to refine and evaluate the mini infiltrometer over a wider range of conditions.

\subsection{Parameter Scaling and Inverse Modeling}

Parameterization of numerical models for heterogeneous porous media remains one of the biggest challenges in our attempts to model vadose-zone transport. The concept of parameter scaling was proposed as a method to overcome this difficulty by incorporating the effect of vertical heterogeneity (Gee and Ward, 2001; Zhang et al, 2002). The concept is based on the scaling of the hydraulic parameters of different soil textures to a single set of reference values. The application of parameter scaling at the local or field-scale provides a way to link the observations at different spatial scales, given the assumption that the values of the scaling factors are invariant across spatial scales. After determining the scaling factors from localscale measurements and assigning these values to the field, the field-scale reference hydraulic parameters can be estimated by inverse modeling of well-designed field experiments. The parameters for individual layers are obtained through inverse scaling of the field-scale reference values using a priori relationships between the reference parameter values and the specific value for each soil texture. 
Work over the last year was successful in applying parameter scaling, coupled with inverse modeling, to a variety of file problems. Results indicate that when local-scale parameter values are used to predict flow, both the water contents and the pressure heads are overestimated for the Hanford measurements, and the pressure heads were predicted relatively poorly for an experiment at Andelfingen. When the field-scale parameter estimates were used to predict the flow, the prediction errors were significantly reduced. The sum of the squared weighted residue (SSWR) decreased by $96 \%$ for the Hanford experiment and by $93 \%$ for the Andelfingen experiment.

Figure 3.23 shows the comparisons between the observations and the predictions using the localscale parameter values. Perfect correlation between the predictions and the observations would produce a slope of unity and an intercept of zero. In Figure 3.23, both the water contents and the pressure heads were overestimated for the Hanford experiment. For the Andelfingen experiment, the water contents were well predicted as shown by the near unity slope $(1.01)$ and high correlation $\left(\mathrm{R}^{2}=0.97\right)$ while the pressure heads were predicted relatively poorly $\left(\mathrm{R}^{2}=0.84\right)$.
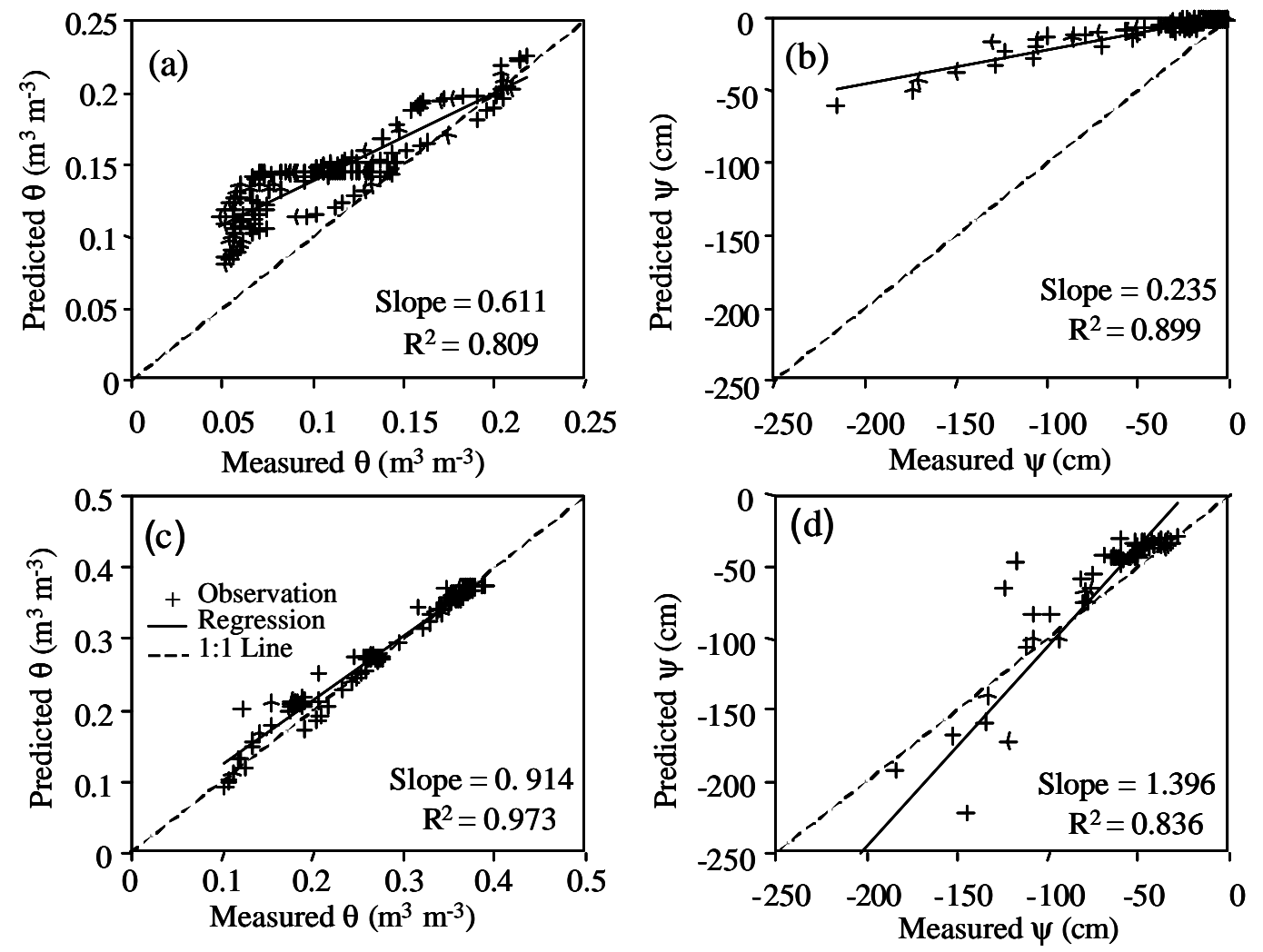

Figure 3.23. Comparison of the Observations and the Predictions of Water Content and Pressure Head Using the Local-Scale Parameter Values. (a) and (b): The Hanford Experiment; and (c) and (d): The Ande lfingen Experiment

When the field-scale parameter estimates were used to predict the flow, the prediction errors were significantly reduced. For the Hanford experiment, the sum of the SSWR decreased by $96 \%$ from 15,484 to 604. For the Andelfingen experiment, the value of SSWR decreased by $93 \%$ from 13,517 to 907. 
Comparisons between the observations and the predictions calculated using the field-scale parameter values are shown in Figure 3.24. The slopes of the plots range from 0.903 to 0.997, which are very close to unity. However, further work is warranted to examine the assumption that the scaling factors are scale invariant. In addition, there is a need to investigate the new approach using error-free data. Such work is in progress with the first evaluation of parameter scaling based on geostatiscally simulated soils nearing completion.
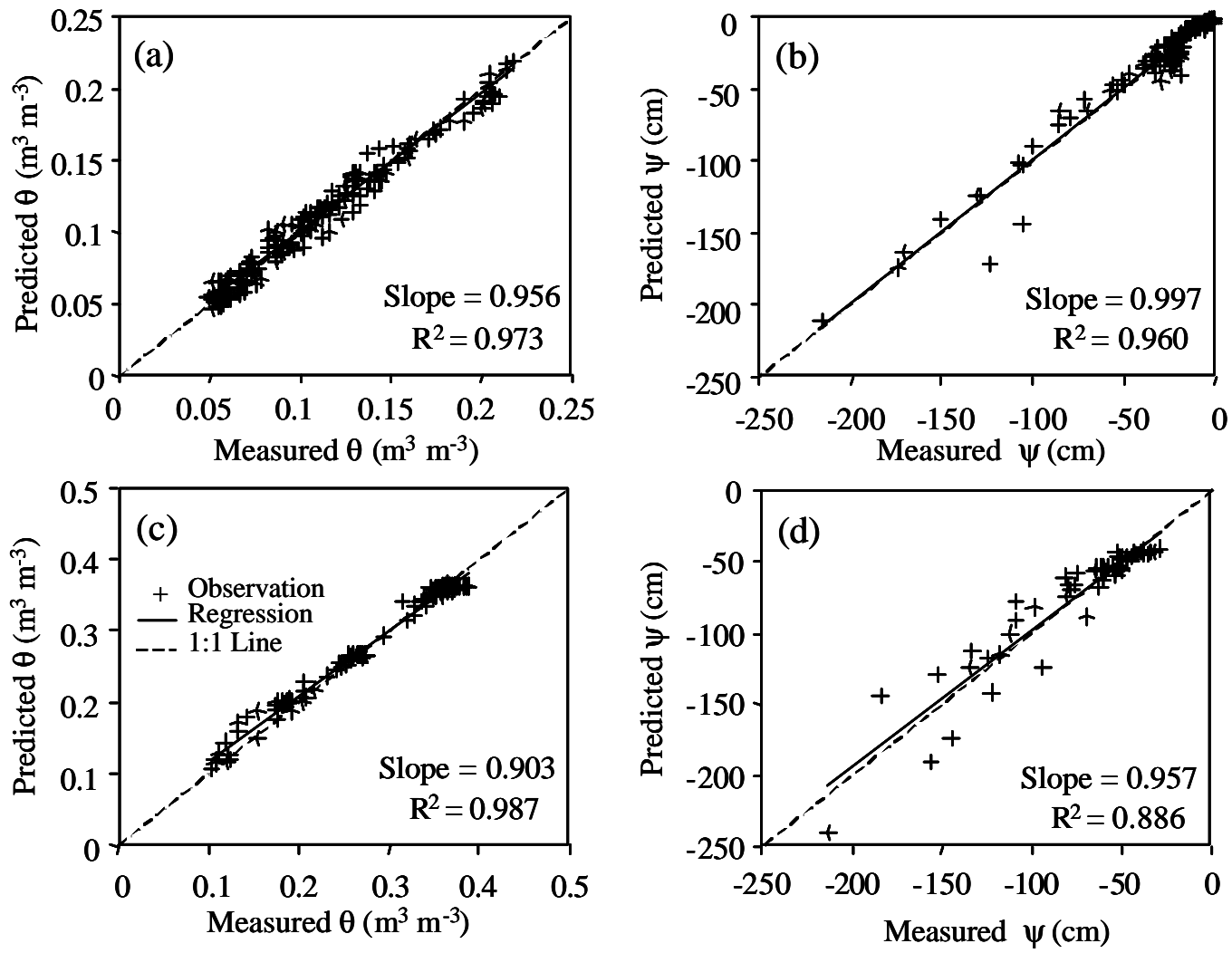

Figure 3.24. Comparison of the Observations and the Predictions of Water Content and Pressure Head Using the Fie Id-Scale Parameter Values Determined Inversely Based on the Non-Similar Scaling Concept, (a) and (b): The Hanford Experiment; and (c) and (d): The Andelfingen Experiment

The concept of parameter scaling has clear advantages over existing approaches for incorporating the effects of vertical heterogeneity into flow models. The advantages can be summarized as follows:

1. It does not require the constitutional materials to be similar.

2. The flow equation can always be expressed in real time and distance regardless of the soil heterogeneity.

3. After scaling, the values of the hydraulic parameters of all the soil textures perfectly reduce to the reference values.

4. The spatial variability of each hydraulic parameter can be expressed by the scaling factors; and when the parameters are to be estimated by an inverse procedure, the number of unknown variables is reduced by a factor of the number of textures. 


\subsection{Pore-scale Anisotropy}

Contaminant plumes in the Hanford vadose zone typically show extensive lateral spreading with splitting along flow paths and multiple zones of high-contaminant concentrations. This directional dependence of flow is a manifestation of anisotropy in the permeability and has proven difficult to predict at Hanford using current models. Understanding the nature of anisotropy and its dependence on saturation is therefore important for improving our ability to predict the movement of water and contaminants through the vadose zone. Lateral spreading is commonly attributed to anisotropy in the hydraulic conductivity tensor, $\mathbf{K}$, caused by local scale changes in the lithology and mineralogy associated with sedimentary facies. The anisotropy factor is defined simply as the ratio $\left(\mathrm{A}_{\mathrm{K}}\right)$ of the hydraulic conductivity parallel to the bedding plane, $\mathrm{K}_{\mathrm{P}}$, and normal to bedding, $\mathrm{K}_{\mathrm{N}}$. However, current approaches for predicting the effect of anisotropy under extreme heterogeneity are limited in their ability to reproduce field observations. Our work is aimed at developing a more robust description of anisotropy. To gain a better understanding of the phenomenon, we start with investigations at the pore scale.

Natural soils typically consist of a variety of particles of different mineralogy, shapes, and orientations. During sedimentation, aggregation, and compaction, irregularly shaped particles typically orient with their longer axis parallel to the plane in which they settle. Plate-like particles therefore orient with their larger surfaces horizontal and the result is a medium in which the rate of flow of mass and energy is strongly dependent on direction. This arrangement often results in more resistant, more tortuous pathways normal to bedding and less resistant, less tortuous pathways parallel to bedding at the pore-scale (Figure 3.25). Thus, under the same potential gradient, convective and diffusive processes could result in very different mass flows in different directions due to anisotropy in the conductivity tensor.
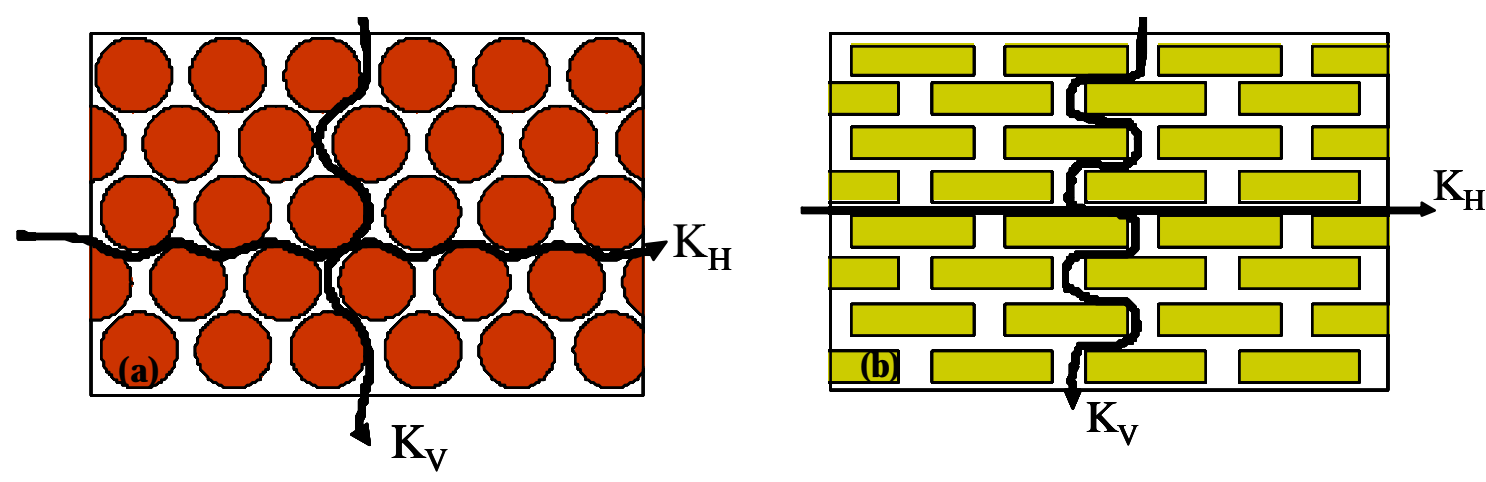

Figure 3.25. Schematic of an Isotropic Soil. Due to spherical particle shape (e.g., sand), the difference in tortuosity is small, and the horizontal $\left(K_{H}\right)$ and vertical $\left(K_{V}\right)$ conductivities are similar.

One way to improve our understanding is to measure the directional unsaturated hydraulic conductivity at different degrees of saturations. However, unsaturated hydraulic conductivity is already difficult enough to measure in one direction using standard methods. An easier approach might be to use directional electrical measurements (dielectric constant and electrical conductivity). In this study, we used a time domain reflectometry technique to measure the directional electrical conductivity during drainage of two types of soil. A 30/40 Accusand (Unimin Corp., Le Sueur, MN) was chosen to represent spherical 
particles while the BWTF sand from Hanford was chosen to represent a real soil with a combination of spherical and flat particles.

Time-domain reflectometry probes were assembled using 10-cm (4-in.) stainless steel rods. The rods were inserted into a PVC tube (probe head) and soldered to a 2-m (6.6-ft)-long piece of RG58/U coaxial cable. The hollow probed head was then filled with epoxy resin and left to cure overnight. Soil columns were packed with three types of soil representing different particle sizes. One column was packed with 30 to 40 accusand to represent spherical particles and a second with BWTF sand from Hanford Sand to represent spherical and flat particles. The columns were saturated from the bottom up after packing the right amount of soil to get a bulk density of $1.6 \mathrm{~g} \mathrm{~cm}^{-3}$. The water content and electrical conductivities were then measured in the vertical and horizontal directions while the soils were still saturated with water. The burette was then lowered by $3 \mathrm{~cm}$ and monit ored until the system reached equilibrium and the drainage stopped. Another set of readings was then taken and recorded for that head. These steps were repeated until the column was completely unsaturated.

As expected, results show no directional dependence of water content-matric potential relationship. However, electrical conductivity shows a directional dependence. Figure 3.10 plots electrical conductivity as a function of water content for the accusand and BWTF soils. As seen in Figure 3.10a, the electrical-conductivity measurements in the accusand show no directional dependence, as hypothesized in our conceptual model in Figure 3.26a. However, the BWTF soil shows a clear dependence on direction with the electrical conductivity in the horizontal direction being higher than in the vertical direction (Figure 3.10b). This is consistent with the hypothesis of a lower tortuosity or higher connectivity in the horizontal direction compared to the vertical (Figure 3.26b).

Anisotropy spans several temporal and spatial scales; at the local scale, pore morphology and topology appear to play a role in rendering sediments anisotropic in their resistance to the flow of electrical currents and therefore water. An improved understanding of the nature and extent of anisotropy in unsaturated soils is important for improving our prediction capability for water moving through the vadose zone. These results suggest that such an understanding can be realized from a study of pore scale electrical properties. These studies will continue in the next fiscal year.

\subsection{A New Conceptual Model for State-Dependent Anisotropy}

Particle shape and alignment, both of which influence pore connectivity and tortuosity, led to the formulation of a hypothesis that anisotropy could be modeled with traditional hydraulic conductivity functions modified to include a connectivity tensor. Description of state-dependent anisotropy would then be simply a case of calculating the ratio of $\mathrm{K}$ for principle directions, with each direction characterized by a connectivity. 

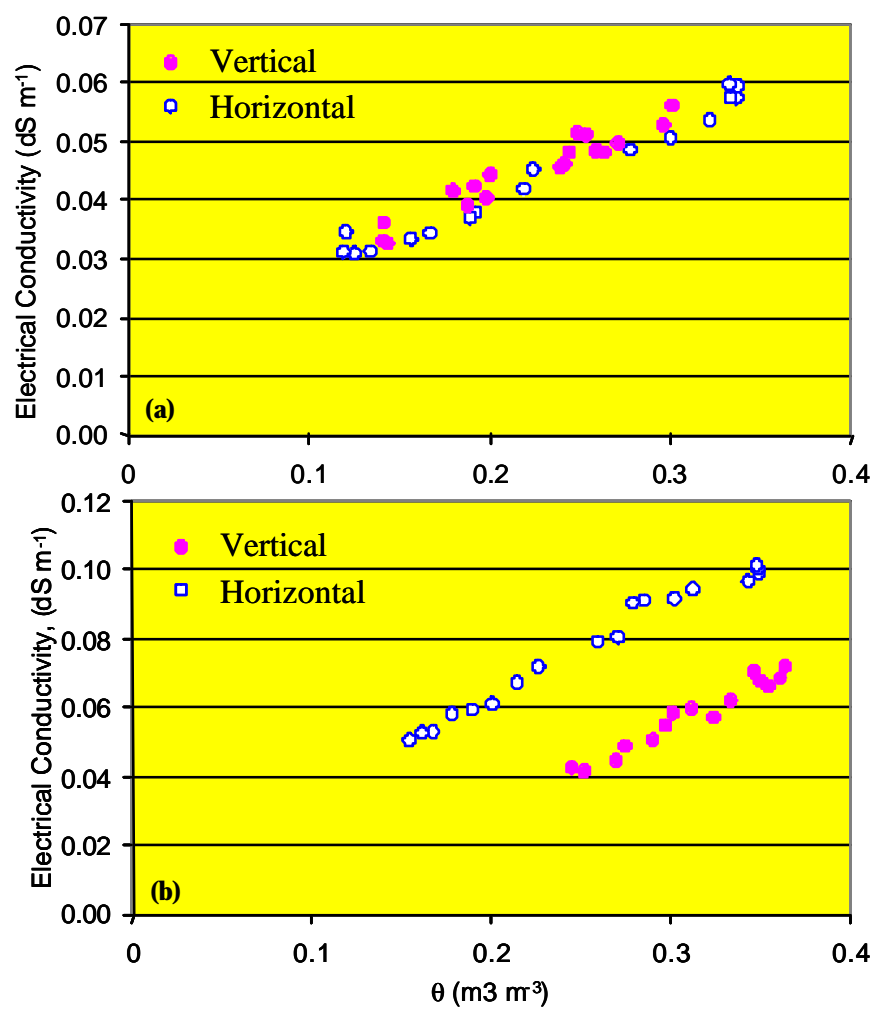

Figure 3.26. Effect of Particle Shape on Directional Electrical Conductivity as Measured by TDR (a) 30 to 40 Accusand, a Surrogate for Spherical Particles, and (b) BWTF Sand from Hanford, a Mixture of Spherical and Flat Particles

The objective of this research is to extend existing hydraulic functions to allow saturation-dependent anisotropy to be described by introducing a tensorial connectivity-tortuosity (TCT) concept. The TCT concept was tested using numerical experiments of 2-D flow through synthetic soils with different degrees of heterogeneity and anisotropy. To test this concept, a series of hypothetical soils was generated using geostatistical techniques as follows. Each soil was generated by assigning different levels of spatial variability and anisotropy. Soil anisotropy was created by assigning different correlation lengths to different directions. The macroscopic hydraulic properties of the soils were then determined by running numerical experiments. The results of the numerical experiments were used to evaluate the ability of the TCT concept to describe the hydraulic properties of the hypothetical soils. The soils were generated to be microscopically isotropic and homogeneous but macroscopically anisotropic and heterogeneous.

Hydraulic properties at spatial location $\mathbf{s}$ are defined by a non-hysteretic water-retention characteristic, $\mathrm{h}(\theta ; \mathbf{s})$, and an unsaturated hydraulic conductivity function, $\mathrm{K}(\mathrm{h} ; \mathbf{s})$. To facilitate description of the heterogeneity, the hypothetical soil is assumed to be Miller-similar (1958) at the macroscopic scale .

Thus, the entire domain is characterized by a reference state $\left\{?_{\mathrm{h}}^{*}, ?_{\mathrm{K}}^{*}, \mathrm{~h}^{*}(\theta), \mathrm{K}^{*}(\theta)\right\}$, with $\chi$ being the characteristic length, and a unique scaling relationship between the hydraulic functions at different spatial locations (Roth 1995). In Miller-similar media, the relationship between $h(\theta)$ at $\mathbf{s}$ and the reference state is given by Sposito and Jury (1990):

$$
\mathrm{h}(\theta) \chi_{\mathrm{h}}=\mathrm{h}^{*}(\theta) \chi_{\mathrm{h}}^{*}
$$

while the relationship between $K(\theta)$ and the reference state is given by 


$$
\frac{K(\theta)}{\chi_{\mathrm{K}}^{2}}=\frac{\left.\mathrm{K}^{*} \theta\right)}{\chi_{\mathrm{K}}^{2}}
$$

To generate fields of $\mathrm{h}(\theta, \mathrm{s}), \chi_{\mathrm{h}}(\mathrm{s})$ was treated as a stationary random function with unique probability density and autocovariance functions. The logarithm of the scaling factor, $f=\log \left(\chi_{\mathrm{h}} \chi_{\mathrm{h}}{ }^{*}\right)$, is assumed to be normally distributed with zero mean and variance $\sigma_{\mathrm{f}}^{2}$ (Roth 1995). An exponential covariance model with correlation lengths being $\lambda_{\mathrm{x}}, \lambda_{\mathrm{y}}$, and $\lambda_{\mathrm{z}}$ along the three principle coordinates was assumed for the autocovariance function, $\mathrm{C}(\mathbf{s})$. An autocovariance function was generated using a sequential Gaussian simulation (SGSIM) program from the Geostatistical Software Library (GSLIB) (Deutsch and Journel 1998) with different correlation lengths $(\lambda)$ in the three principle directions. The full scaling invariance of the Richards equation over the whole soil domain requires a power-law dependence of hydraulic conductivity on matric potential (Snyder 1996):

$$
\chi_{\mathrm{K}}=\left(\chi_{\mathrm{h}}\right)^{?}
$$

The values of $\chi_{\mathrm{K}}$ were calculated using Eq. (9) with the assumption that $\omega=0.8$.

In this study, four levels of soil heterogeneity (i.e., $\sigma_{\mathrm{f}}^{2}=0.1,0.25,0.5$, and 1.0) and four levels of soil anisotropy (i.e., 1:1, 10:1, 50:1, and 100:1) were generated on a $1.0 \mathrm{~m}^{3}\left(35.3 \mathrm{ft}^{3}\right)$ domain uniformly discretized with the grid spacing of $0.02 \mathrm{~m}(0.07 \mathrm{ft})$. This produced a total of 16 synthetic soils. Soil anisotropy was described by the ratio $\left(\mathrm{R}_{\mathrm{pn}}\right)$ of the correlation lengths of $f$ at a direction perpendicular to that normal to soil strata. The van Genuchten (1980) model was chosen to describe the hydraulic properties of the soils. The remaining parameters were set being constants, i.e., $\mathrm{n}=4.0, \theta_{\mathrm{s}}=0.40 \mathrm{~m}^{3} \mathrm{~m}^{-3}$, $\theta_{\mathrm{r}}=0.0 \mathrm{~m}^{3} \mathrm{~m}^{-3}$, and $\mathrm{L}=0.5$.

Figure 3.27 provides examples of the spatial distribution of $Y=\ln \left(\mathrm{K}_{\mathrm{s}}\right)$ of the soils with the variance of $\mathrm{Y}, \sigma_{\mathrm{Y}}^{2}$ being about 2.0 and with different levels of anisotropy. As the value of $\mathrm{R}_{\mathrm{pn}}$ becomes larger, the soil shows stronger layering, suggesting greater connectivity in the principle direction.

Using the generated hydraulic soils, multi-step numerical experiments of gravity-induced flow were conducted under constant-head boundary conditions at the top and bottom boundaries. The head values at the top and bottom boundaries were kept the same at a specific time so that gravity was the only driving force, i.e., flow occurred under a unit hydraulic gradient. Thus, at steady state, the water fluxes at the top and bottom were the same and equal to the hydraulic conductivity at the corresponding soil-water pressure-head. After steady-state conditions were reached at a given pressure, the pressure heads at the two boundaries were adjusted to new values, and $\mathrm{K}$ was determined. This process was repeated in $10-\mathrm{cm}$ increments from 0 to $2.0 \mathrm{~m}$ of suction. Flow in the synthetic soils was simulated using the STOMP flow simulator. In the interest of time, simulations of flow in a 2-D domain were estimated over a 160-year period. Each numerical experiment started at saturation, and the soil was dewatered gradually at 32 steps of pressure heads from 0.0 to $2.0 \mathrm{~m}(0.0$ to $6.6 \mathrm{ft})$. To make sure the flow was at steady state at each pressure head, the durations for each step were between 0.5 and 10 years. The simulation time was longer when the soil became drier since the flow became slower. We could tell if the system was in steady state by examining the water fluxes at the top and bottom boundaries. If the values of the fluxes at two boundaries were not equal, the system had not reached steady state at that pressure-head step. Then the numerical experiment was redone by assigning longer times to each pressure step. 


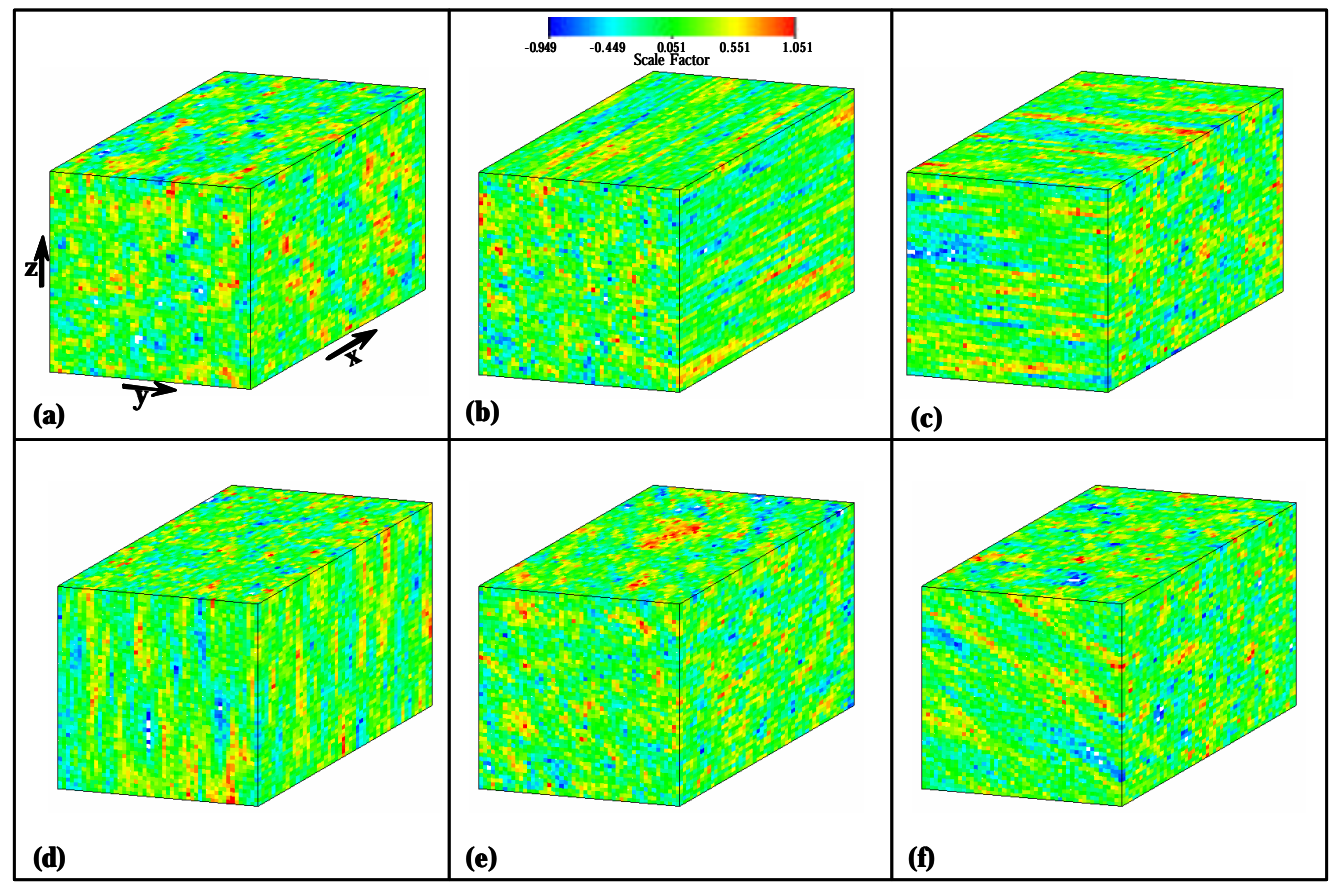

Figure 3.27. Realizations of Different Degrees of Heterogeneity and Connectivity for Hypothetical Soils, (a) Isotropic, (b) Preferential x-Direction Connectivity, (c) Preferential yDirection Connectivity, (d) Preferential z-Direction Connectivity, (e) Connectivity Preferential in y-Direction at $45^{\circ}$, and (f) Preferential z-Direction Connectivity at $45^{\circ}$ and $y$ at $30^{\circ}$.

After the completion of the determination of the unsaturated hydraulic conductivity at the direction normal to soil strata, $K_{n}(h)$, the soil slice was rotated $90^{\circ}$. Then another numerical experiment was carried out to determine the conductivity at the direction parallel to soil strata, $K_{p}(h)$. The mean values of $h$ and $\theta$ of each step were then calculated. In all, there were 64 pairs of $h(\theta), 32$ pairs of $K_{p}(h)$, and 32 pairs of $\mathrm{K}_{\mathrm{n}}(\mathrm{h})$ data for each soil. We chose to use the van Genuchten (1980) model to describe the soil-water retention curve. Since the soil-water retention curve is independent of soil anisotropy, as will be shown in the next section, all the 64 pairs of $h(\theta)$ data were used to optimize the effective $\alpha$ and $n$ while parameters $\theta_{\mathrm{s}}$ and $\theta_{\mathrm{r}}$ were fixed. After this, the parameters at the direction parallel to soil strata, $\mathrm{K}_{\mathrm{sp}}$ and $\mathrm{L}_{\mathrm{p}}$, were optimized to the $\mathrm{K}_{\mathrm{p}}(\mathrm{h})$ data using the already optimized $\alpha$ and $\mathrm{n}$ as constants. Similarly, the parameters at the direction normal to soil strata, $K_{\mathrm{sn}}$ and $\mathrm{L}_{\mathrm{n}}$, were optimized to the $\mathrm{K}_{\mathrm{n}}(\mathrm{h})$ data.

As can be expected, the numerical experiments show that the retention curves are independent of soil direction. The retention curves obtained when the flow was parallel to soil strata were the same as those when the flow was normal to soil strata (Figure 3.28). 

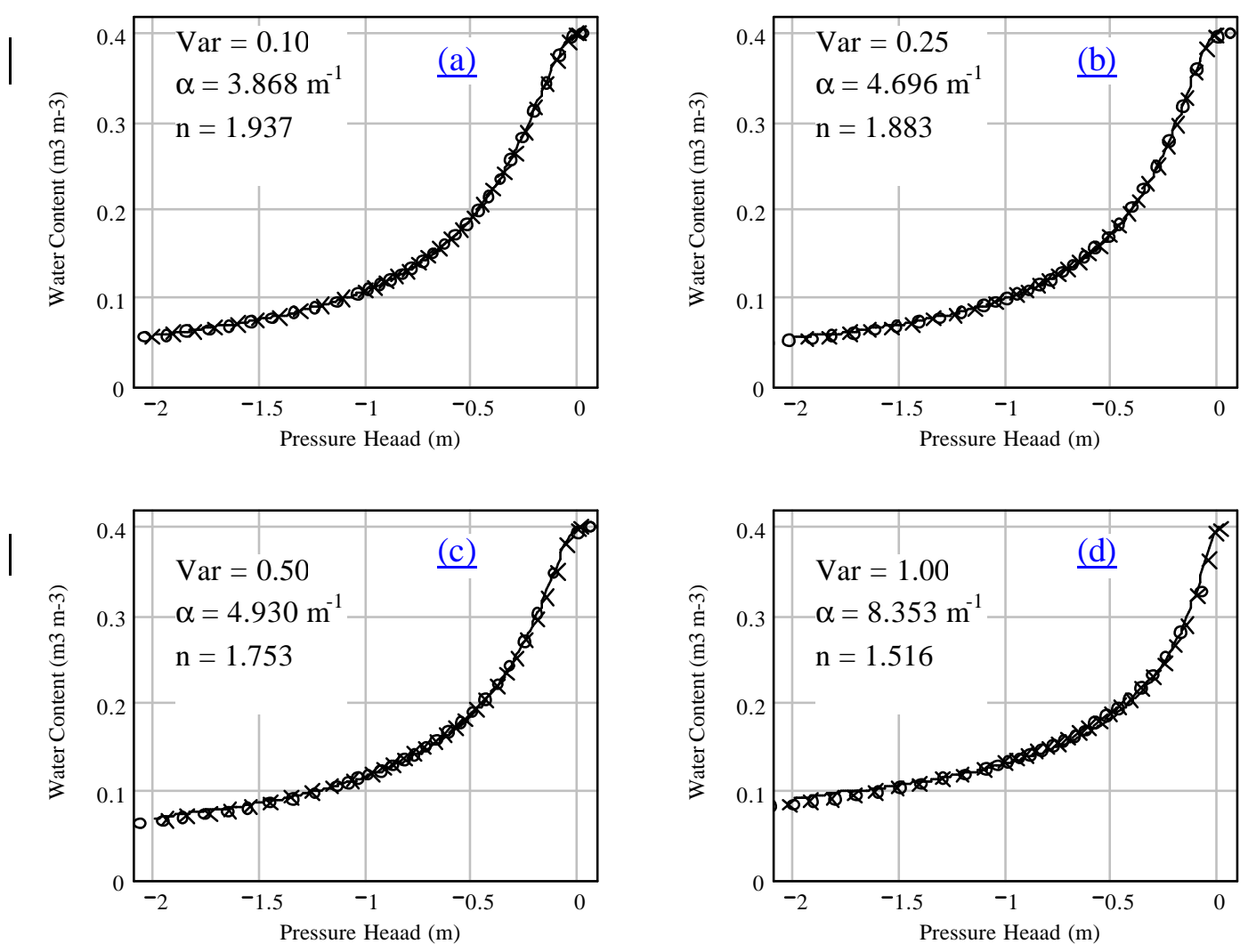

Figure 3.28. Retention Curves of Anisotropic Soils with Different Levels of Heterogeneities and the Correlation Ratio of 50 Between the Correlation Lengths at the Direction Parallel to and Those Perpendicular to the Strata

However, the water-retention curves/functions of a heterogeneous soil varies as the heterogeneity of the soil varies. The effective value $\left(\alpha_{\mathrm{e}}\right)$ of parameter $\alpha$ is positively correlated with the $\sigma_{\mathrm{Y}}^{2}$ of the soil, while the effective value $\left(n_{e}\right)$ of $n$ is negatively correlated with it and indicates that both $\alpha_{e}$ and $n_{e}$ are functions of soil heterogeneity but independent of soil anisotropy. This suggests that $\alpha_{\mathrm{e}}$ tends to increase with spatial scale, and $n_{\mathrm{e}}$ tends to decrease with scale should their mean values be scale invariant since soil heterogeneity often increases with spatial scale.

Figure 3.29 shows the effects of soil anisotropy on the unsaturated hydraulic conductivity. In an isotropic soil $\left(\mathrm{R}_{\mathrm{pn}}=1\right)$, the unsaturated hydraulic conductivity at a given pressure head at the direction parallel to soil strata $\left(\mathrm{K}_{\mathrm{p}}\right)$ were the same as that normal to soil strata $\left(\mathrm{K}_{\mathrm{n}}\right)$ as expected (Figure 3.29a). As the $\mathrm{R}_{\mathrm{pn}}$ became larger, $K_{p}(h)$ became larger while $K_{n}(h)$ became smaller (Figure 3.29b,c,d) than the values of $\mathrm{K}(\mathrm{h})$ of the isotropic soil with nearly the same heterogeneity (Figure 3.29a). The difference between $\mathrm{K}_{\mathrm{p}}(\mathrm{h})$ and $\mathrm{K}_{\mathrm{n}}(\mathrm{h})$ became larger as $\mathrm{h}$ became more negative. For example, for Soil \#11 with $\sigma_{\mathrm{Y}}{ }^{2}=2.0$ and $\mathrm{R}_{\mathrm{pn}}=50$ (Figure 3.29c), when the soil was saturated, the saturated hydraulic conductivities at the two directions were $\mathrm{K}_{\mathrm{sp}}=1.56 \times 10^{-4}$ and $\mathrm{K}_{\mathrm{sn}}=5.08 \times 10^{-5}$; hence $\mathrm{K}_{\mathrm{sp}} / \mathrm{K}_{\mathrm{sn}}=3.1$. When the pressure head is -2.0 $\mathrm{m}(-6.6 \mathrm{ft})$, the hydraulic conductivities at the two directions were $\mathrm{K}_{\mathrm{p}}=7.36 \times 10^{-9}$ and $\mathrm{K}_{\mathrm{n}}=1.88 \times 10^{-10}$; hence $\mathrm{K}_{\mathrm{p}} / \mathrm{K}_{\mathrm{n}}=391.5$. This means that unsaturated hydraulic conductivity is more anisotropic when the soils become drier. These results are consistent with findings of previous studies. 

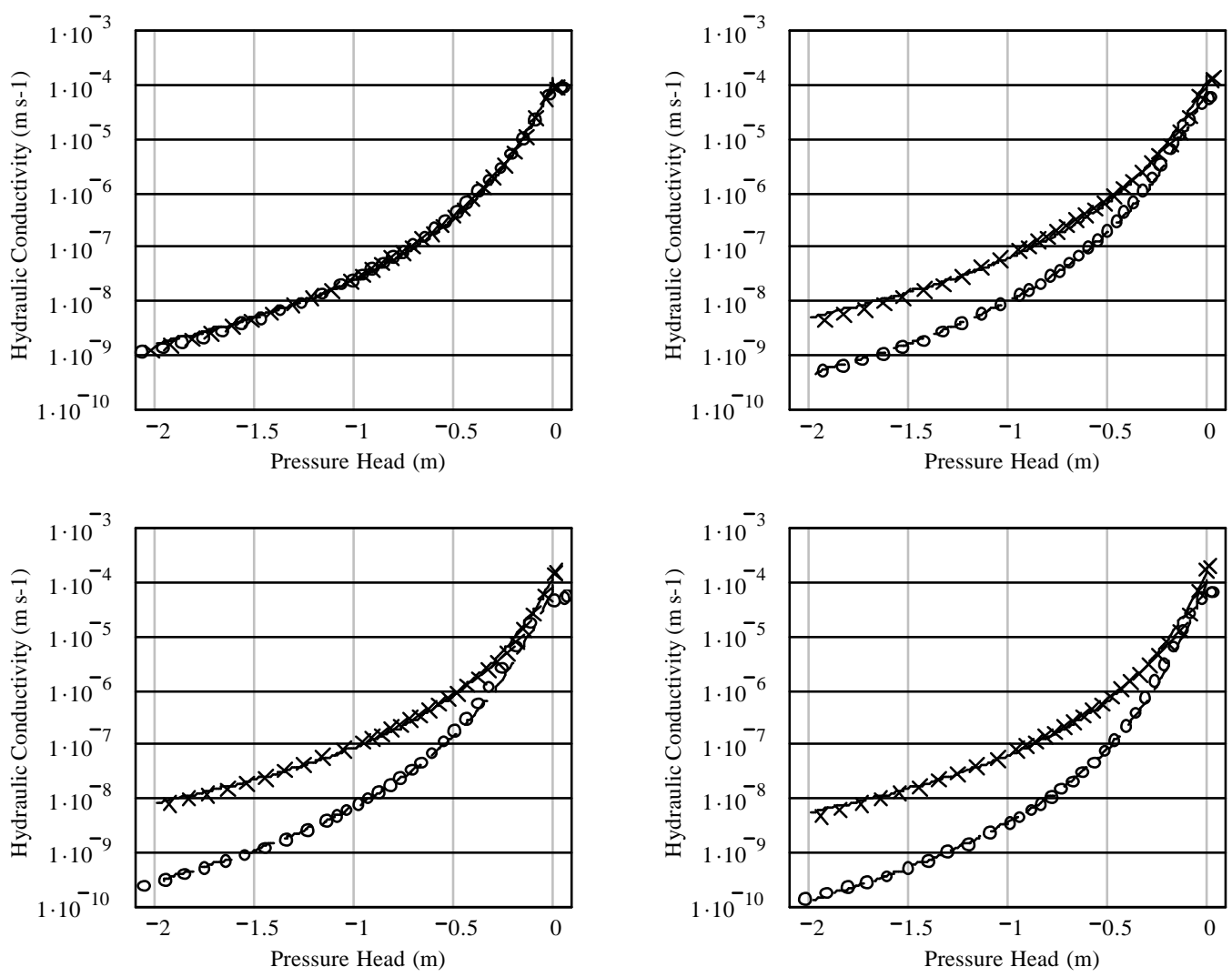

Figure 3.29. The Unsaturated Hydraulic Conductivity of Anisotropic Heterogeneous Soils with the $\sigma_{\mathrm{Y}}^{2}=2.0$-Cross: Parallel to Soil Strata; and Circle: Normal to Soil Strata

Unsaturated-hydraulic-conductivity functions of anisotropic soil can therefore be described by the TCT model. The generated unsaturated hydraulic conductivity curves were fitted to this model with variable connectivity, $\mathrm{L}, \mathrm{K}_{\mathrm{s}}$. Generally, the simulated values fit the observations well. The fitting error was generally less than $20 \%$ when $\mathrm{h}$ ranges from about -0.4 to $-2.0 \mathrm{~m}(-1.3$ to $-6.6 \mathrm{ft})$. The error was slightly larger but no more than $50 \%$ when $\mathrm{h}>-0.4 \mathrm{~m}(-1.3 \mathrm{ft})$. Considering that the measurement error of hydraulic conductivity under controlled conditions is often larger than this error, it can be concluded that the TCT model can accurately describe the unsaturated hydraulic functions of anisotropic soils. Work will continue on the development of this concept in FY 2003 under an EMSP award. 


\subsection{Conclusions}

Two field infiltration experiments were conducted at the Army Loop Road test site in FY 2002 with the primary objective of obtaining hydrologic, geophysical, and geochemical data from a controlled field study to reduce the uncertainty in vadose-zone conceptual models and to facilitate the calibration of numerical models for water flow and contaminant transport through Hanford's heterogeneous vadose zone. The study was designed to assure the observation of flow-and-transport properties over multiple scales of heterogeneity, a pre-requisite for developing suitable techniques for upscaling and for extrapolating parameters from clean representative sites to contaminated sites with minimal characterization. The experiment was also designed to permit identification of correlation lengths and quantification of the dispersion tensor.

A 60-m (197-ft)-long transect was instrumented with sensors for monitoring water content, matric potential, and the collection of pore water samples. Water content was monitored with TDR probes installed at $0.5-\mathrm{m}(1.6-\mathrm{ft})$ intervals along the transect to depths of $1.0 \mathrm{~m}, 0.8 \mathrm{~m}, 0.4 \mathrm{~m}$, and $0.2 \mathrm{~m}(3.3,2.6$, 1.3 , and $0.66 \mathrm{ft}$ ). During the infiltration and drainage phases, the matric potential was motored with tensiometers installed at depths of $0.8 \mathrm{~m}$ and $0.4 \mathrm{~m}(2.6$ and $1.3 \mathrm{ft})$. During the transport phase, tensiometers were converted over to suction lysimeters, which were used to collect pore water samples. In addition, PVC access tubes were used for cross-borehole GPR and neutron-probe measurement. Surface GPR was used to track the wetting front and identify subsurface heterogeneities. The plot was irrigated via a line source, and tracers were used to determine transport properties.

A preliminary analysis of results shows that the design was successful in its ability to meet the objectives. Field observations are consistent with premodeling results with respect to the distribution of moisture and matric potential However, there were significant discrepancies with respect to transport. Predictions using current modeling approaches suggest uniform distribution of solutes, which was observed on the sand. However, observations on the dike suggest the need for a bicontinuum model for transport at this and similar sites. Surface GP measurements were successful in identifying small-scale heterogeneities, although the antenna frequencies will need optimization to improve the accuracy of water-content estimates. Water-content distributions derived from GPR, neutron probe, and TDR all show a significant lateral component to flow caused by a sill near the surface. In addition to the fieldwork, we continued on the improvement of our conceptual model for vadose-zone flow and transport. Significant progress was made in the development of a model of state-dependent anisotropy and in a method for measuring anisotropic conductivity in the field. During the next year, work will continue on the analysis of the large dataset and the publication of the first set of transport properties and their correlation structure for Hanford's vadose zone. This information is critical input to site wide assessment of risk. 


\subsection{References}

Allen JRL. 1984. Sedimentary Structures, Their Character and Physical Basis. Developments in Sedimentology 30, Elseveier, Amsterdam.

Baumgartner N, GW Parkin and DE Elrick. 1994. "Soil-Water Content and Potential Measured by Hollow Time-Domain Reflectometry Probe.” Soil Sci. Soc. Am. J. 58 (2):315-318.

Boulton GS, and P Caban. 1995. "Groundwater Flow Beneath Ice Sheets, Part II. Its Impact on Glacier Tectonic Structures and Moraine Formation.” Quat. Sci. Rev. 14:563-587.

Broster BE. 1991. "Glaciotectonic Deformation in Sediment and Bedrock, Hat Creek, British Columbia." Geogr. Phys. Quat. 45:5-20.

Cassel DK, and A Klute. 1986. "Water Potential: Tensiometry." In Methods of Soil Analysis, Part 1. Physical and Mineralogical Methods, Agronomy Monograph 9, ed. A Klute, pp. 563-596. American Society of Agronomy, Madison, WI.

Deutsch CV, and AG Journel. 1998. GSLIB, Geostatistical Software Library and User's Guide, Oxford University Press.

Dreimanis A, and M Rappol. 1997. "Late Wisconsian Sub-Glacial Clastic Intrusive Sheets Along Lake Erie Bluffs, at Bradtville, Ontario, Canada.” Sedimentary Geol. 111:225-248.

Dreimanis A. 1992. "Downward Injected Till Wedges and Upward Injected Till Dikes." In Quaternary Stratigraphy, Glacial Morphology and Environmental Changes, eds. AM Roberston, U Miller, and L Brunnberg. Res. Pap., Geol. Surv. Sweden, Ser., Ca81:91-96.

Du S, and P Rummel. 1994. "Reconnaissance Studies of Moisture in the Subsurface with GPR." In Proceedings of the Fifth International Conference on Ground Penetrating Radar. GPR '94:1241-1248.

Fayer MJ, EM Murphy, JL Downs, FO Khan, CW Lindenmeier, and BN Bjornstad. 1999. Recharge Data Package for the Immobilized Low-Activity Waste 2001 Performance Assessment. PNNL-13033, Pacific Northwest National Laboratory, Richland, WA.

Gardner WR. 1958. "Some Steady-State Solutions of the Unsaturated Moisture Flow Equation with Applications to Evaporation from a Water Table." Soil Sci. 85:228-232.

Gee GW, and AL Ward. 2001. Vadose Zone Transport Field Study: Status Report. PNNL-13679, Pacific Northwest National Laboratory, Richland, WA.

Huisman JA, C Sperl, W Bouten, JM Verstraten. 2001. "Soil Water Content Measurements at Different Scales: Accuracy of Time Domain Reflectometry and Ground-Penetrating Radar." J. Hydrol. 245:48-58.

Kachanoski RG, E Pringle, and AWard. 1992. "Field Measurement of Solute TravelTimes Using Time Domain Reflectometry.” Soil Sci. Soc. Am. J. 56 (1):47-52. 
Leij FJ, TH Skaggs, and MTh van Genuchten. 1991. "Analytical Solutions For Solute Transport In 3-Dimensional Semi-Infinite Porous-Media." Water Resour. Res. 27:2719-2733.

Miller, E.E., and Miller, R.D. 1956. "Physical theory for capillary flow phenomena." J. Appl. Phys. 27:324-332.

Murray CJ, AL Ward, JL Wilson, PE Long, BJ Lechler, WP Clement, PK Kannberg, and GW Gee. 2001. "The Effects of Clastic Dikes on Vadose Zone Transport at the Hanford Site, Southcentral Washington." In 2001 American Geophysical Union (AGU) Fall Meetings.

National Academy of Science (NAS). 2000. Research Needs in Subsurface Science. National Academy Press, Washington, D.C.

Parker JC, and MTh van Genuchten. 1984. "Flux-Averaged and Volume-Averaged Concentrations in Continuum Approaches to Solute Transport." Water Resour. Res. 20:866-872.

Philip JR. 1971. "General Theorem on Steady Infiltration from Surface Sources, with the Application to Point and Line Sources." Soil Sci. Soc. Am. Proc. 35:867-871.

Reidel SP, and DG Horton. 1999. Geologic Data Package for Immobilized Low-Activity Waste 2001 Performance Assessment. PNNL-12257, Pacific Northwest National Laboratory, Richland, WA.

Roth K. 1995. "Steady State Flow in an Unsaturated, Two-Dimensional, Macroscopically Homogeneous, Miller-Similar Medium.” Water Resour. Res. 31:2127-2140.

Russo D. 1988. "Determining Soil Hydraulic Properties by Parameter Estimation: on the Selection of a Model for the Hydraulic Properties." Water Resour. Res. 24:453-459.

Snyder VA. 1996. "Statistical Hydraulic Conductviity Models and Scaling of Capillary Phenomena in Porous Media." Soil Sci. Soc. Am. J. 60:771-774.

Sposito GS, and WA Jury. 1990. "Miller Similitude and Generalized Scaling Analy sis." In Scaling in Soil Physics: Principles and Applications, ed. D Hillel and DE Elrick, pp. 13-22. SSSA Special Publication No 25. Madison, WI., Soil Sci. Soc. Am.

Stevenson FJ. 1986. "The Sulfur Cycle.” Cycles of Soil. John Wiley, NY.

Topp GC, JL Davis, and AP Annan. 1980. "Electromagnetic Determination of Soil Water Content: Measurements in Coaxial Transmission Lines." Water Resour. Res. 16:574-582.

U.S. Department of Energy (DOE). 1999. 200-BP-1 Prototype Barrier Treatability Test Report. DOE/RL-99-11, Richland, WA.

van Genuchten MTh. 1980. "A Closed Form Equation for Predicting the Hydraulic Conductivity of Unsaturated Soils.” Soil Sci. Soc. Am. J. 44:892-898.

Ward AL, and GW Gee. 1997. "Performance Evaluation of a Field-Scale Surface Barrier." J. Environ. Qual. 26:694-705.

Ward AL, and GW Gee. 2000. Vadose Transport Field Study: Detail Test Plan for Simulated Leak Tests. PNNL-13263, Pacific Northwest National Laboratory, Richland, WA. 
Ward AL, and GW Gee. 2001. Vadose Zone Transport Field Study: FY 2001 Test Plan. PNNL-13451, Rev. 1. Pacific Northwest National Laboratory, Richland, WA.

Ward AL, and GW Gee. 2002. Vadose Zone Transport Field Study: FY 2002 Test Plan. PNNL-13857, Pacific Northwest National Laboratory, Richland, WA.

Ward AL, and RG Kachanoski. 1989. "A Field Study of Solute Transport During Three-Dimensional Infiltration.” Agronomy Abstracts, p. 194, American Society of Agronomy, Madison WI.

Ward AL, RG Kachanoski, and DE Elrick. 1994. "Laboratory Measurements of Solute Transport Using Time Domain Reflectometry.” Soil Sci. Soc. Am. J. 58:1031-1039.

Yilmaz O. 1987. "Seismic Data Processing." Society of Exploration Geophysicists, Investigations in Geophysics, v. 2, ed. S. M. Doherty.

Zhang RD. 1997. "Determination of Soil Sorptivity and Hydraulic Conductivity from the Disk Infiltrometer." Soil Sci. Soc. Am. J. 61: 1024-1030.

Zhang ZF, RG Kachanoski, GW Parkin, and B Si. 2000. "Measuring Hydraulic Properties Using a Line Source: II. Field Test." Soil Sci. Soc. Am. J. 64:1563-4569. 
PNNL-14150

\section{Distribution}

No. of

Copies

\section{OFFSITE}

Wesley L. Bratton

Vista Engineering

8203 W. Quinault Ave

Kennewick, WA., 99336

2 Lawrence Livermore National Laboratory

L-130

Livermore, California 94550

Attn: William D. Daily

Abe Ramirez

2 Lawrence Berkley National Laboratory

Department of Earth and Planetary Sciences

MS 4767

1 Cyclotron Road

Berkeley, California 94720-4767

Attn: Donald J. DePaolo

Mark Conrad

James B. Fink

HydroGEOPHYSICS, Inc.

5865 South Old Spanish Trail

Tucson, Arizona 85747

Sandra Lilligren

Nez Perce Tribe, ERWM

P.O. Box 365

Lapwai, Idaho 83450

Rosemary J. Knight

Stanford University Mitchell Bldg

Satnford, CA., 94305-2215
No. of

Copies

\section{OFFSITE}

Jan W. Hopmans

Hydrology Program

Department of Land, Air and Water Resources

123 Veihmeyer Hall

University of California

Davis, CA 95616

Peter C. Lichtner

Los Alamos National Laboratory

Environmental Sciences Division (EES-5)

MS F-649

Los Alamos, New Mexico 87545

Brian J. Andraski

U.S. Geological Survey

333 W Nye Ln., Rm. 203

Carson City, NV, 89706

Ernest L. Majer

Lawrence Berkeley National Laboratory

1 Cyclotron Road (MS 90-116)

Berkeley, California 94720

Earl D. Mattson

Idaho National Engineering and Environmental Laboratory

P.O. Box 1625

2251 N. Boulevard

Idaho Falls, Idaho 83415-2107

Gregory A. Newman

Sandia National Laboratories

P.O. Box 5800

MS-0750

Albuquerque, New Mexico 87185-0750

Distr. 1 


\section{Distribution (Contd)}

\section{No. of \\ Copies}

\section{OFFSITE}

James B. Sisson

Idaho National Engineering and Environmental Laboratory, BBWI

P.O. Box 1625, MS-2107

Idaho Falls, Idaho 83415-2107

John Baker

USDA-ARS

Department of Soil, Water, \& Climate

439 Borlaug Hall

University of Minnesota

1991 Upper Buford Circle

St. Paul, MN 55108

Alan and Lorrie Flint

US Geological Survey

Placer Hall

6000 J Street

Sacramento CA, 95819-6129

Rien van Genuchten

U.S. Salinity Laboratory

450 West Big Springs Road

Riverside, CA 92507-4617

John Nimmo

U.S. Geological Survey

345 Middlefield Road, MS-421

Menlo Park, CA 94025

Michael H. Young

Div. of Hydrologic Sciences, Desert Research Institute

755 E. Flamingo Road, Las Vegas, NV 89119
No. of

Copies

\section{OFFSITE}

2 Los Alamos National Laboratory

Environmental Science Group

MSJ495

Los Alamos, New Mexico 87545

Attn: Everett P. Springer

Brent Neuman

Carl. I. Steefel

Lawrence Livermore National Laboratory

L-204

P.O. Box 808

Livermore, California 94551

P. J. Wierenga

Soil, Water, and Environmental Science

University of Arizona

Tucson, Arizona 85721

Michael Wilt

EMI

1301 S. $46^{\text {th }}$ St.

UCRFS Bldg. 300

Richmond, California 94804

T.C. Jim Yeh

University of Arizona

Department of Hydrology and Water Resources

The University of Arizona, Bldg. 11

Tucson, Arizona 85721

Distr. 2 


\section{Distribution (Contd)}

No. of

Copies

ONSITE

2 DOE Office of River Protection

C. A. BabelH6-60

R. M. Yasek H6-60

9 DOE Richland Operations Office

B. L. Foley

J. P. Hanson

R. D. Hildebrand

K. A. Kapsi

R. W. Lober

J. G. Morse

K. M. Thompson

R. M. Yasek

3 Bechtel Hanford Inc.

R. L. Biggerstaff

L. R. Curry

K. R. Fecht

7 CH2M Hill Hanford Group

J. W. Cammann

A. J. Knepp

F. M. Mann

D. A. Myers

V. J. Rohay

L. C. Swanson

C. D. Wittreich

2 MACTER-ERS

J. F. Bertsch

R. G. McCain
B2-62

A6-38

K8-50

A5-13

K8-50

H6-60

A5-13

A6-38

H6-60

H0-02

H0-09

$\mathrm{H} 0-02$

T4-08

$\mathrm{H} 0-22$

E6-35

E6-35

E6-35

H9-02

H9-03

B1-42
No. of

Copies

ONSITE

3 Waste Management Technical Services

M. G. Gardner H1-11

J. E. Meisner H1-11

R. K. Price H1-11

6 Washington Department of Ecology

F. W. Bond B5-18

J. Caggiano B5-18

D. Goswami B5-18

A. Huckaby B5-18

S. Leja B5-18

N. H. Uziemblo B5-18

1 U.S. Environmental Protection Agency
D. A. Faulk
B5-01

5 Fluor Federal Services

R. J. Fabre X5-50

B. H. Ford E6-35

R. Jackson E6-35

R. Khaleel E6-17

R. T. Wilde E6-35

Distr. 3 


\section{Distribution (Contd)}

No. of

Copies

\section{ONSITE}

79 Pacific Northwest National Laboratory

B. Barnett

K6-81

W. F. Bonner

K9-14

R. W. Bryce

E6-35

R. E. Clayton

P8-37

P. W. Eslinger

K6-80

M. J. Fayer

K3-33

M. D. Freshley (2)

H0-21

G. W. Gee (10)

K9-33

J. O. Goreham

K9-33

T. J. Gilmore

K6-81

D. G. Horton

K6-81

J.M. Keller (10)

K9-36

C. T. Kincaid

K9-33

G. V. Last

K6-81

P. E. Long

K9-33

W. J. Martin

K3-54

P. D. Meyer

BPO

C. J. Murray

K6-81

S. M. Narbutovskih

K6-96

Mart Oostrom

K9-33

W. E. Nichols

K9-33

S. P. Reidel

K6-81

M. L. Rockhold

K9-33

R. J. Serne

K6-81

C. E. Strickland

K9-36

M. D. Sweeney

K6-81

M. J. Truex

K2-10

A. L. Ward (15)

K9-33

K. Waters-Husted

K9-33

M. White

K9-36

B. A. Williams

K6-81

M. D. Williams

K9-36

S. B. Yabusaki

K9-36

J. M. Zachara

K8-96

F. Zhang (10)

K9-33

Technical Report Files (2)

Distr. 4 